\title{
MATERIAL SELECTION FOR ELECTROOPTIC DEFLECTORS
}

SEPTEMBER 1988

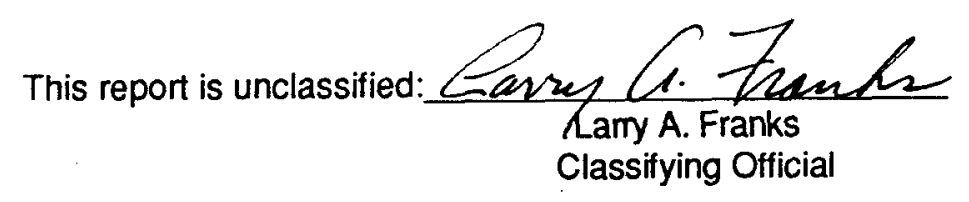

\section{DISCLAIMER}

This report was prepared as an account of work sponsored by an agency of the United States Government. Neither the United States Government nor any agency thereof, nor any of their employees, makes any warranty, express or implied, or assumes any legal liability or responsibility for the accuracy, completeness, or usefulness of any information, apparatus, product, or process disclosed, or represents that its use would not infringe privately owned rights. Reference herein to any specific commercial product, process, or service by trade name, trademark, manufacturer, or otherwise does not necessarily constitute or imply its endorsement, recommendation, or favoring by the United States Government or any agency thereof. The views and opinions of authors expressed herein do not necessarily state or reflect those of the United States Government or any agency thereof.

SANTA BARBARA OPERATIONS 130 Robin Hill Road, Goleta, California 93116

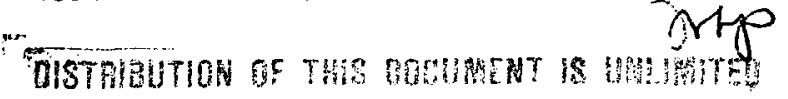




\section{DISCLAIMER}

This report was prepared as an account of work sponsored by an agency of the United States Government. Neither the United States Government nor any agency Thereof, nor any of their employees, makes any warranty, express or implied, or assumes any legal liability or responsibility for the accuracy, completeness, or usefulness of any information, apparatus, product, or process disclosed, or represents that its use would not infringe privately owned rights. Reference herein to any specific commercial product, process, or service by trade name, trademark, manufacturer, or otherwise does not necessarily constitute or imply its endorsement, recommendation, or favoring by the United States Government or any agency thereof. The views and opinions of authors expressed herein do not necessarily state or reflect those of the United States Government or any agency thereof. 


\section{DISCLAIMER}

Portions of this document may be illegible in electronic image products. Images are produced from the best available original document. 

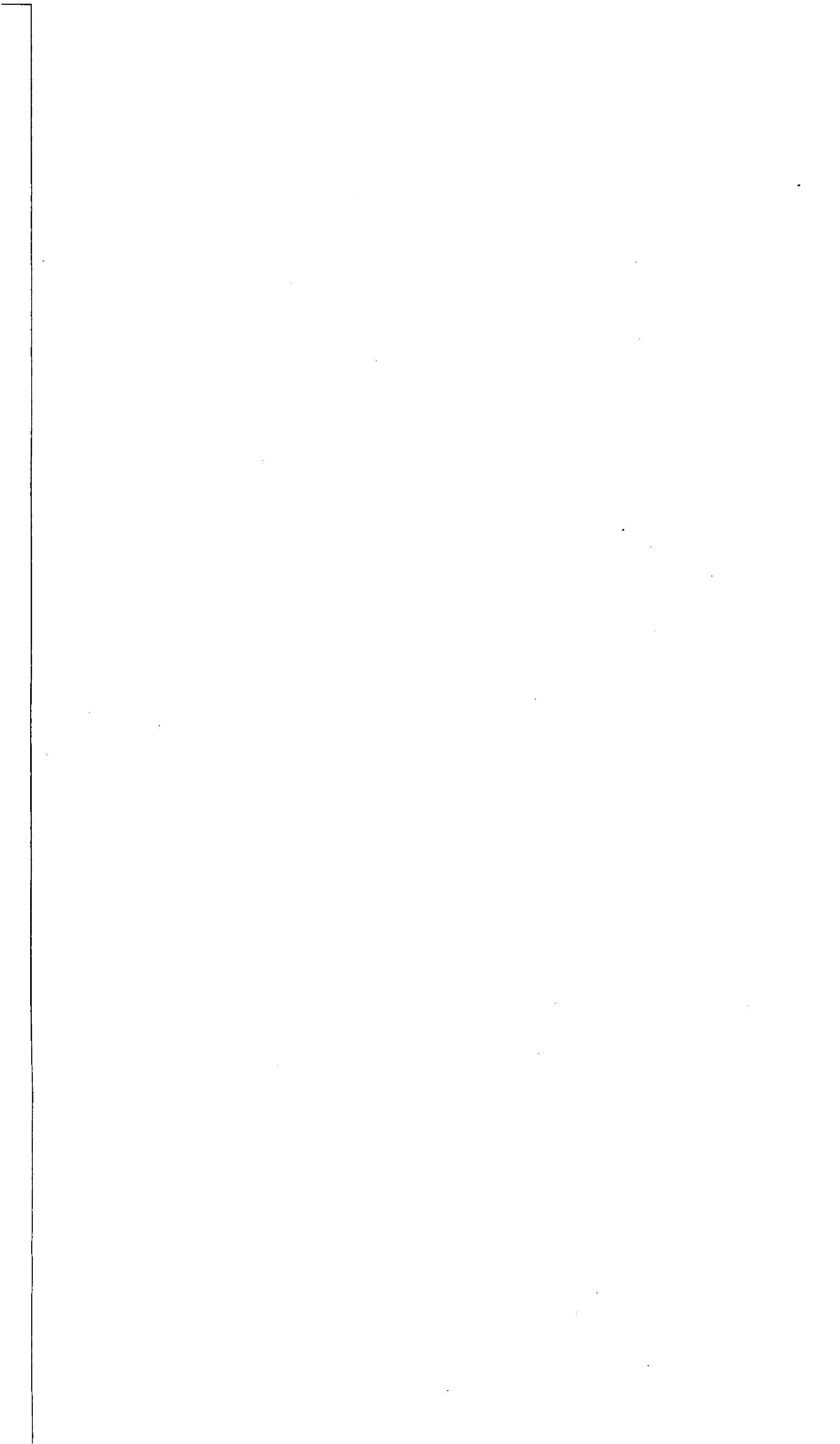


\begin{abstract}
The selection of a material for a practical device is generally guided by a number of criteria, including cost, size, difficulty of fabrication, durability, driver requirements, and system constraints. A quantitative analysis can usually be made for comparison, or a figure of merit can be computed. In the case of materials for electrooptical (EO) devices the choice is often made based on the availability of materials meeting some minimum system requirement. For fast EO deflectors, where a large number of resolvable spots is required, the choice of materials is quite limited. A model of just such a device is proposed; it is based on the resolution of 400 spots and reasonable boundary conditions. The model predicts that to be successful, an EO material must be chosen that has a linear EO coefficient $\left(r_{33}\right)$ of at least $336 \mathrm{pm} N$. A survey was conducted of the EO materials which are generally available. Based on the model and the survey, Czochralski crystal growth of strontium barium niobate (SBN:60) is recommended. Although SBN:60 does not have the largest EO coefficient, it may be the easiest to grow in the required size and optical quality, thus satisfying the availability criterion. It should be borne in mind that many materials may be grown by this technique and there are many new and potential applications for EO materials.
\end{abstract}

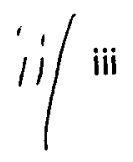




\section{TABLE OF CONTENTS}

1 INTRODUCTION .................................................................................................

2 THEORY OF ELECTROOPTIC DEFLECTION ..............................................................

2.1 EO Deflector Principles ..........................................................................................

2.1.1 Linear field gradient deflection ..........................................................................

2.1.2 Uniform field, multiple prism deflection ........................................................5

2.1.3 Number of resolvable spots ............................................................................6

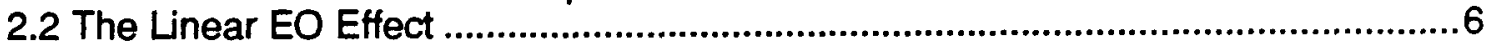

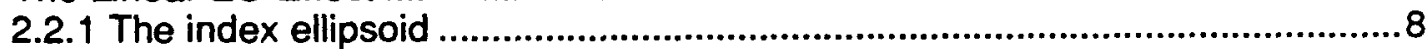

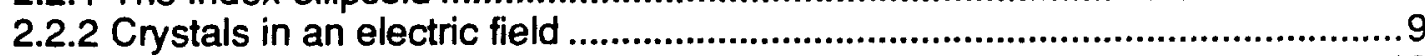

2.2.3 Figure of merit......................................................................................................12

2.3 State-of-the-art................................................................................................... 14

3 EO COEFFICIENT REQUIREMENT ........................................................................17

3.1 Estimate of Required EO Coefficient ..................................................................17

3.2 List of Candidate Materials ............................................................................... 18

3.3 Transverse vs Longitudinal EO Coefficients ........................................................18

4 SPECIFIC CRYSTALS, GROWING TECHNIQUES, RECOMMENDATIONS ............23

4.1 Specific Materials Discussions ……….....................................................................23

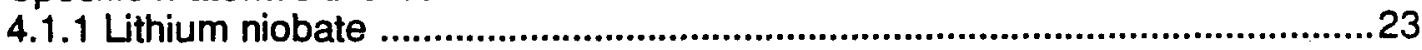

4.1.2 Lithium tantalate ....................................................................................23

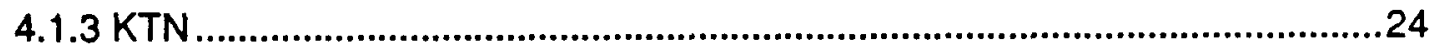

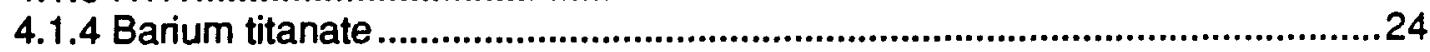

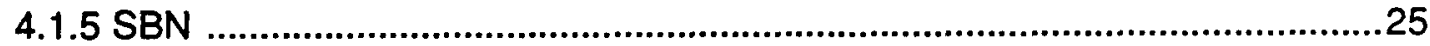

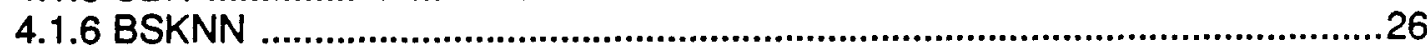

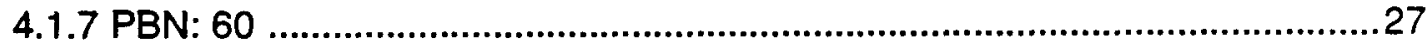

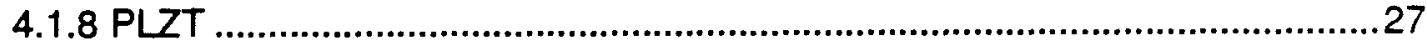

4.1.9 SCNN ...................................................................................................27

4.2 Specific Data Sheets for Selected Materials .........................................................27

4.3 Ranking of Materials ..............................................................................................37

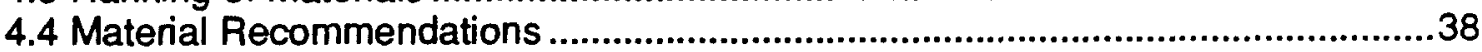

5 TUNGSTEN BRONZE MATERIALS ……...............................................................41

5.1 Discussion of Tungsten Bronze Properties ........................................................41

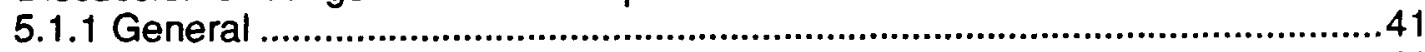

5.1.2 Morphotropic phase boundary compositions .................................................4

5.1.3 Striations .........................................................................................................4

5.1.4 Photorefractive properties..............................................................................45

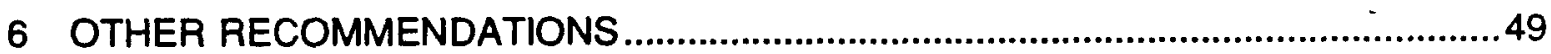

6.1 Build Optical Expertise ..........................................................................................49

6.2 System Aspects of EO Deflectors .....................................................................49

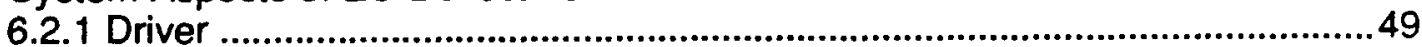

6.2.2 Type of deflector .........................................................................................49

6.2.3 Optical coupling .....................................................................................................49

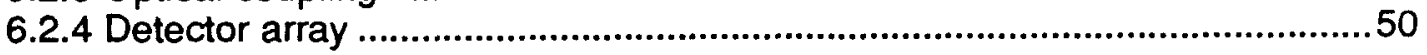

$$
\text { iv/ }
$$




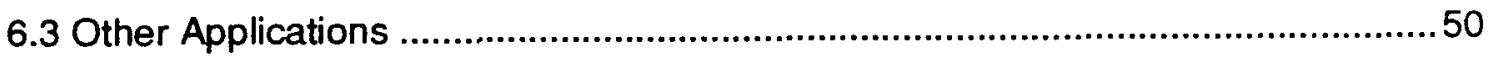

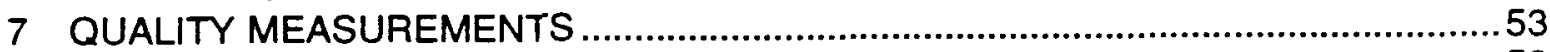

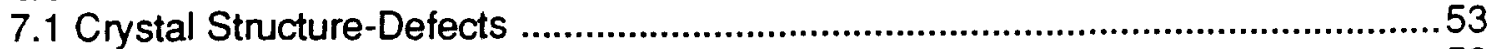

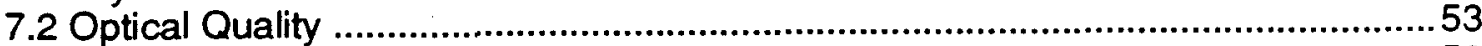

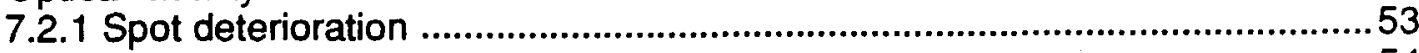

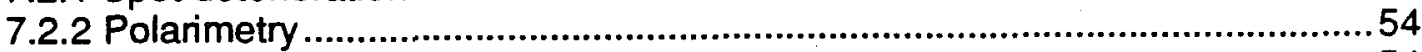

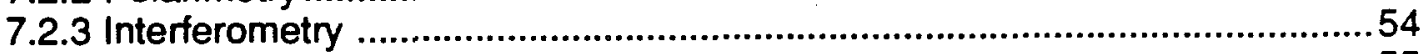

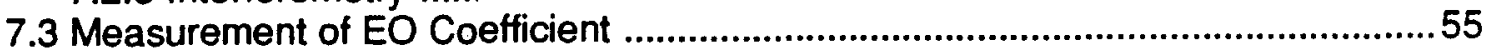

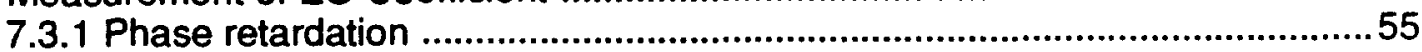

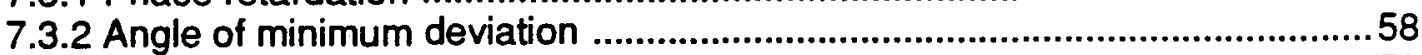

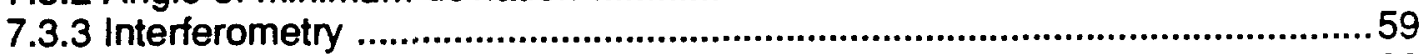

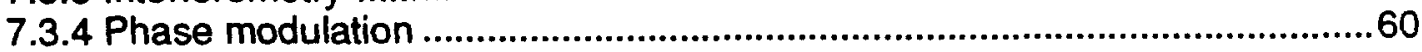

7.3.5 Speckle photography ..........................................................................60

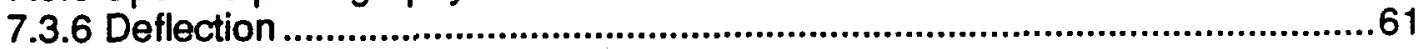

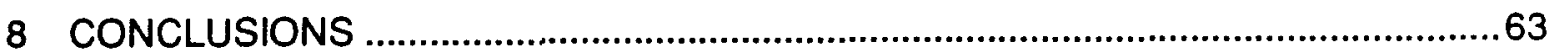

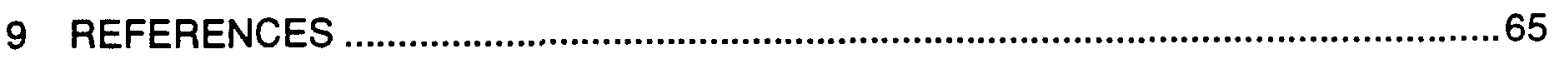

APPENDIX: Report of visit to Neurgaonkar's laboratory .....................................A-1 


\section{TABLE OF FIGURES}

Figure 1. An electrooptic deflector based on a linear gradient in the index of refraction .... 3

Figure 2. An electrooptic deflector based on a prism-pair in a uniform electric field ...........5

Figure 3. An electrooptic deflector using a multiple prism configuration ............................7

Figure 4. An electrooptic deflector utilizing induced prisms in a single crystal..................7

Figure 5. Use of the index ellipsoid for finding the index of refraction for the two unique planes of polarization for an EM wave propagating in a uniaxial crystal

Figure 6. Electrooptic tensors for three noncentrosymmetric crystal point groups

Figure 7. Three examples of an electrooptic deflector based on a quadrupole field

Figure 8. A photonic data recorder using electrooptic deflection

Figure 9. Calculation of required EO coefficient

Figure 10. Spatial arrangements of input beam, beam polarization, and coordinate system in the crystal and direction of applied electric field

Figure 11. Comparison of a material with $r_{33}$ dominant with one having $r_{51}$ dominant

Figure 12. Czochralski crystal puller

Figure 13. Facets on tungsten bronze crystals ..........................................................43

Figure 14. A phase diagram for the PBN system ......................................................44

Figure 15. Striations in SBN:60 with and without automatic diameter control ..................46

Figure 16. Optical quality by spot deterioration .............................................................54

Figure 17. Optical quality by interferometry ...............................................................55

Figure 18. Measurement of EO coefficient by phase retardation ...................................56

Figure 19. Determination of $n$, change in $n$ and $E O$ coefficient by AMD method ..............58 


\section{TABLE OF TABLES}

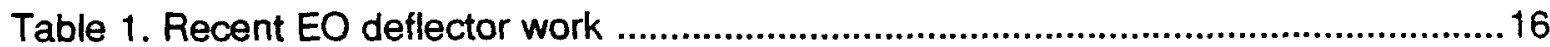

Table 2. Electrooptic materials .......................................................................... 19

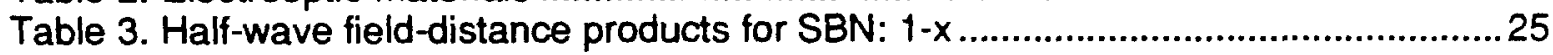

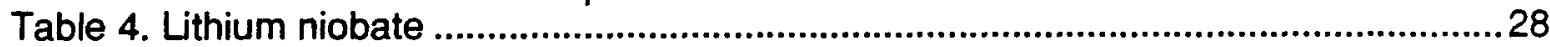

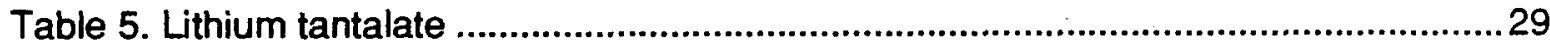

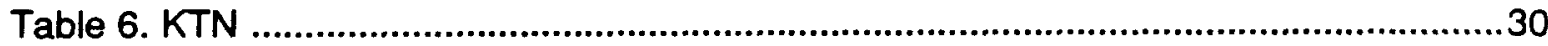

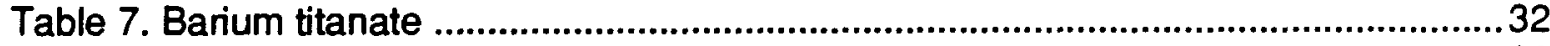

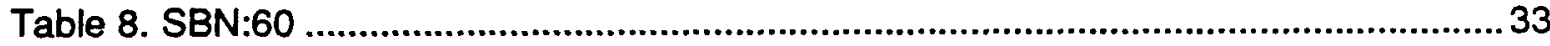

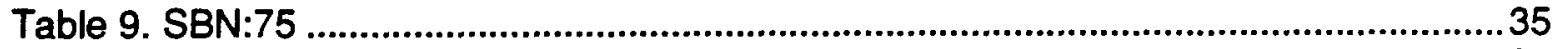

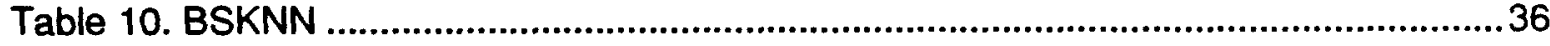

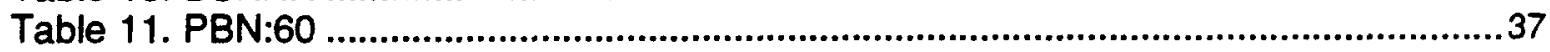

Table 12. Ranking of EO materials ..............................................................................39

Table 13. List of tungsten bronze crystals and properties .........................................42

Table 14. Ferroelectric properties at MPB for tungsten bronze crystals .........................45 


\section{INTRODUCTION}

The purpose of this document is to report on the state of the art of electrooptical (EO) materials and more specifically to give recommendations on which materials are the strongest candidates for the application of optical beam deflection. Growth techniques for candidate materials are given in detail. Almost all of the candidate materials can be grown by the Czochralski crystal pulling method.

Generally the choice of a material for a practical application is guided by an optimization with respect to a number of properties: cost, difficulty of fabrication, performance, durability, size, driver requirements, and system constraints. In principle a quantitative comparative analysis of properties of available materials can be carried out and relative figures of menit assigned. In the case of optical devices, however, the choice is often dictated by availability of materials meeting some basic minimum system requirement. A mathematical optimization analysis of ferroelectric materials for guided-wave EO applications has been carried out recently by Holman et al. $^{3}$ Performance quantities such as power supply constraints, and data rate were analyzed as a function of system variables and a relative ranking of 12 materials was made. Many of the same materials discussed in this report were considered by the above-mentioned authors. The top four materials chosen by them were 1) $\mathrm{KNbO}_{3}\left(\mathrm{r}_{42}\right)$, 2) $\mathrm{BaTiO}_{3}\left(\mathrm{r}_{51}\right)$, 3) $\mathrm{KNbO}_{3}\left(\mathrm{r}_{33}\right)$, and 4) $\mathrm{LiNbO}_{3}\left(\mathrm{r}_{33}\right)$. The same analysis cannot be used for choosing a fast beam deflector for streak applications due to different power requirements (single shot vs continuous operation) and different physical dimensions. Additionally, the top two ranked materials use the longitudinal EO coefficient $r_{51}=r_{42}$. It is not clear, as discussed in this report, how this component can be used efficiently to produce a large change in index refraction for EO deflectors. In addition, materials problems such as growth difficulties and ease of handling, machining, and polishing were not considered.

There is not much room for flexibility in choosing materials for fast EO deflectors if a large number of resolvable spots are required, since that requires a large deflection angle compared to the diffraction spot size (in angle) for the limiting aperture of the system. A large change in index of refraction with electric field, and therefore a large EO coefficient, are necessary. Previous attempts to make such deflectors have centered on $\mathrm{LiNbO}_{3}$, mainly because of its relatively large EO coefficient compared to that for other readily available materials. Performances of up to 200 resolvable spots have been reached with this material; however, large driving voltages were required, material durability problems were experienced, and long optical paths in the materials were necessary.

A material other than $\mathrm{LiNbO}_{3}$ is definitely needed to make a fast optical deflector practical. In 1967 Bell Labs scientists ${ }^{2}$ successfully grew moderately large crystals of strontium barium niobate (SBN) with various ratios of strontium to 
barium and measured transverse EO coefficients $\left(r_{33}\right)$ one to two orders of magnitude larger than $r_{33}$ values for $\mathrm{LiNbO}_{3}$. Other workers successfully grew SBN crystals a few years later. ${ }^{3-5}$ More recently large crystals of SBN and other crystals in the same family, the tungsten bronzes, have been grown in sizes up to 2 to $3 \mathrm{~cm}$ in diameter and 7 to $10 \mathrm{~cm}$ in length by $R$. Neurgaonkar and his coworkers $^{6-13}$ at the Rockwell International Science Center. (See the Appendix.)

In order to lay the groundwork for material selection the basic theory of EO deflectors and the linear EO effect are discussed, after which desired material properties and some potential materials are mentioned. A discussion of the desirability of the transverse EO coeffecient over the longitudinal coefficient is presented. Detailed properties of candidate materials are given along with crystal growing techniques for several of them. Additionally some optical quality measurements are discussed briefly and other applications of EO crystals are mentioned. A final section contains recommendations on what crystal(s) to grow and other recommendations for an EO deflector program. Other topics of concern to EO deflection such as optimum crystal configuration, driver requirements and design, optical damage, and optical coupling schemes are not discussed in this report. 


\section{THEORY OF ELECTROOPTIC DEFLECTION}

An understanding of the basic theory of EO deflectors is necessary to make an optimum material selection. Operating principles of EO deflectors have been discussed by several workers. ${ }^{14-32}$ Basically all EO deflectors work on the principle of changing the direction of an optical beam by changing the index of refraction of a material as a result of varying an applied electric field. For the purposes of this section it is assumed that the materials all have a linear dependence of index of refraction on applied electric field. Generally two categories of deflectors are described: one using a linear gradient in the applied electric field, and the other a uniform field.

\subsection{EO DEFLECTOR PRINCIPLES}

\subsubsection{Linear Field Gradient Deflection}

A linear electric field gradient can be produced by an electric quadrupole arrangement which will be described later. Figure 1 shows a rectangular-shaped single crystal of length $L$ with a plane optical wave incident from the left and to which an electric field is applied in the $z$ direction with a linear gradient in the

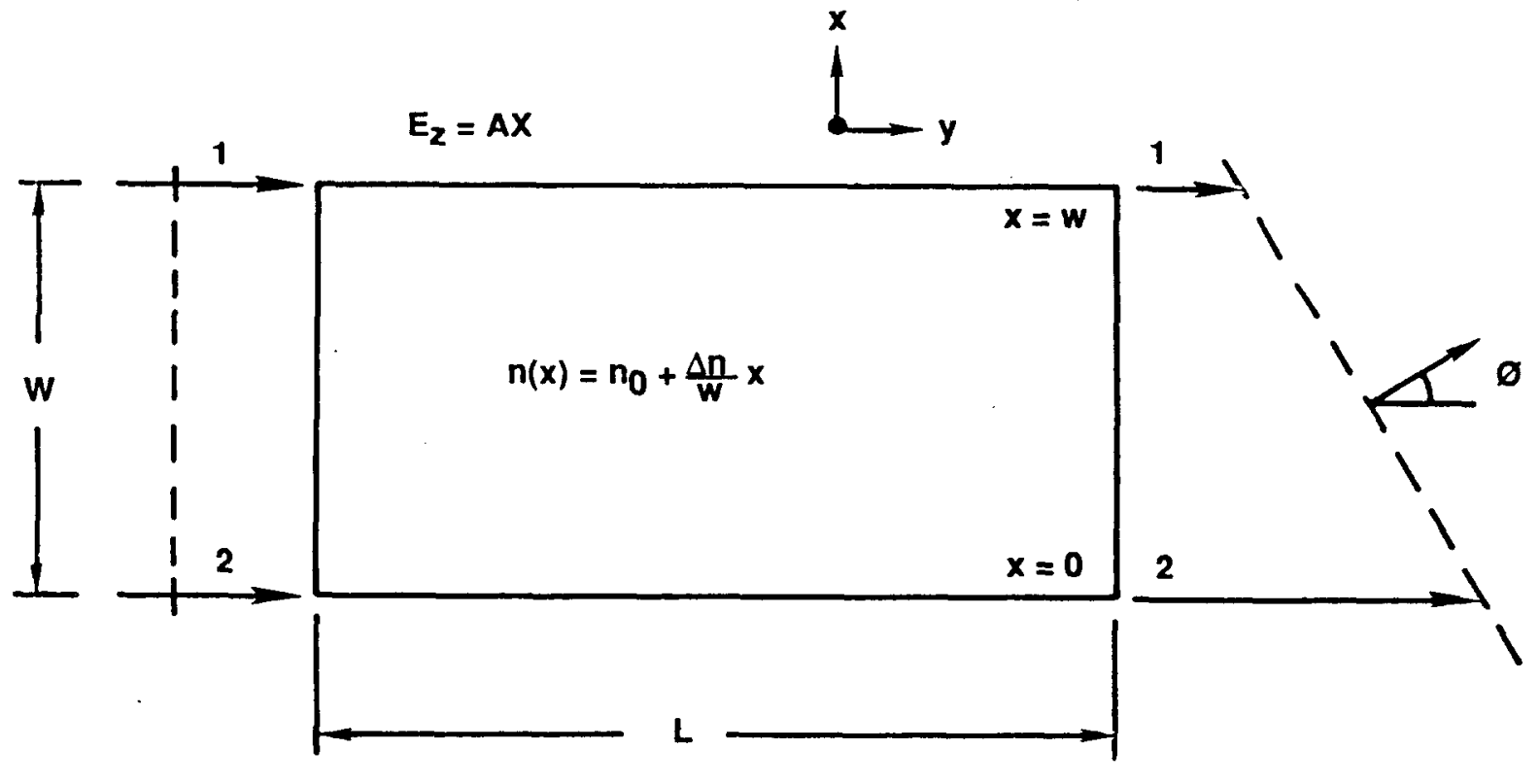

Figure 1. EO deflector based on linear field gradient. 
$x$ direction. The index of refraction varies with $x$ from $n_{0}$ at $x=0$ to $n_{0}+(\Delta n / w) x$ at $x=w$. As a result the propagation velocity varies with $x$ also, so ray 1 would travel slower than ray 2 , resulting in a deflected plane wave. The transit time for ray 1 is:

$$
t_{1}=\frac{L}{c}\left(n_{0}+\Delta n\right)
$$

and for ray 2:

$$
\mathrm{t}_{2}=\frac{\mathrm{L}}{\mathrm{c}} \mathrm{n}_{0}
$$

The difference in transit time then is:

$$
\Delta t=\frac{\mathrm{L}}{\mathrm{c}} \Delta \mathrm{n}
$$

which results in a plane wave at the exit end deflected by the internal angle

$$
\Theta \approx \frac{\Delta y}{w}=\frac{L}{n_{0}} \frac{\Delta n}{w}
$$

where $\Delta y$ is the difference in path length traveled by the two rays. With the aid of Snell's law, the external deflection angle is determined:

$$
\Theta \approx \frac{\mathrm{L}}{\mathrm{w}} \Delta \mathrm{n}
$$

for small deflection angles. A departure from a linear gradient in the applied field or the material obeying the quadratic EO effect rather than the linear effect would still result in deflection of the wave but it would have a curved wavefront. 


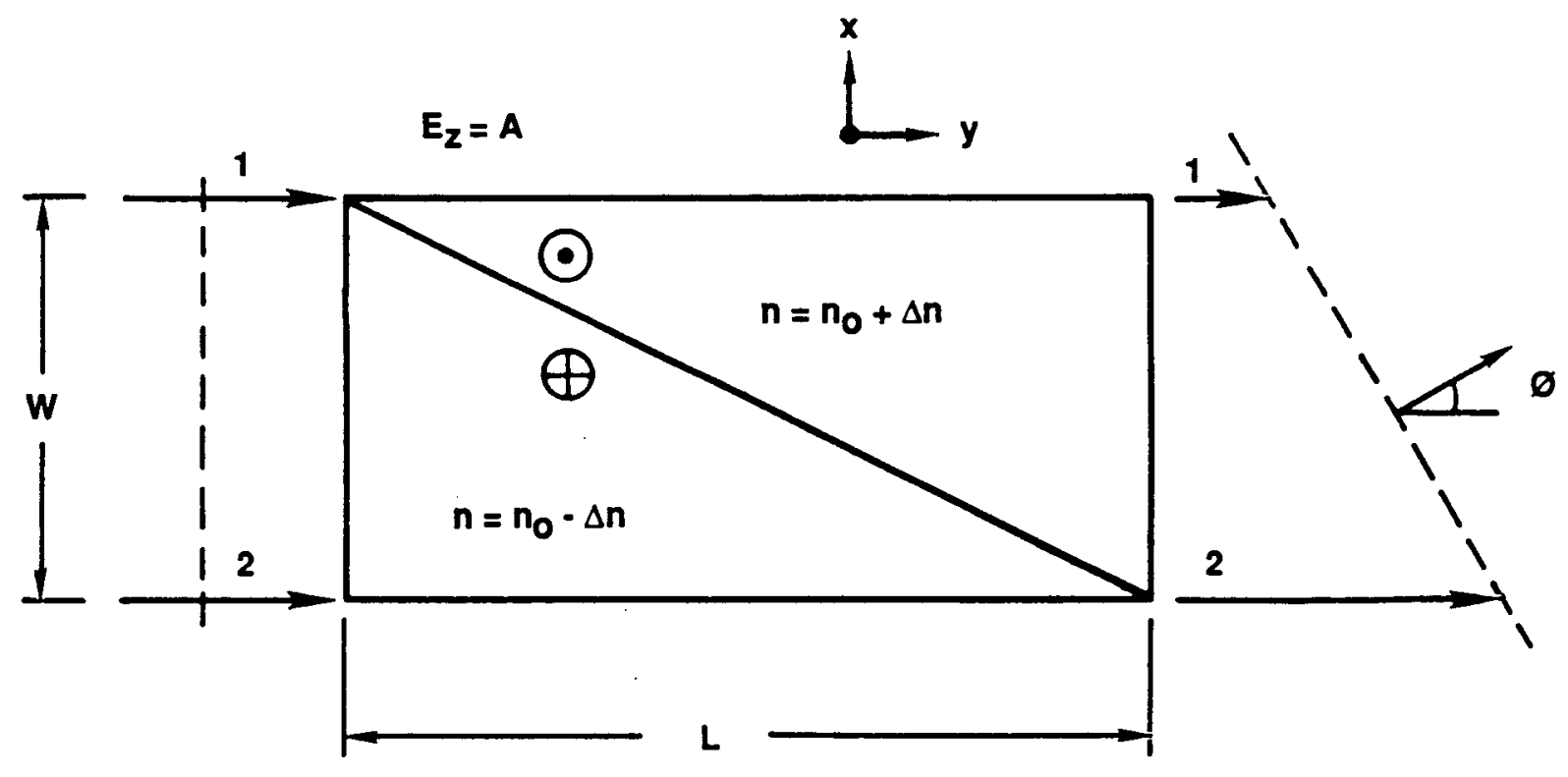

Figure 2. EO deflector using two prisms in uniform field.

\subsubsection{Uniform Field, Multiple Prism Deflection}

Another common arrangement for an EO deflector is shown in Figure 2 where two prisms are shown with their $\mathbf{z}$ axes oppositely oriented and electrodes deposited on the top and bottom surfaces of the double prism. In this arrangement a voltage is applied to the two electrodes causing the index in one prism to increase and decrease in the other. As in the first example a plane optical wave is incident from the left. Ray 1 travels slower than ray 2, resulting in a deflected plane wave as shown. The deflection angle is given by:

$$
\Theta=\frac{\mathrm{L}}{\mathrm{w}} \Delta \mathrm{n}
$$

An estimate of the size of the deflection angle to be expected can be made assuming a deflector of width $0.1 \mathrm{~cm}$ and length $5 \mathrm{~cm}$. $A \cdot \Delta \mathrm{n}$ value for $\mathrm{LiNbO}_{3}$ in a field of $10,000 \mathrm{~V} / \mathrm{cm}$ would be about 0.0002 . This would produce a deflection of only $10 \mathrm{mr}$. 
Another multiple-prism technique using several prisms with z-axes oppositely oriented in adjacent prisms is shown in Figure 3. This arrangement has been described by a few investigators. A single slab-shaped crystal using induced prisms with isolated electrodes was developed by Ninomiya ${ }^{19,20}$ and later used by Garside and Park $^{21}$ in an 8-prism pair format. This concept is illustrated in Figure 4 for a single prism pair. This technique has the advantage that only one slab-shaped crystal is required; however, the gap between the prism-shaped electrodes causes fringing fields which can produce distortion.

\subsubsection{Number of Resolvable Spots}

The most important property of an optical beam deflector is the number of resolvable spots, $N$, which is a function of the applied electric field, the pertinent index of refraction of the crystal, aperture size, the wavelength, and optical quality of the crystal. The limiting aperture of the deflecting system diffracts the beam, resulting in a minimum resolution angle given by

$$
\delta \Theta=\frac{1.22 \lambda}{w}
$$

for a circular aperture of diameter $w$. In practice the beam diameter will be somewhat smaller than the crystal dimension to avoid vignetting problems. The number of resolvable spots for a deflector is given by

$$
\mathrm{N}=\frac{\Theta}{\delta \Theta}=\frac{\mathrm{L} \Delta \mathrm{n}}{1.22 \lambda}
$$

Equation (8) basically describes the resolution of the deflector.

\subsection{THE LINEAR EO EFFECT}

The number of resolvable spots defined in Equation $(8)$ is dependent on the change in index of refraction produced by an applied electric field. Therefore, the successful operation of a deflector is determined by the sensitivity of the index change to the applied electric field. The EO coefficient is used to quantify that dependence. The theory of the EO effect in crystals has been treated thoroughly 


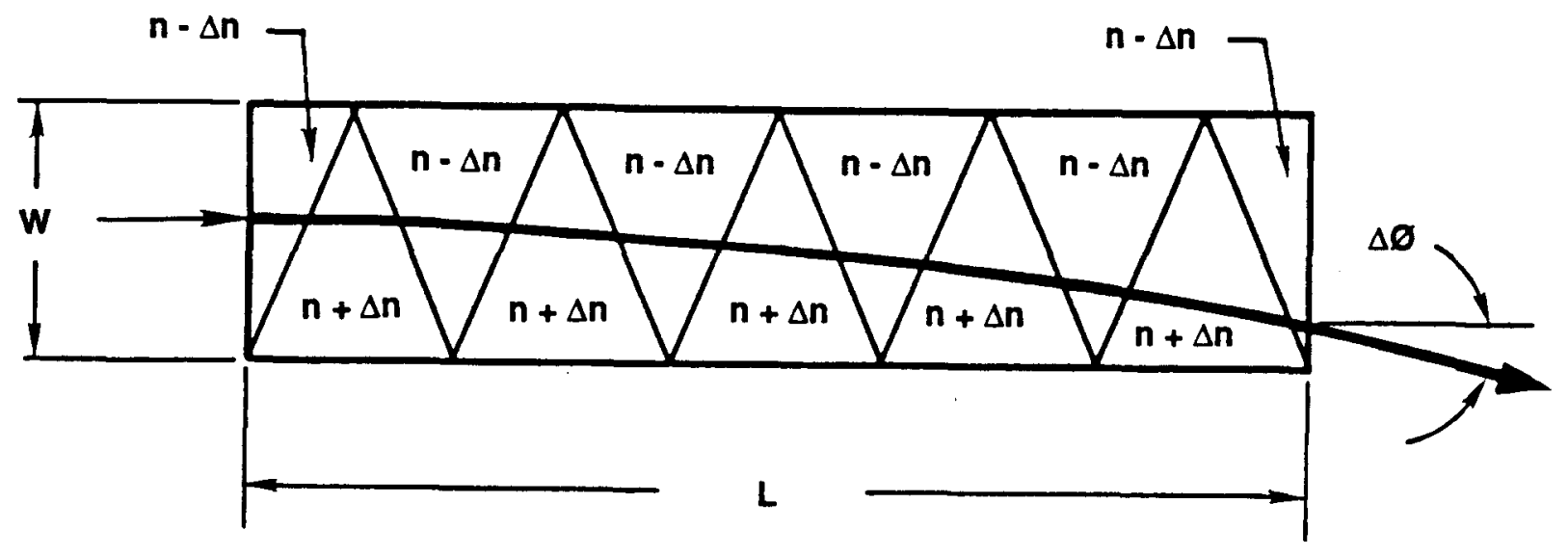

Figure 3. Multiple prism deflector in uniform field.

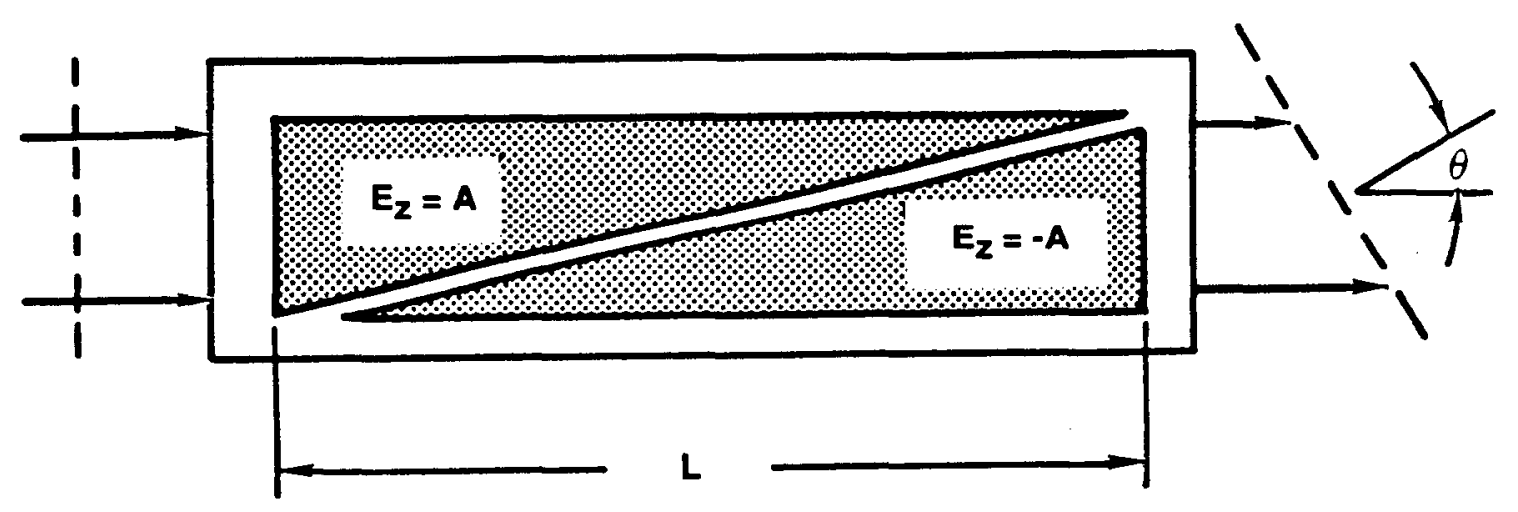

Figure 4. EO deflector using induced prisms in a single crystal. 
in references such as Yariv and $\mathrm{Yeh}^{13}$ Kaminow and Turner, ${ }^{14}$ and Gottlieb, Ireland and Ley. ${ }^{15}$ The EO effect is often discussed simply in terms of the change in the quantity $\left(1 / n^{2}\right)$ by

$$
\frac{1}{n^{2}}=\frac{1}{n^{2}(0)}+r E+R E^{2}+\ldots
$$

where $n(0)$ is the index with no electric field present and $r$ and $R$ are the linear and quadratic EO coefficients respectively. Only noncentrosymmetric crystals exhibit a linear effect since a reversal of the sign of the electric field in a crystal having inversion symmetry (centrosymmetric) requires that the optical properties remain the same. This can only happen if the EO coefficient is zero. The quadratic effect is not so limited. Application of an electric field can also produce a change in $n$ through elasto-optic strain (i.e., electrostrictive or piezoelectric effects). The latter effects can decrease or increase the size of the primary EO effect, but at higher frequencies crystals cannot strain macroscopically and only the primary EO effect is important.

\subsubsection{The Index Ellipsoid}

Proper descriptions of the change in index of refraction induced in a crystal by an electric field must take into account the vector nature of the field, the orientation of the crystal axes, and the light propagation direction and polarization. For any ray incident on a crystal, two independent directions of polarization are allowed and the two corresponding velocities of propagation (or indices of refraction) can be found with the aid of the index ellipsoid. In a principal coordinate system the index ellipsoid, in the absence of an electric field, takes the form: $:^{13}$

$$
\frac{x^{2}}{n_{x}^{2}}+\frac{y^{2}}{n_{y}^{2}}+\frac{z^{2}}{n_{z}^{2}}=1
$$

The $x, y$, and $z$ axes are the principal axes of the crystal, the terms $\left(1 / n_{x}\right)^{2},\left(1 / n_{y}\right)^{2}$, and $\left(1 / n_{z}\right)^{2}$, are the principal dielectric constants (at optical frequencies) for the crystal, and the n's are the principal indices of refraction. If all three indices are equal, the crystal is isotropic; if two indices are equal, the crystal is

uniaxial; and if all three indices are different, the crystal is biaxial. For example, for a uniaxial crystal, the index ellipsoid is:

$$
\frac{\mathrm{x}^{2}}{\mathrm{n}_{0}^{2}}+\frac{\mathrm{y}^{2}}{\mathrm{n}_{0}^{2}}+\frac{\mathrm{z}^{2}}{\mathrm{n}_{\mathrm{e}}^{2}}=1
$$



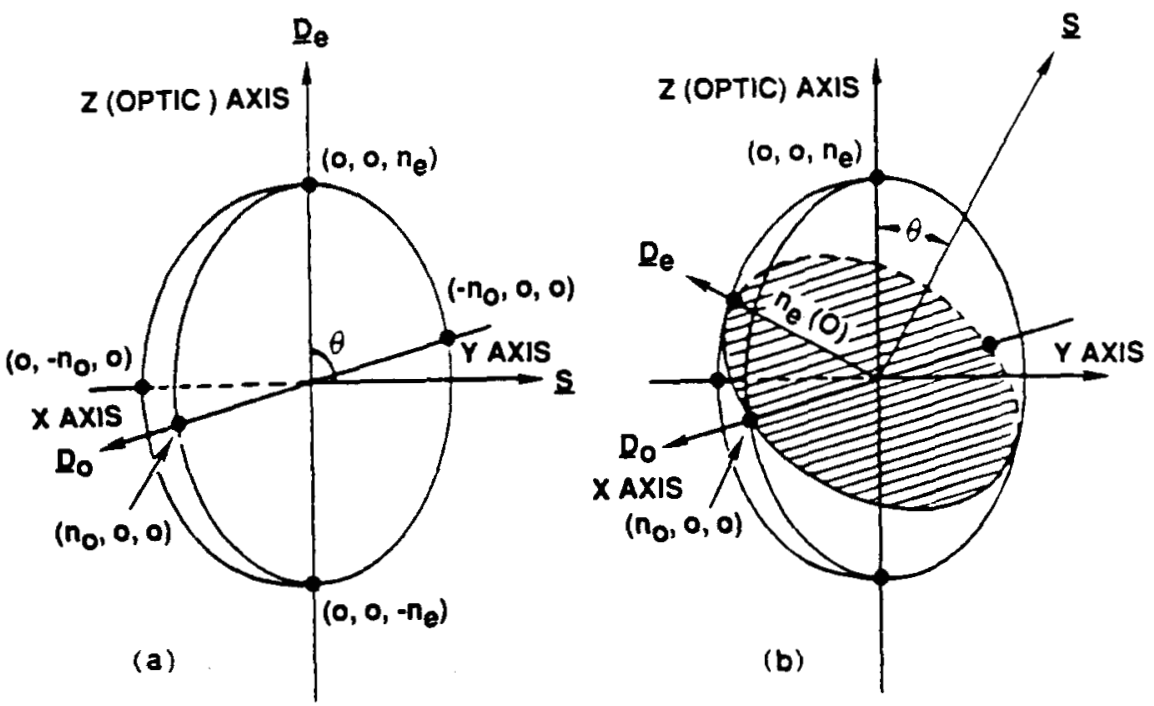

Figure 5. The index ellipsoid can be used for finding the refractive index for the two unique planes of polarization associated with an electromagnetic wave propagating in a uniaxial crystal. In example (a) the ray $\underline{S}$ is propagating at an angle of $90^{\circ}$ to the $z$ axis; the two refractive indices are $n_{0}$ and $n_{0}$. In (b) a general case is shown where the ray is traveling in an arbitrary direction: one index is $n_{0}$, but the other is a function of the angle between the ray and the $z$ axis as given in the text.

where $n_{0}$ is the ordinary index of refraction and $n_{0}$ is the extraordinary index of refraction. In the conventional manner the $z$ axis is the axis of symmetry. The use of the index ellipsoid for finding the two allowed indices of refraction for a ray traveling at an angle of $\Theta=\pi / 2$ with respect to the $z$ axis and a ray traveling at an arbitrary direction in the crystal is illustrated in Figure $5 .{ }^{15}$ The unique indices of refraction are equal to the lengths of the semimajor and semiminor axes of the ellipse formed by the intersection of the index ellipsoid and the plane perpendicular to the ray drawn through the origin. In the arbitrary case one index is equal to the ordinary index and the other index depends on the angle with respect to the $z$ axis and is given by

$$
\frac{1}{n_{e}^{2}(\Theta)}=\frac{\cos ^{2} \Theta}{n_{0}^{2}}+\frac{\sin ^{2} \Theta}{n_{e}^{2}}
$$

\subsubsection{Crystals in an Electric Field}

written

Application of an electric field distorts the index ellipsoid ${ }^{12.10}$ which can be

$$
\begin{aligned}
& \left(\frac{1}{n_{x}^{2}}+r_{1 x} E_{k}\right) x^{2}+\left(\frac{1}{n_{y}^{2}}+r_{2 k} E_{k}\right) y^{2}+\left(\frac{1}{n_{z}^{2}}+r_{3 k} E_{k}\right) z^{2} \\
& +2 r_{4 k} E_{k} y z+2 r_{5 k} E_{k} z x+2 r_{6 k} E_{k} x y=1
\end{aligned}
$$


where $k=1,2,3$ and the convention of summation of repeated indices is used. The electro-optic tensor, $r_{i k}$ is a $6 \times 3$ matrix whose form can be determined by symmetry relations for 21 noncentrosymmetric point groups. ${ }^{13}$ The forms for three frequently used EO crystals are shown in Figure 6 for point groups $42 \mathrm{~m}, 3 \mathrm{~m}$, and $4 \mathrm{~mm}$. Potassium dihydrogen phosphate (KDP), ammonium dihydrogen phosphate (ADP), and isomorphs are examples of the first group; lithium niobate and its isomorphs are examples of the second group, and barium titanate, potassium tantalate niobate (KTN), and SBN are examples of the third group. As an example we will consider the third group with an applied electric field along the $z$ axis, then the index ellipsoid, using Equation (13), becomes:

$$
\left(\frac{1}{n_{0}^{2}}+r_{13} E_{z}\right) x^{2}+\left(\frac{1}{n_{0}^{2}}+r_{13} E_{z}\right) y^{2}+\left(\frac{1}{n_{e}^{2}}+r_{33} E_{z}\right) z^{2}=1
$$

In this particular example the index ellipsoid remains in principal axis form. In general, this is not always the case; for example, if the electric field is applied parallel to the $z$ axis in crystals such as KDP, an xy or mixed term occurs. A new coordinate system can be found, however, such that after a transformation, all mixed terms disappear and the index ellipsoid can be written in principal form again. (See References 13 and 17.)

Previously it was stated that the most important quantity for EO deflector materials is the change in index of refraction produced by the electric field. This can be obtained from Equation (13) written in the form:

$$
\Delta\left(\frac{1}{n^{2}}\right)=r_{t k} E_{k}
$$

For small changes in $\mathrm{n}$ the following approximation holds:

$$
\Delta n_{t} \approx-\frac{1}{2} n_{t}^{3} \Delta\left(\frac{1}{n^{2}}\right)
$$

Consider, for example, lithium niobate; $\Delta \mathrm{n}_{\mathrm{x}}$ is the largest change in index since $\mathrm{r}_{30}$ is the largest EO component for that material with a value of $30.8 \times 10^{.12} \mathrm{~m} / \mathrm{V}$. 


$$
r_{\mathrm{tk}}=\quad\left(\begin{array}{ccc}
42 \mathrm{~m} \\
0 & 0 & 0 \\
0 & 0 & 0 \\
0 & 0 & 0 \\
\mathrm{r}_{41} & 0 & 0 \\
0 & \mathrm{r}_{41} & 0 \\
0 & 0 & \mathrm{r}_{63}
\end{array}\right)
$$

$$
\left(\begin{array}{ccc}
0 & -r_{22} & r_{13} \\
0 & r_{22} & r_{13} \\
0 & 0 & r_{33} \\
0 & r_{51} & 0 \\
r_{51} & 0 & 0 \\
-r_{22} & 0 & 0
\end{array}\right)
$$

$$
\left(\begin{array}{ccc}
0 & 4 m \\
0 & 0 & r_{13} \\
0 & 0 & r_{13} \\
0 & 0 & r_{33} \\
0 & r_{51} & 0 \\
r_{51} & 0 & 0 \\
0 & 0 & 0
\end{array}\right)
$$

Figure 6. Electrooptic tensors for three noncentrosymmetric crystal point groups. 
This is 4 times larger than $r_{13}$, almost 10 times larger than $r_{22}$, and about $10 \%$ larger than $r_{\text {s. }}$. The value of $n_{2}$ with $E=E_{2}$ is:

$$
n_{z}=n_{e}-\frac{1}{2} n_{e}^{3} r_{33} E_{z}
$$

It will be shown in the next section that this material is only marginally useful for deflection purposes in spite of the fact that its coefficient $r_{33}$ is larger than most and its widespread use as a general EO material for other applications.

\subsubsection{Figure of Merit}

Equation (8) together with Equation (20) can be used to describe the number of resolvable spots for a deflector in terms of the EO coefficient and the electric field. For a material with $\mathrm{r}_{33}$ the dominant $\mathrm{EO}$ component:

$$
\mathrm{N}=\frac{\Theta}{\delta \Theta}=\frac{\mathrm{Ln}_{\mathrm{e}}^{3} \mathrm{r}_{33} \mathrm{E}_{2}}{1.22 \lambda}
$$

The term, $n_{e}^{3} T_{33}$ is called the figure of merit, $M$ :

$$
M_{r}=n_{e}^{3} r_{33}
$$

This figure of merit relates to the number of resolvable spots. Another figure of merit relating to the temporal resolution, Mt has been used occasionally in the literature and is obtained from the equation for temporal resolution ${ }^{13}$ :

$$
\delta \mathrm{t}=\frac{1.22 \lambda \mathrm{d} \varepsilon_{0} \varepsilon_{\mathrm{r}}}{\mathrm{n}_{\mathrm{e}}^{3} \mathrm{r}_{33} \mathrm{I}}
$$

where $d$ is the thickness of the crystal, $\varepsilon_{r}$ is the pertinent component of the relative dielectric constant for the material, $\varepsilon_{0}$ is the permittivity of free space and $I$ is the driver current. Mt is:

$$
\mathrm{M}_{\mathrm{t}}=\frac{\mathrm{n}_{\mathrm{e}}^{3} \mathrm{r}_{33}}{\varepsilon_{\mathrm{r}}}
$$

These two expressions for figure of merit contain crystal properties only. 


\subsection{STATE OF THE ART}

Early interest in EO deflectors centered on their use as potential rasterscanned deflection systems for displays and other applications. This application did not work out due to material (sonic shocks and thermal effects) and driver problems. (See References 29-32.) Interest was revived for possible application as a crystal streak camera in the mid-1970s. Since this is the principal application of interest to $E G \& G / E M$, it is worthwhile to summarize the recent work for that application.

In 1976 Stan Thomas of LLNL published results with a commercial beam deflector using ammonium dihydrogen phosphate (ADP). ${ }^{16} \mathrm{He}$ achieved about 18 resolvable spots with a temporal resolution of $50 \mathrm{ps}$ at a wavelength of $532 \mathrm{~nm}$ with an effective aperture of $1.89 \mathrm{~mm}$ driven by a $\pm 2-k V, 20-A$, supply with a 20-ns ramp.

In 1979, Ireland (then at AWRE, Aldermaston; now at J-K Lasers) used $\mathrm{LiNbO}_{3}$ in quadrupole form as shown in Figure 7 to produce 200 resolvable spots with a temporal resolution of 20 ps. ${ }^{17}$ The crystal dimensions were $5 \times 5 \times 32 \mathrm{~mm}$ and a driving voltage of $8 \mathrm{kV}$ was used. In order to achieve these results he had to double-pass the crystal. Other versions of the quadrupole arrangement are shown in Figure 7. One is referred to as a truncated quadrupole in which some of the material has been removed, thus lowering the capacitance by a factor of two. An optimized form using three electrodes in which nearly half the material has been removed would result in further reduction of capacitance. At this time it is believed that neither of the latter two versions have been investigated experimentally. In Discussions with Ireland and John Ley (formerly with Electro-Optics, Ltd.) who made the crystals for Ireland, it became clear that their system was marginal due to short crystal life and poor driver operation. The crystals developed cracks, possibly from sonic shocks. ${ }^{23}$ Ley had an instrument on the market, but withdrew it because of the problems just described; he has not pursued the work because of the lack of a significant potential market.

In 1983 Garside and Park ${ }^{29}$ reported a $\mathrm{LiNbO}_{3} \mathrm{EO}$ deflector which had 150 resolvable spots and a temporal resolution of 20 ps. The design was an 8-prism pair in the form of a single-crystal slab with induced prisms similar to the design of Figure 4. The crystal was $50 \mathrm{~mm}$ long and $150 \mathrm{~mm}$ thick. The voltage ramp was $2 \mathrm{kV}$. While this deflector produced a reasonable number of resolvable spots, the ratio of thickness to length of the crystal was so small that it might be difficult to use in a practical system. The reason for the small thickness was to increase the electric field in the material. The above-mentioned authors have not pursued bringing a crystal streak camera to market, but instead started looking into a device with a smaller number of resolvable spots for a different application where the driver requirements can be met with a low-voltage avalanche transistor supply.

Davis and Chang (at Kaman Sciences) are currently pursuing the use of $\mathrm{LiNbO}_{3}$ in single-passed quadrupole form. ${ }^{24}$ They have achieved about 50 resolvable spots at $632.8 \mathrm{~nm}$ and are developing better drivers for the deflector. Davis has described difficulties with the quality of the $\mathrm{LiNbO}_{3}$ crystal causing distortion of 


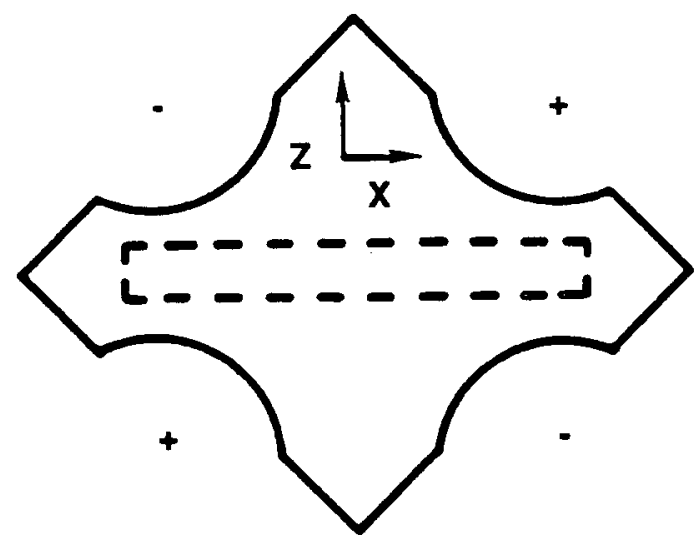

(a) End view of crystal machined so that electrodes or curved surfaces produce quadrupole field

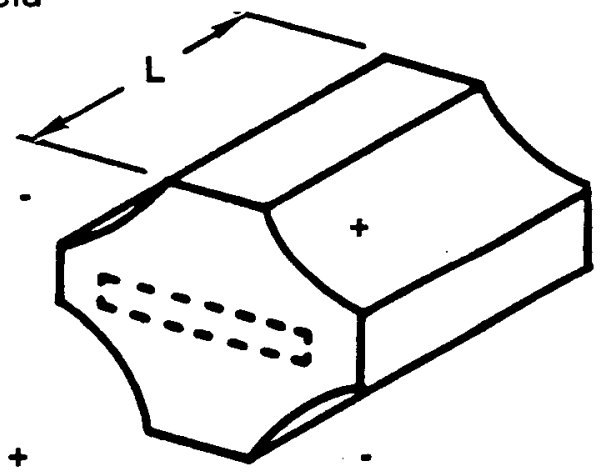

(b) Truncated version of above

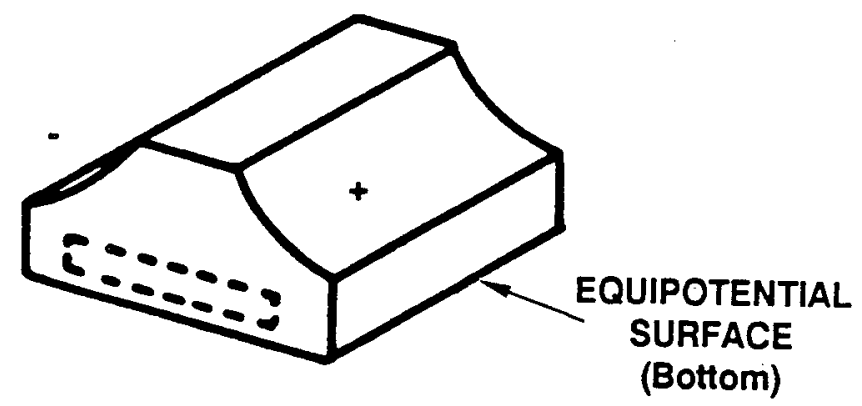

(c) Optimized version, showing less material, therefore less capacitance

Figure 7. Three examples of EO deflector based on a linear field gradient produced by a quadrupole field. 
the optical beam, thereby reducing the number of resolvable spots for the deflector. The experimental setup is shown in Figure 8 . He is now trying to get better quality crystals and is taking extra care in machining the crystals. He would prefer dependable 50 resolvable spots for his application, which is more of an optical sampler than a streak camera. He is interested in better materials and the optical streak camera application also. From recent discussions with Chang, it appears that Kaman Sciences will market a "photonic recorder" in the near future.

Researchers at LLNL (led by Dr. L. Jelsma) are pursuing the crystal streak camera application with SBN:60 crystals obtained from $R$. Neurgaonkar. These crystals have more than an order of magnitude larger $\mathrm{r}_{33}$ than that of $\mathrm{LiNbO}_{3}$. Personal conversation with Mr. Neurgaonkar (see Appendix) indicates that this group is measuring the EO coefficient of the material, and also is successfully producing deflection with the material. This was verified in later discussions with Jelsma at SBO. The work being carried on at LLNL will be summarized in papers to be presented in the near future. ${ }^{33,34}$

Table 1.

A summary of the recent work on crystal streak cameras is given in

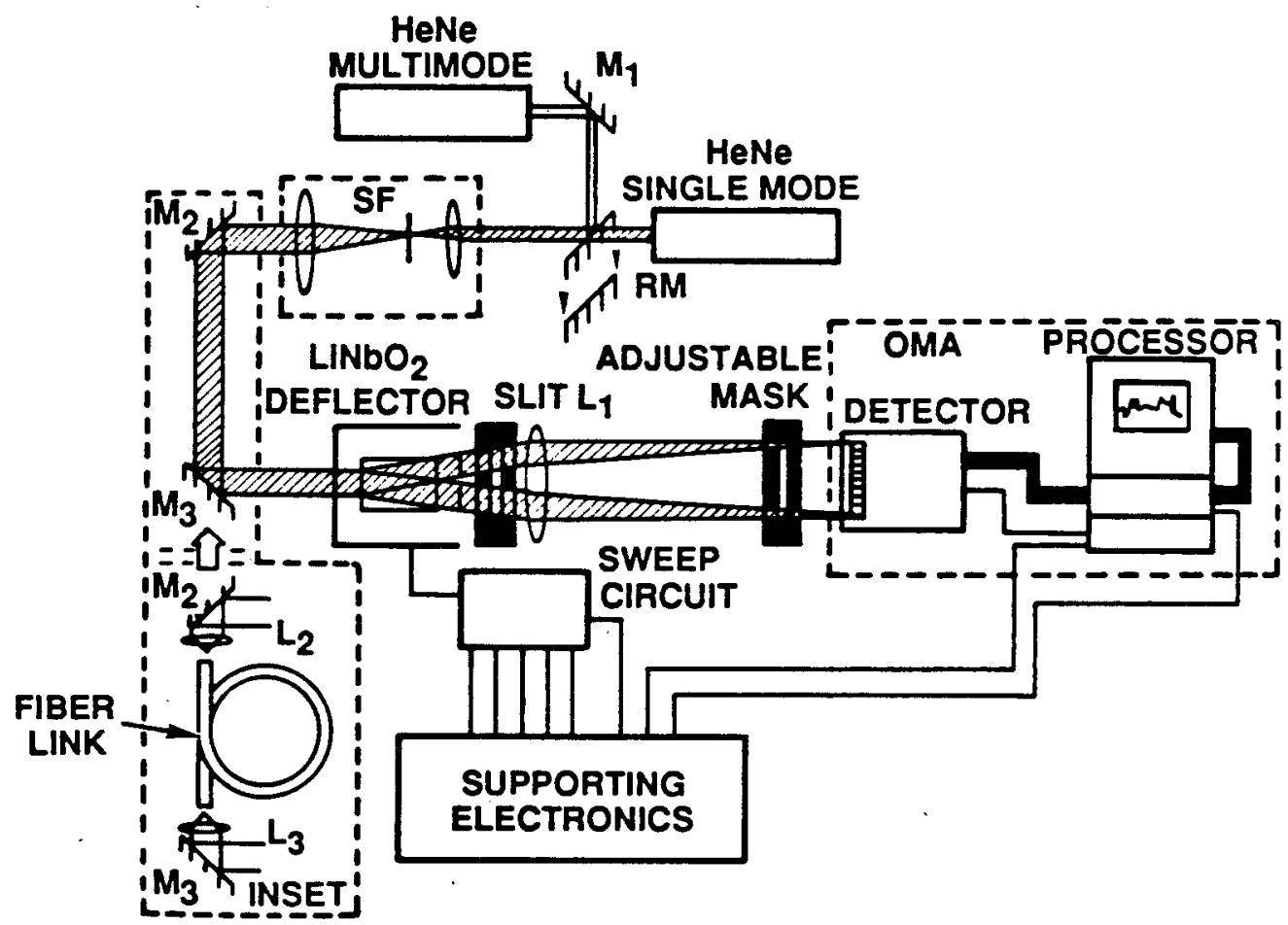

Figure 8. Diagram of an experimental setup for a photonic data recorder using EO deflection. Inputs from single-mode and multimode lasers as well as from a fiber optic link are shown. 
Table 1. Recent EO deflector work

\begin{tabular}{|l|l|l|l|l|l|}
\hline Date & Workers & Crystal & $\begin{array}{l}\text { Number } \\
\text { Resolv. } \\
\text { Spots }\end{array}$ & $\begin{array}{l}\text { Temp. } \\
\text { Resol. } \\
(\mathrm{ps})\end{array}$ & $\begin{array}{l}\text { Wave- } \\
\text { Length } \\
(\mathrm{nm})\end{array}$ \\
\hline 1976 & S. Thomas & ADP & 9 & 120 & 1063 \\
\hline 1976 & S. Thomas & “ & 18 & 60 & 532 \\
\hline 1978 & C.L.M. Ireland & LiNbO $_{3}$ & 33 & 100 & 532 \\
\hline 1979 & C.L.M. Ireland & “ & 200 & 20 & 532 \\
\hline 1983 & R. Park, B. Garside & LiNbO $_{3}$ & 150 & 20 & visible \\
\hline 1986 & P. Davis, et al. & LiNbO & 50 & 1000 & 633 \\
\hline 1987 & L. Jelsma, et al. & SBN: 60 & - & - & - \\
\hline
\end{tabular}




\section{EO COEFFICIENT REQUIREMENT}

\subsection{ESTIMATE OF REQUIRED EO COEFFICIENT}

An estimate of the magnitude of EO coefficient required to produce a desired performance with a given set of system parameters is made in this section. While the choice of system numbers is somewhat arbitrary, the values for crystal length, width, wavelength, index, and driving voltage are all reasonable choices. The length of the crystal should be as small as possible in order to reduce static and dynamic material distortions; the thickness should be small in order to have a fairly large electric field thereby reducing driving voltage requirements, yet not so small that it limits the optical beam or increases the capacitance to such a high value that the current requirements are too large. The index of refraction of most of the materials under strong consideration is nearly the same (about 2.3), and therefore is not a factor.

We will assume a requirement that the deflector must achieve 400 resolvable spots. The system parameters are listed below:

$$
\begin{array}{ll}
\text { number of resolvable spots } & =N=400 \\
\text { length }(\mathrm{cm}) & =L=5 \\
\text { wavelength }(\mathrm{nm}) & =\lambda=850 \\
\text { index } & =n=2.3 \\
\text { voltage } & =V=2000 \\
\text { thickness }(\mathrm{mm}) & =d=1
\end{array}
$$

The deflector consisting of two prisms is shown in Figure 9. The number of resolvable spots, from Equations (8) and (21), is

$$
\mathrm{N}=\frac{\Delta \mathrm{nL}}{1.22 \lambda}=\frac{\mathrm{n}_{e}^{3} \mathrm{r}_{33} \mathrm{VL}}{1.22 \lambda \mathrm{d}}
$$

In terms of the figure of merit, $M r$, we have:

$$
\mathrm{M}_{\mathrm{r}}=\frac{\mathrm{N} \cdot 1.22 \lambda \mathrm{d}}{\mathrm{VL}}=4.15 \times 10^{-9} \mathrm{~m} / \mathrm{V}
$$

The required EO coefficient is then

$$
\mathrm{r}_{33}=336 \times 10^{-12} \mathrm{~m} / \mathrm{V}=336 \mathrm{pm} / \mathrm{V}
$$



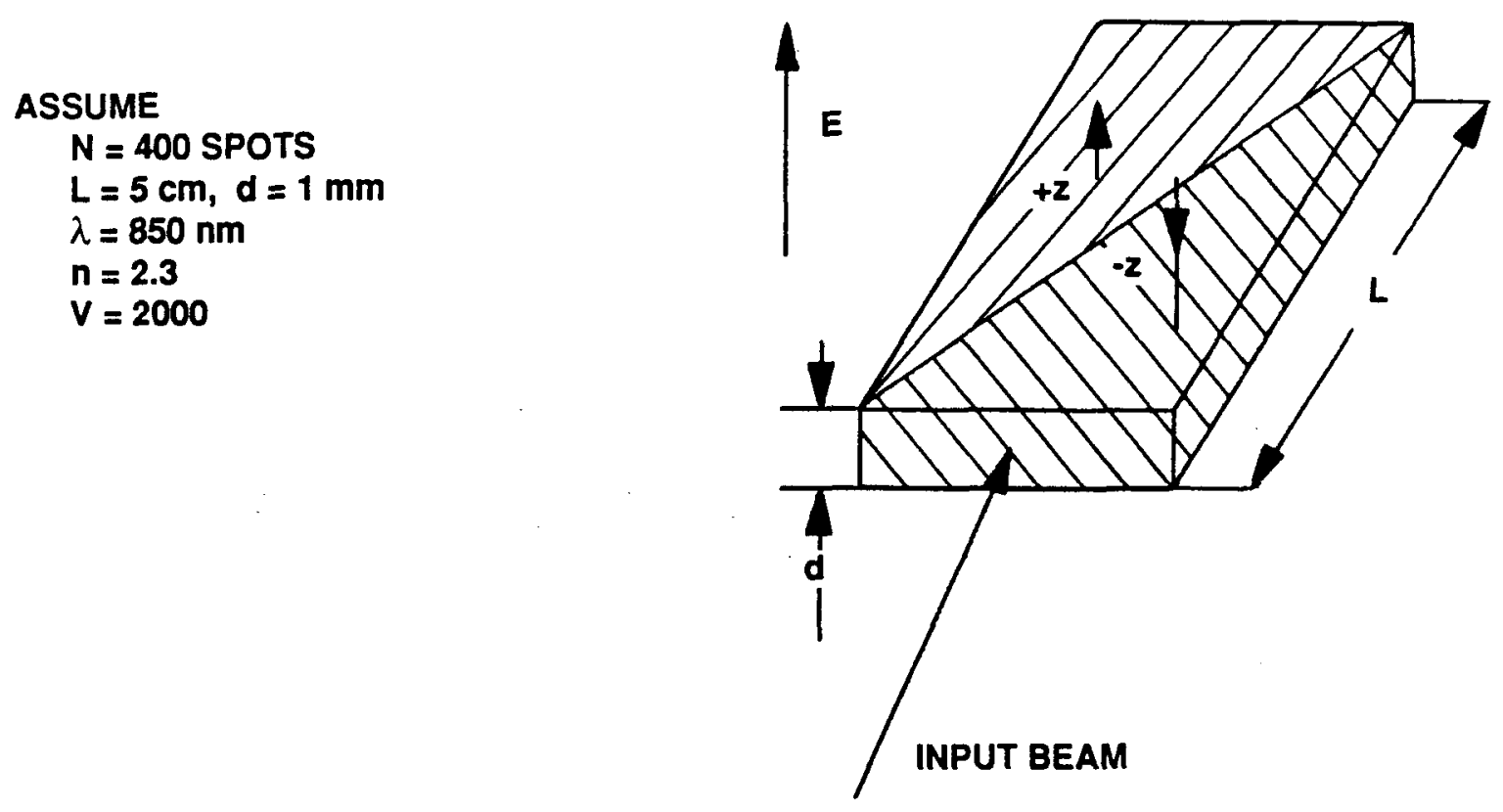

Figure 9. Calculation of required EO coefficient.

\subsection{LIST OF CANDIDATE MATERIALS}

How does the required value of EO coefficient derived in the previous section compare with available EO coefficients? Long lists of EO coefficient values can be found in handbooks and other articles. ${ }^{14,35,36}$ However, it becomes obvious on examining these lists that only a few materials have coefficients close to the required value. Familiar EO materials like $K D P, K D * P$, and even $\mathrm{LiNbO}_{3}$ have coefficients more than an order of magnitude too small. Several materials chosen for their large coefficients, along with some other common materials, are listed in Table 2. Some of the listed materials have coefficients large enough for the example considered, but, for reasons discussed in section 3.2, were deemed unsatisfactory.

\subsection{TRANSVERSE VS LONGITUDINAL EO COEFFICIENTS}

Some of the largest coefficients in Table 2 are longitudinal $r_{51}$, and some are transverse $r_{33}$ components. In many instances in the literature, the figure of merit for an EO deflector is given as $n^{3} r_{i j}$ regardless of what the values of $i$ and $\mathrm{j}$ are. This is at best misleading. For example, consider the two materials SBN:60 and $\mathrm{BaTiO}_{3}$; the former has a transverse $\mathrm{EO}$ coefficient $\mathrm{r}_{33}=420 \mathrm{pm} /$ and the latter has a longitudinal EO coefficient $r_{s 1}=820 \mathrm{pm} / \mathrm{N}$. Therefore, one might expect 
Table 2. EO materials

\begin{tabular}{|l|c|c|c|}
\hline Material & $\begin{array}{c}\text { EO Coefficient } \\
(\mathrm{pm} N)\end{array}$ & Index & $\begin{array}{c}\text { Dielectric Constant } \\
\text { (Relative) }\end{array}$ \\
\hline $\mathrm{KTN}\left(\mathrm{r}_{51}\right)$ & 8000 & 2.32 & - \\
$\mathrm{SCNN}\left(\mathrm{r}_{33}\right)$ & $>1800$ & -- & 1700 \\
$\mathrm{SBN}: 75\left(r_{33}\right)$ & 1340 & 2.30 & 3400 \\
$\mathrm{PBN}: 60\left(r_{33}\right)$ & 1000 & - & 310 \\
$\mathrm{BaTiO}{ }_{3}\left(r_{51}\right)$ & 820 & 2.41 & 60 \\
$\mathrm{SBN}: 60\left(r_{33}\right)$ & 420 & - & 880 \\
$\mathrm{KN}\left(r_{51}\right)$ & 380 & - & - \\
$\mathrm{SNN}\left(r_{51}\right)$ & 420 & - & 1500 \\
$\mathrm{BSKNN}\left(r_{33}\right)$ & $150-270$ & - & 200 \\
$\mathrm{BSN}\left(r_{51}\right)$ & 92 & - & 57 \\
$\mathrm{KLN}\left(r_{33}\right)$ & 80 & - & 115 \\
$\mathrm{LiNbO}\left(r_{33}\right)$ & 31 & 2.27 & 28 \\
$\mathrm{LiTaO}{ }_{3}\left(r_{33}\right)$ & 30 & 2.18 & 43 \\
$\mathrm{KD}{ }^{\star} \mathrm{P}\left(r_{63}\right)$ & 24 & 1.51 & 58 \\
$\mathrm{KDP}\left(r_{63}\right)$ & 9 & 1.51 & 44 \\
\hline
\end{tabular}

$\mathrm{BaTiO}_{3}$ to produce a larger deflection for the same applied electric field. In order to make use of the material with the tranverse coefficient, the electric field must be chosen parallel to the $z$ axis. For light propagating along the $y$ direction and polarized parallel to $z$, the change in index is:

$$
\Delta n_{z}=(-1 / 2) n_{e}^{3} r_{33} E_{z}
$$

The spatial arrangement of the electric field, polarization, and crystal axes are shown in Figure 10. However, if an orthogonal arrangement in a material with the longitudinal component is chosen such that $E$ is parallel to the $x$ axis and light propagated along $z$ (as shown in Figure 10), the change in index has a secondorder dependence on both $E$ and $\mathrm{rr}^{::^{37}}$

$$
\Delta n_{x}=\frac{n_{e}^{3} r_{51}^{2} E_{x}^{2}}{2\left(n_{0}^{-2}-n_{e}^{-2}\right)}
$$




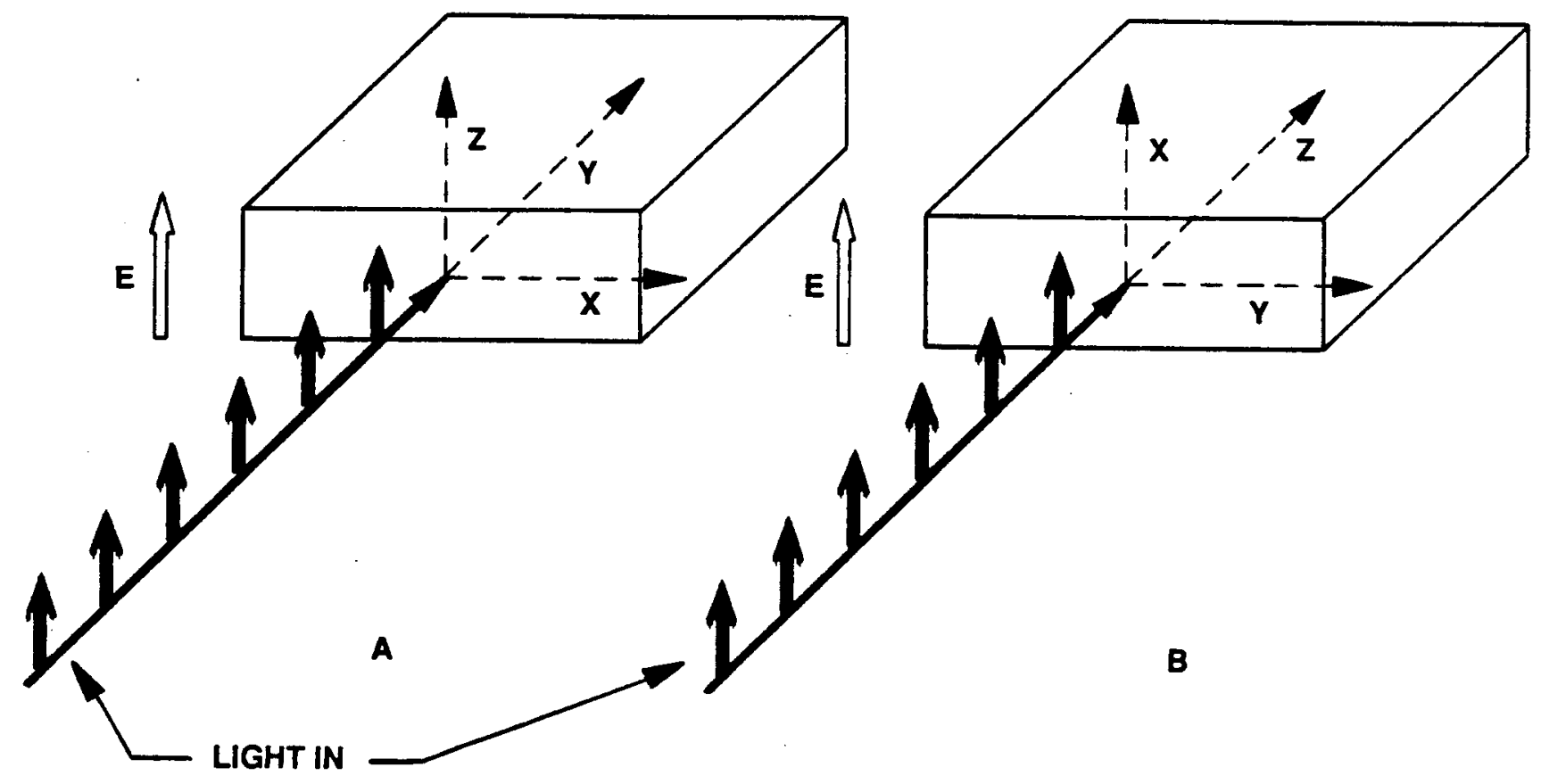

Figure 10. Geometries for making use of a transverse (A.) and longitudinal (B.) electrooptic coefficient.

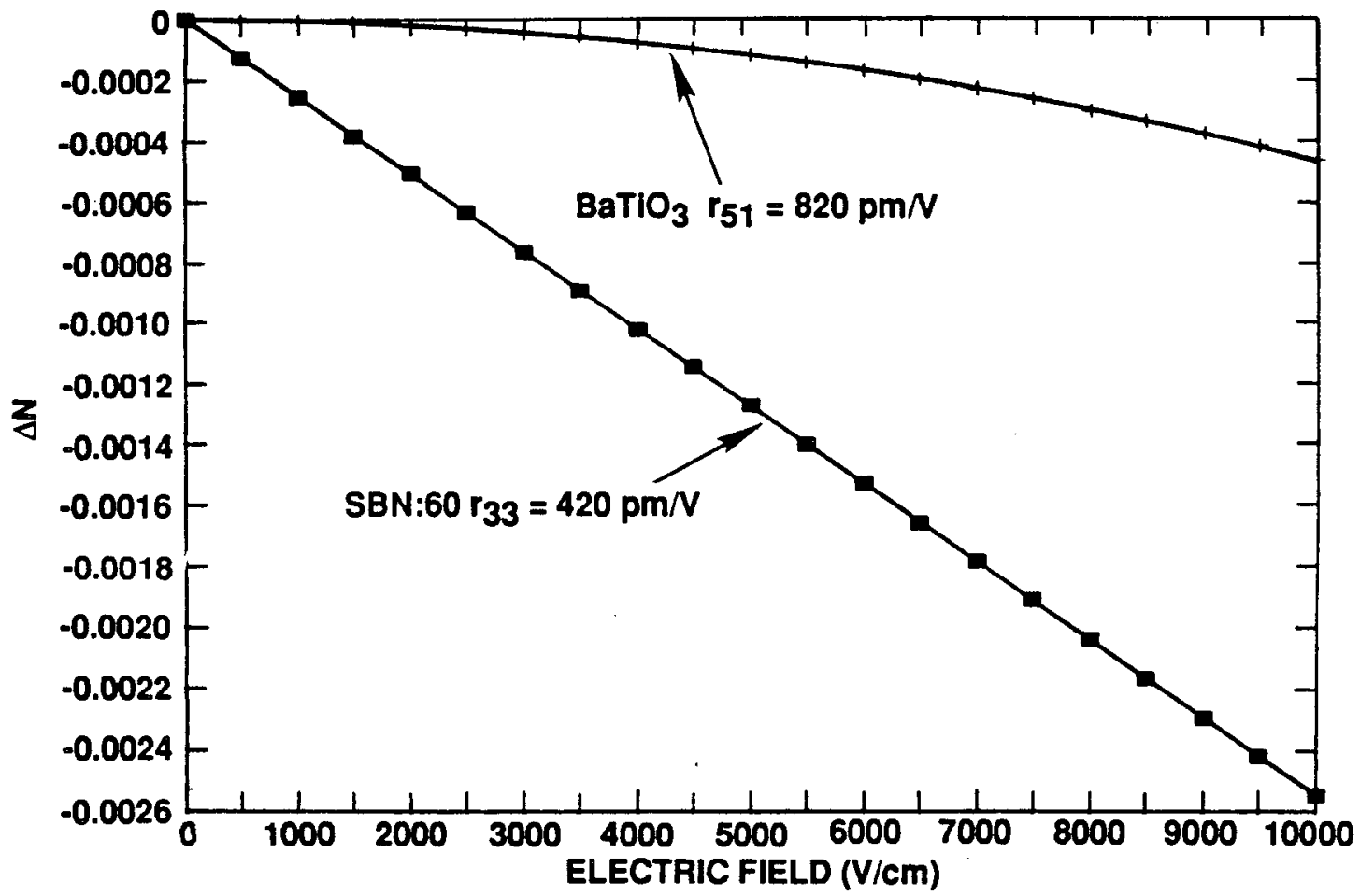

Figure 11. Comparison of the change in index of refraction for EO materials having coefficients $r_{33}$ and $r_{51}$. 
The two expressions were evaluated and plotted in Figure 11. For reasonable field strength the effect for $\mathrm{BaTiO}_{3}$ is much smaller than that for SBN:60 even though the EO coefficient for the former material is a factor of two larger. It is interesting to note that the field strength required for the quadratic response in $\mathrm{BaTiO}_{3}$ to equal the linear response of SBN:60 calculated from Equations (28) and (29) is about $60 \mathrm{kV} / \mathrm{cm}$. BaTiO 3 can, however, be used as a beam deflector with a large response when operated above its Curie temperature (about $120^{\circ} \mathrm{C}$ ) where it has a cubic structure. . $^{\text {s.so }}$ In this mode of operation the EO coefficient is large and quadratic. 


\section{SPECIFIC CRYSTALS, GROWING TECHNIQUES, RECOMMENDATIONS}

This section contains discussion and data sheets on several candidate materials. Detailed growing techniques are included for several of the more likely candidates, with references to further sources of information in the reference list at the end of the report. Comparisons are made and the materials ranked in order of preference for growing for the application of $E O$ deflector. A new material, SCNN ( $\mathrm{Sr}_{2-x} \mathrm{Ca}_{2} \mathrm{NaNb}_{5} \mathrm{O}_{15}$ ), is mentioned in the literature ${ }^{12}$ and apparently is being developed by Neurgaonkar. It is reported to have an $r_{33}$ value greater than $1800 \mathrm{pm} / \mathrm{V}$ and dielectric constant $\varepsilon_{33}=\varepsilon_{11}=1700$. Growth and other details of this material are not included in the following as they are not yet available. The values for EO coefficients and indices of refraction given here have been obtained from the literature and for the most part have been determined in the visible, often at either $633 \mathrm{~nm}$ or $532 \mathrm{~nm}$.

\subsection{SPECIFIC MATERIALS DISCUSSIONS}

\subsection{1 $\quad \mathrm{LiNbO}_{3}$}

This material is discussed first to serve as a reference point since it is one of the most common EO materials in use. Its widespread use is in part due to the fact that it has the largest EO coefficient of readily available materials. It can be supplied by several commercial suppliers in large sizes, and is not hygroscopic as, for example, KDP and its isomorphs. $\mathrm{LiNbO}_{3}$ is a ferroelectric material of the perovskite group with rombohedral symmetry and belongs to the point group $3 \mathrm{~m}$. Crystals can be grown in sizes larger than $5 \mathrm{~cm}$ with good optical quality and they can be cut and polished without fracturing or depoling problems. They can be poled into single ferroelectric domains and are not easily depoled due to the high Curie temperature $\left(1150^{\circ} \mathrm{C}\right)$. The largest EO component is $r_{30}=30.8 \mathrm{pm} / \mathrm{V}$. The crystals are grown by the Czochralski crystal pulling technique at a growth temperature of $1253^{\circ} \mathrm{C}$. The spectral transmission is high over the range 400 to $5000 \mathrm{~nm}$. (See References 38-41 for further discussions of material properties; $42-43$ for growth techniques; and Section 4.2 for a detailed data sheet.)

\subsection{2 $\quad \underline{\mathrm{LiTaO}_{3}}$}

This material is mentioned here because, like $\mathrm{LiNbO}_{3}$, it is available commercially. It is also a perovskite belonging to the point group $3 \mathrm{~m}$ with the largest $E O$ coefficient $r_{33}=30.3 \mathrm{pm} / \mathrm{N}$, which is nearly as large as the value for $\mathrm{LiNbO}_{3}$. It is somewhat more difficult to grow because the growth temperature is 
about $400^{\circ}$ higher than for $\mathrm{LiNbO}_{3}$. Its Curie temperature $\left(1010^{\circ} \mathrm{C}\right)$ is well above room temperature. Discussions regarding this material with Dr. Clive Ireland, ${ }^{23}$ who did the quadrupole deflector work with $\mathrm{LiNbO}_{3}$, reveal that he feels that it could stand up better to the shocks produced from the electrical driving energy, as the unclamped (low-frequency) and clamped (high-frequency) values of the EO coefficient are nearly the same and therefore less energy may go into low-frequency sonic shock. The transmission range is 400 to $5000 \mathrm{~nm}$. (See References 44 and 45 for more details, and the data sheet in Section 4.2.)

\subsection{3 $\mathrm{KTN}\left(\mathrm{KTa}_{\mathbf{2}} \mathrm{Nb}_{1-x} \mathrm{O}_{3}\right)$}

The material $\mathrm{KTN}$ is a solid solution of the perovskites $\mathrm{KTaO}_{3}$ and $\mathrm{KNbO}_{3}$ which have nearly the same lattice constants in their cubic phases; however, their Curie temperatures are quite different $\left(-289^{\circ} \mathrm{C}\right.$, and $405^{\circ} \mathrm{C}$, respectively). The Curie temperature for the solution varies with $x$ over the range $10-17^{\circ} \mathrm{C}$. For $x=0.65$ the Curie temperature is about $10^{\circ} \mathrm{C}$, resulting in the crystal being cubic at room temperature. ${ }^{46} \mathrm{KTN}$ is tetragonal and belongs to the same symmetry group as $\mathrm{BaTiO}_{3}, 4 \mathrm{~mm}$, below its Curie temperature. In the tetragonal phase the largest EO coefficient (unclamped) is $r_{51}=3000-8000 \mathrm{pm} / \mathrm{V}$ (depending on composition and temperature). Chen et al. ${ }^{18}$ have reported a change in index of $7 \times 10^{-3}$ in a prism deflector operated in the quadratic mode at the angle of minimum deviation in a temperature-controlled chamber.

One disadvantage of operating a material near its Curie temperature is that the EO coefficient and dielectric constant are strongly temperature-dependent, often following the Curie-Weiss law with a dependence of $\left(T-T_{0}\right)^{-1}$ where $T$ is the variable temperature and $T_{e}$ is the Curie temperature. Another problem with materials having Curie temperatures close to room temperature is that they easily become unpoled when being polished or cut.

KTN is difficult to grow reliably, but has been grown in small sizes by Bonner et al. ${ }^{46}$ and also by Fukuda and Hirano. ${ }^{47}$ Dr. Henry Taylor at Texas A\&M reports that another professor at his institution, Dr. Pandey, has grown fairly large $(1.5 \mathrm{~cm}) \mathrm{KTN}$ crystals successfully. This is encouraging, however the other difficulties with the material remain.

\subsection{4 $\quad \underline{\mathrm{BaTiO}_{3}}$}

Barium titanate is also a ferroelectric perovskite having a tetragonal crystal structure with point group symmetry $4 \mathrm{~mm}$ at room temperature. The largest EO coefficient is $r_{k 2}=r_{51}=820 \mathrm{pm} / \mathrm{V}$. Consequently, as discussed in Section 3.3, a small second order effect occurs when the electric field is parallel to the $x$ (or $y$ ) axis at room temperature. However, it can produce a large quadratic EO effect when operated above its Curie temperature $\left(120^{\circ} \mathrm{C}\right) 4^{400}$

$\mathrm{BaTiO}_{3}$ is a difficult material to grow in large sizes and to cut and polish, and does not permit rough handling. Furthermore it is not readily available in 
optical quality. The only commercial source in the U.S. is Sanders Associates where the top-seeded growth method of $\mathrm{Linz}^{51}$ is used to grow $0.5-\mathrm{cm}$ sized crystals. Thin plates can also be grown by the Remeika technique..$^{52}$

Another problem with $\mathrm{BaTiO}_{3}$ is a result of its prototype symmetry of $3 \mathrm{~mm}$, which has three equivalent 4-fold axes resulting in frequent $90^{\circ}$ twin problems. In spite of its problems, however, $\mathrm{BaTiO}_{3}$ has been used as a modulator ${ }^{3.54}$ and is being studied for its photorefractive effects. ${ }^{55.56}$

\subsection{5 $\mathrm{SBN}\left(\mathrm{Sr}_{1-\times} \mathrm{Ba}_{\times} \mathrm{Nb}_{2} \mathrm{O}_{6}\right)$}

SBN is a ferroelectric crystal belonging to the photorefractive tungsten bronze family. It is a solid solution of $\mathrm{Sr}_{7} \mathrm{Nb}_{2} \mathrm{O}_{6}$ and $\mathrm{BaNb}_{2} \mathrm{O}_{6}$ and can be grown with $x$ values ranging from 0.25 to 0.75 . SBN:60 is the only congruent melting mixture in the system and therefore is the easiest to grow. The only known grower of large quality SBN crystals in the U.S. at present is Dr. R. Neurgaonkar at the Rockwell Science Center. However, earlier growth of SBN was accomplished by Ballman and Brown at Bell Laboratories in 1967 using the Czochralski technique. 23,4 They grew crystals over the composition range $x=0.25$ to 0.75 . Lenzo and coworkers ${ }^{57,15,8}$ measured the EO coefficients, indices of refraction, and dielectric constants of SBN crystals and at frequencies from dc to $100 \mathrm{MHz}$. The values for the voltage required to produce one-half wave relative phase shift between ordinary and extraordinary rays are listed in Table 3.

Table 3. Half-Wave Field-Distance Products for SBN: $1-x$

$$
(\lambda=633 \mathrm{~nm})
$$

\begin{tabular}{|cccc|}
\hline$f(\mathrm{MHz})$ & \multicolumn{3}{c|}{$(\mathrm{E} \cdot \mathrm{L}) \lambda / 2(\mathrm{~V})$} \\
& $1-\mathrm{x}=0.75$ & $1-\mathrm{x}=0.50$ & $1-\mathrm{x}=0.25$ \\
$\mathrm{dc}$ & 37 & 250 & - \\
1 & 80 & 676 & 1340 \\
15 & 48 & 580 & 1236 \\
100 & - & 580 & - \\
\hline
\end{tabular}


For comparison, the half-wave voltage for $\mathrm{LNbO}_{3}$ would be $2.8 \mathrm{kV},{ }^{57}$ a factor of 60 larger than for SBN:75. From those measurements the $r_{33} E O$ coefficients for SBN:75 and SBN:60 are calculated to be $1340 \mathrm{pm} / \mathrm{V}$ and $420 \mathrm{pm} / \mathrm{V}$ respectively. The value of $\mathrm{r}_{51}$ for SBN:75 was determined by an indirect method of measuring the second order change in index of refraction (see Section 3.3). To my knowledge, these are the only published measurements of the EO coefficient for SBN although LLNL and perhaps others are in the process of making such measurements presently.

The properties and applications of SBN (and other tungsten bronze crystals) are described in References 2-12 and 59-68 while SBN growth techniques are provided in References 2-7. The Curie temperature of SBN:60 is $75^{\circ} \mathrm{C}$, and $56^{\circ} \mathrm{C}$ for SBN:75. The growth temperatures are nearly the same, about $1500^{\circ} \mathrm{C}$. Specific growth details and other data are given in the next section. (The Appendix is a report of a visit made to Dr. Neurgaonkar's laboratory, and which contains further details.) Neurgaonkar has spent 9 years developing the crystal growth of SBN and other tungsten bronze materials, with financial support from DARPA, ONR, AFOSR, $A R O$, and other sources. The potential applications extend beyond use as an EO deflector. Funding agencies are interested in its other applications using the EO effect, such as integrated optical waveguide components; photorefractive properties for various optical processing components, which are enhanced by doping with $\mathrm{Fe}$, $\mathrm{Ce}$, etc.; its millimeter wave properties for modulators and switches; its pyroelectric properties in the infrared (IR); and more recently its use as a substrate for growing high-temperature superconductors. (See Section 6.3 for further discussion of other applications.)

Crystals of SBN, especially SBN:60, have excellent optical quality and can be easily cut, machined, and polished with ordinary glass processing machines. Additionally, SBN does not suffer from the twin problems that $\mathrm{BaTiO}_{3}$ does, as its prototype paraelectric form has a symmetry that has only one axis with 4-fold symmetry. A critical factor in growing SBN is control of the temperature of the solid-liquid interface temperature.

\subsubsection{BSKNN (Baz-x $\left.\mathrm{Sr}_{x} \mathrm{~K}_{1} \mathrm{Na}_{y} \mathrm{Nb}_{5} \mathrm{O}_{15}\right)$}

Barium strontium potassium sodium niobate (BSKNN) is another tungsten bronze crystal which can be grown with tetragonal (4-mm) or orthorhombic $(2-\mathrm{mm})$ symmetry. Growth techniques are still being developed by Neurgaonkar at Rockwell, however it has been investigated recently as a self-pumped phase conjugator. ${ }^{65}$ Four different compositions have been grown at Rockwell: BSKNN-1, 2, 3 and 4. Crystals in this solid solution have higher Curie temperatures than for SBN, varying from $180^{\circ} \mathrm{C}$ for BSKNN-3 to $209^{\circ} \mathrm{C}$ for BSKNN-1. The Czochralski technique is used with a growth temperature of $1475-1480^{\circ} \mathrm{C}$. BSKNN-1, 2, 3 have EO coefficients $r_{30}=150,170$, and $270 \mathrm{pm} / \mathrm{V}$ and $r_{51}=200$, 350 , and $400 \mathrm{pm} / \mathrm{V}$, respectively. The crystals are reported to have good optical quality. The true congruent temperature has not been established yet, but it is believed that BSKNN-2 is closer to the congruent melting composition than BSKNN-1, as the latter is more difficult to grow. In addition some cracking is 
observed when cycling through the paraelectric/ferroelectric phase transition. (See the data sheet in the next section.)

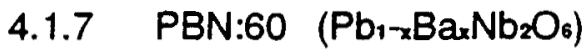

Lead barium niobate (PBN) is another ferroelectric crystal belonging to the tetragonal bronze family with $4 \mathrm{~mm}$ symmetry. ${ }^{0-12}$ However, this material can be grown with orthorhombic structure by varying the $\mathrm{Pb} / \mathrm{Ba}$ ratio. For $1-x=0.6$, the largest $E O$ coefficient is $r_{33}=1000 \mathrm{pm} / \mathrm{V}$.

That composition has a growth temperature of $1350^{\circ} \mathrm{C}$ and a Curie temperature of $350^{\circ} \mathrm{C}$. In the orthorhombic state $r_{s i}$ becomes the largest EO coefficient. This material exhibits very interesting properties near a morphotropic phase boundary (MPB) where EO and dielectric constants can be very large. This is discussed in Section 5.1.2. Also see the specific data sheet in Section 4.2.

\subsubsection{PLZT (Pbo.88La0.00(Ti0.35Zro.85) $\left.\mathrm{O}_{3}\right)$}

This is a ceramic material with $m$ symmetry and an effective transverse figure of merit, according to Yariv, ${ }^{13}$ of $2320 \mathrm{pm} / \mathrm{N}$, or an effective EO coefficient of about $140 \mathrm{pm} / \mathrm{V}$ at $540 \mathrm{~nm}$. The Curie temperature is $63^{\circ} \mathrm{C}$ and it exhibits a large quadratic EO effect above the Curie temperature. PLZT has found use in fast spatial light modulators, ${ }^{70}$ however its use as a transmissive deflector is somewhat limited as the optical quality is not very good and the absorption is high.

\subsubsection{SCNN ( $\left.\mathrm{S}_{2.2} \mathrm{Ca}_{2} \mathrm{NaNb}_{5} \mathrm{O}_{15}\right)$}

This is a new material developed by Neurgaonkar et al. ${ }^{12}$ which is reputed to have an EO coefficient ( $\left.\mathrm{r}_{33}\right)$ greater than $1800 \mathrm{pm} / \mathrm{N}$. If this is true, and if it can be grown with good optical quality, it could exceed the capabilities of SBN.

\subsection{SPECIFIC DATA SHEETS FOR SELECTED MATERIALS}

This section contains more specific information for each material. These materials include some of those crystals from which a ranking will be made for most suitable for EO deflector work:

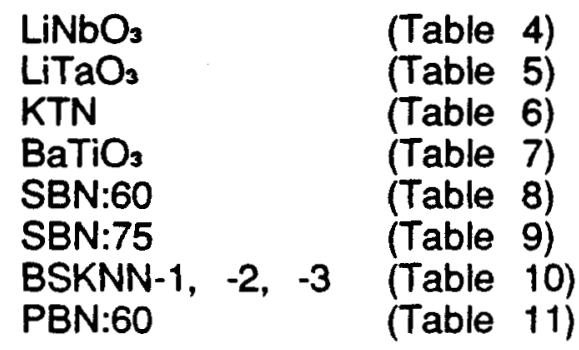


Table 4. Data sheet for $\mathrm{LiNbO}_{3}$

\begin{tabular}{|c|c|}
\hline Crystal type & Negative uniaxial-rhombohedral (3m) \\
\hline EO coefficients & $\begin{array}{l}r_{33}=30.8 \mathrm{pm} N \\
r_{51}=28.0 \mathrm{pm} N \\
r_{13}=8.6 \mathrm{pm} N \\
r_{22}=3.4 \mathrm{pm} N\end{array}$ \\
\hline Figure of merit $\left(r_{33}\right)$ & $360 \mathrm{pm} N$ \\
\hline Index of refraction & $\begin{array}{l}n_{e}=2.200(\text { at } 0.633 n \mathrm{~nm}) \\
n_{0}=2.286(\text { at } 0.633 \mathrm{~nm})\end{array}$ \\
\hline Relative dielectric constant & 28 \\
\hline Curie temperature & $1150^{\circ} \mathrm{C}$ \\
\hline Melt temperature & $1253^{\circ} \mathrm{C}$ \\
\hline Crystal growth technique & Czochralski \\
\hline $\begin{array}{l}\text { Pulling rate } \\
\text { Rotation rate } \\
\text { Remarks }\end{array}$ & $\begin{array}{l}1-10 \mathrm{~mm} / \mathrm{h} \\
60 \mathrm{rpm} \\
\text { Temperature of melt must be carefully controlled }\end{array}$ \\
\hline Size & $>5 \mathrm{~cm}$ \\
\hline Quality & High, easily poled into single domain \\
\hline Mechanical characteristics & Easily cut and polished, tolerates rough handling \\
\hline Transmission range & $400-5000 \mathrm{~nm}$ \\
\hline \multirow[t]{7}{*}{ Comments } & See References 38-43. \\
\hline & $\begin{array}{l}\text { The only material successfully used to date for fast } \\
\text { EO deflector with number of resolvable spots in the } \\
100 \text { range. }\end{array}$ \\
\hline & $\begin{array}{l}\text { The most commonly used EO material for Q-switches, } \\
\text { modulators, integrated optics substrates. Also used for } \\
\text { pulsed second harmonic generation and parametric } \\
\text { amplifiers. }\end{array}$ \\
\hline & Excellent optical quality and low transmission loss. \\
\hline & Easily machined, polished and worked. \\
\hline & $\begin{array}{l}\text { Suffers from photorefractive optical damage in the } \\
\text { visible; can be reduced with doping. Photorefraction } \\
\text { can also be increased with doping. }\end{array}$ \\
\hline & $\begin{array}{l}\text { Demonstrates physical damage when operated as a } \\
\text { fast EO streak camera possibly due to acoustical } \\
\text { resonances. }\end{array}$ \\
\hline
\end{tabular}


Table 5. Data sheet for $\mathrm{LiTaO}_{3}$

\begin{tabular}{|c|c|}
\hline Crystal type & Positive uniaxial-hombohedral (3m) \\
\hline EO coefficients & $\begin{array}{l}r_{33}=30.3 \mathrm{pm} N \\
r_{51}=20.00 \mathrm{pm} N \\
r_{13}=7.5 \mathrm{pm} N \\
r_{22}=1.0 \mathrm{pm} N\end{array}$ \\
\hline Figure of merit $\left(r_{33}\right)$ & $314 \mathrm{pm} N$ \\
\hline Index of refraction & $\begin{array}{l}n_{e}=2.180(\text { at } 0.633 \mathrm{~nm}) \\
n_{0}=2.176(\text { at } 0.633 \mathrm{~nm})\end{array}$ \\
\hline Relative dielectric constant & 43 \\
\hline Curie temperature & $610^{\circ} \mathrm{C}$ \\
\hline Melt temperature & $1650^{\circ} \mathrm{C}$ \\
\hline Crystal growth technique & Czochralski \\
\hline Size & $2-3 \mathrm{~cm}$ \\
\hline Quality & High optical quality, easily poled into single domain. \\
\hline Mechanical characteristics & Easily cut and polished, tolerates rough handling. \\
\hline Transmission range & $400-4000 \mathrm{~nm}$ \\
\hline \multirow[t]{7}{*}{ Comments } & See References 44-45. \\
\hline & $\begin{array}{l}\text { Commonly used for EO modulators in the bire- } \\
\text { fringent mode. }\end{array}$ \\
\hline & $\begin{array}{l}\text { Excellent optical quality and extremely low transmis- } \\
\text { sion loss. }\end{array}$ \\
\hline & Easily machined, polished, and worked. \\
\hline & $\begin{array}{l}\text { Does not suffer from photorefractive optical damage } \\
\text { in the visible like } \mathrm{LiNbO}_{3} \text {. }\end{array}$ \\
\hline & $\begin{array}{l}\text { Differs importantly from } \mathrm{LiNbO}_{3} \text { in having little dif- } \\
\text { ference in clamped and unclamped values for EO } \\
\text { coefficient, therefore chances of acoustic damage } \\
\text { are less. }\end{array}$ \\
\hline & Pyroelectric and acoustooptic properties. \\
\hline
\end{tabular}


Table 6. Data sheet for KTN $(x=0.63)$

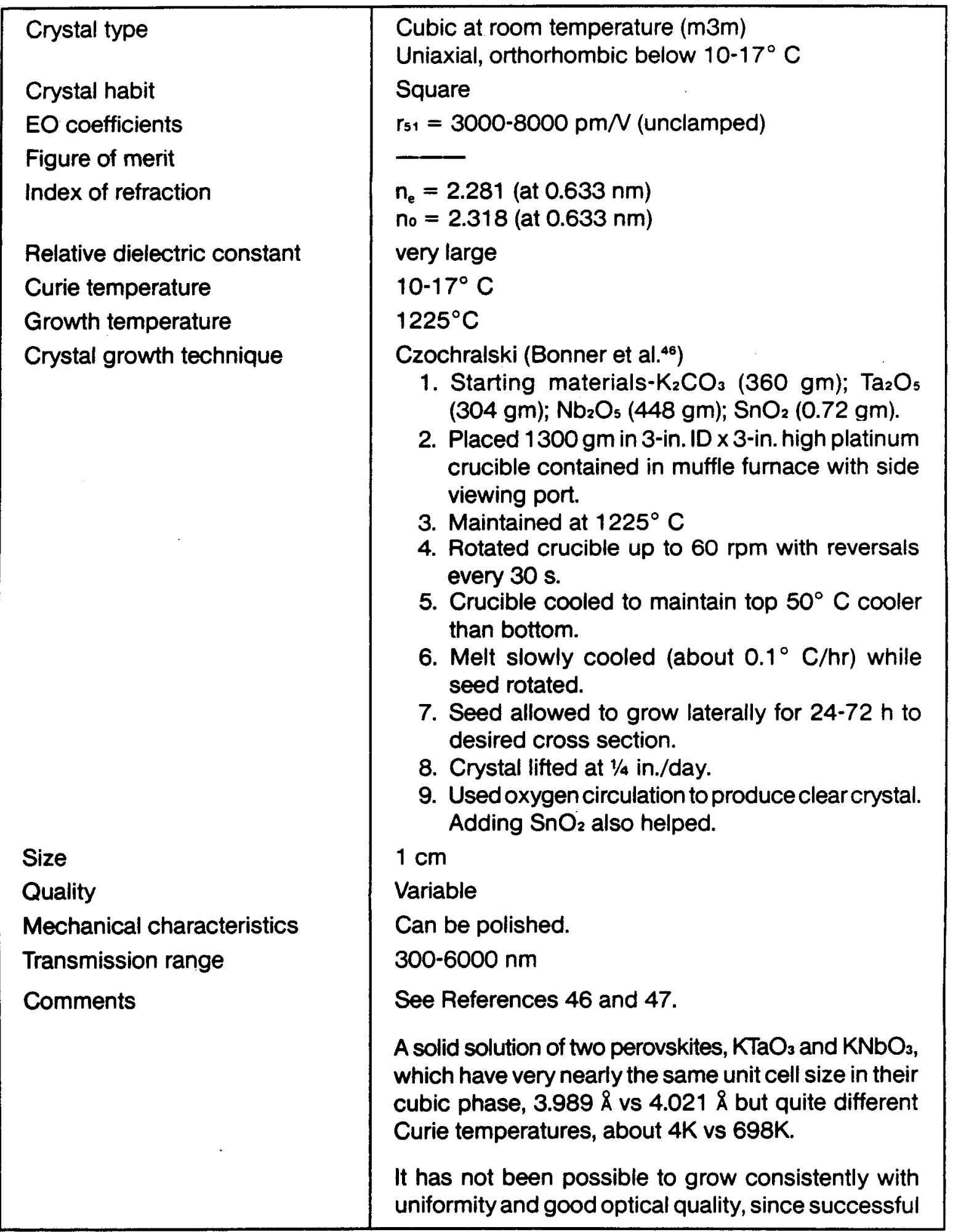


Table 6 Data sheet for KTN (cont.)

\begin{tabular}{|c|c|}
\hline Comments & $\begin{array}{l}\text { work by Bonner et al. in } 1965 \text {. However, recent results } \\
\text { by Pandey have produced } 1 \times 1.5-\mathrm{cm} \text { crystals which } \\
\text { look good visually. } \\
\text { Would normally be used in the quadratic mode at } \\
\text { room temperture where the EO effect is large. Proper- } \\
\text { ties would, however, be very temperature-dependent. } \\
\text { Temperature control to a small fraction of a degree is } \\
\text { probably necessary for EO use. }\end{array}$ \\
\hline
\end{tabular}


Table 7. Data sheet for $\mathrm{BaTiO}_{3}$

\begin{tabular}{|l|l|}
\hline Crystal type & Negative uniaxial-tetragonal (4mm) \\
EO coefficients & $r_{13}=8 \mathrm{pm} N$ \\
& $r_{33}=28 \mathrm{pm} N$ \\
$r_{51}=820 \mathrm{pm} N$
\end{tabular}




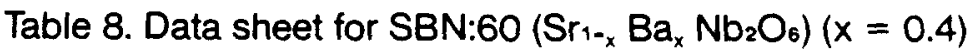

Crystal type
Crystal habit
EO coefficients
Figure of merit
Index of refraction
Relative dielectric constant
Curie temperature
Growth temperature
Crystal growth technique

Size

Quality

Mechanical characteristics

Transmission range

Comments
Negative uniaxial tetragonal tungsten bronze $(4 \mathrm{~mm})$

Cylindrical

$\mathrm{r}_{33}=420 \mathrm{pm} / \mathrm{N}$

$\mathrm{r}_{51}=42 \mathrm{pm} / \mathrm{N}$

$r_{13}=$

(r33) $5180 \mathrm{pm} / \mathrm{N}$

$\mathrm{n}_{\mathrm{e}}=2.28($ at $0.633 \mathrm{~nm})$

$n_{0}=2.31$ (at $\left.0.633 \mathrm{~nm}\right)$

$880\left(e_{3}\right) ; 470\left(e_{1}\right)$

$75^{\circ} \mathrm{C}$

$1510^{\circ} \mathrm{C}$

(See References 2-7)

1. Starting materials-melted pure $30.56 \% \mathrm{SrCO}_{3}$, $19.54 \% \mathrm{BaCO}_{3}$ and $49.92 \% \mathrm{Nb}_{2} \mathrm{O}_{5}$ (Sr.6 $\mathrm{Ba} .39 \mathrm{Nb}_{2} \mathrm{O}_{6}$ )

2. Ball-milled in acetone for $10-15 \mathrm{~h}$

3. Slurry air dried and fired in a platinum dish at $1000-1300^{\circ} \mathrm{C}$ for $24 \mathrm{~h}$

4. Placed sintered powder in 2-in. platinum or iridium crucible.

5. Melted by if heating.

6. Pulled crystal with SBN seed using Czochralski technique.

7. Growth along c-axis.

8. Pulling rate $5-7 \mathrm{~mm} / \mathrm{h}$

9. Rotation rate $15-25 \mathrm{rpm}$.

10. Remarks-Temp. of melt and diameter of crystal and thermal gradient near the solid-liquid interface must be carefully controlled.

$>2-3 \mathrm{~cm}$ diam, several $\mathrm{cm}$ long.

High optical quality, easily poled into single domain with $5-8 \mathrm{kV} / \mathrm{cm}$ along c-axis.

Can be cut and polished, crack-free.

$400-5000 \mathrm{~nm}$

Large EO coefficients first measured in 1967. Has large favorable $\mathrm{r}_{33} \mathrm{EO}$ component, unlike $\mathrm{BaTiO}_{3}$. Does not have twinning and cracking problems of $\mathrm{BaTiO}_{3}$.

The only congruent melting composition in the $\mathrm{SrNb}_{2} \mathrm{O}_{6}-\mathrm{BaNb}_{2} \mathrm{O}_{6}$ system. Growth of $\mathrm{SBN}: 60$ and 
Table 8. Data sheet for SBN:60 (cont.)

\section{Comments}

SBN:50 easier than other bronze compositions. Crystals are of excellent quality: clear and transparent (if grown in $\mathrm{O}_{2}$ ). They exhibit well-defined facets. Striations can occur; need automatic diameter control. Strong influence dopants and contaminants. Thermal gradient in the solid near the solid/liquid interface should be low $\left(10-40^{\circ} \mathrm{C}\right)$.

Crystal quality found to depend on:

1. Impurities in starting materials: $\mathrm{Ca}^{2+}, \mathrm{Fe}^{3+}$, $\mathrm{Mg}^{2+}, \mathrm{Na}^{+}$.

2. Need faster rotation and pulling rates to control temperature instability from poor thermal conductivity.

3. Cooling rate affects relative amounts of $\mathrm{Sr}^{2+}$ and $\mathrm{Ba}^{2+}$ on 15- and 12-fold coordinated sites. 
Table 9. Data sheet for SBN:75 $\left(\mathrm{Sr}_{1-x} \mathrm{Ba}_{\mathrm{x}} \mathrm{Nb}_{2} \mathrm{O}_{6}\right)(x=0.25)$

\begin{tabular}{|c|c|}
\hline Crystal type & Negative uniaxial tetragonal tungsten bronze $(4 \mathrm{~mm})$ \\
\hline Crystal habit & Cylindrical \\
\hline EO coefficients & $\begin{array}{l}r_{33}=1300-1400 \mathrm{pm} N \\
r_{51}=42 \mathrm{pm} N \\
r_{13}=\end{array}$ \\
\hline Figure of merit & $\left(r_{33}\right) 17300 \mathrm{pm} N$ \\
\hline Index of refraction & $\begin{array}{l}n_{e}=2.2987(\text { at } 0.633 n m) \\
n_{0}=2.3117(\text { at } 0.633 n m)\end{array}$ \\
\hline Relative dielectric constant & $3400\left(e_{3}\right) ;-\left(e_{1}\right)$ \\
\hline Curie temperature & $56^{\circ} \mathrm{C}$ \\
\hline Growth temperature & near $1500^{\circ} \mathrm{C}$ \\
\hline Crystal growth technique & Czochralski with if heating \\
\hline Size & $>$ Few $\mathrm{cm}$ \\
\hline Transmission range & $400-5000 \mathrm{~nm}$ \\
\hline \multirow[t]{4}{*}{ Comments } & $\begin{array}{l}\text { Large EO coefficients first reported in } 1967 . \text { Has } \\
\text { large favorable } r_{33} \mathrm{EO} \text { component, unlike } \mathrm{BaTiO}_{3} \text {. } \\
\text { Does not have twinning and cracking problems of } \\
\text { BaTiO. }_{3}\end{array}$ \\
\hline & $\begin{array}{l}\text { Has much larger } \mathrm{r}_{33} \text { component than SBN: } 60 \text {; therefore } \\
\text { could be very useful for EO devices. }\end{array}$ \\
\hline & $\begin{array}{l}\text { Not much in literature-apparently much harder to } \\
\text { grow high-quality crystals than SBN: } 60 \text {. }\end{array}$ \\
\hline & See Table 8 for growth technique. \\
\hline
\end{tabular}


Table 10. Data sheet for BSKNN (Ba2-x $\left.\mathrm{Sr}_{x} \mathrm{~K}_{1-y} \mathrm{Na}_{y} \mathrm{Nb}_{5} \mathrm{O}_{15}\right)$

$(x=0.5, y=0.25-B S K N N-1 ; x=1, y=0.5-B S K N N-2 ; x=1, y=0.75-B S K N N-3)$

\section{Crystal type \\ Crystal habit \\ EO coefficients}

Figure of merit

Index of refraction

Relative dielectric constant

Curie temperature $\left({ }^{\circ} \mathrm{C}\right)$

Growth temperature $\left({ }^{\circ} \mathrm{C}\right)$

Crystal growth technique

Size $(\mathrm{cm})$

Quality

Transmission range

Comments
BSKNN-1 Tetragonal tungsten bronze $(4 \mathrm{~mm})$

BSKNN-2 Tetragonal tungsten bronze $(4 \mathrm{~mm})$

BSKNN-3 Tetragonal tungsten bronze $(4 \mathrm{~mm})$

BSKNN-1 Square BSKNN-2 Octahedron

BSKNN-3 Octahedron

BSKNN-1 $r_{33}(\mathrm{pm} / \mathrm{N}) 150$ BSKNN-2 170

BSKNN-3 270

BSKNN-1 $r_{51}(\mathrm{pm} / \mathrm{N}) 200$ BSKNN-2 350

BSKNN-3 400

BSKNN-1 ( $\left.r_{33}\right) 1873 \quad$ BSKNN-2 2123

BSKNN-3 3372

BSKNN-1 (pm $N)$

$n_{\mathrm{e}}=-\cdots$

$n_{0}=-$

BSKNN-1 e e 120 BSKNN-2 170

BSKNN-3 270

BSKNN-1 e 360 BSKNN-2 750

BSKNN-3 780

BSKNN-1 209 BSKNN-2 175 BSKNN-3 180

BSKNN-1 $1480 \quad$ BSKNN-2 1475

BSKNN-3 1475

Czochralski with if heating

BSKNN-1 1.0 BSKNN-2 1.5 BSKNN-3 1.5

Good optical quality, some cracking

Large unit cell tungsten bronze with $r_{33}$ EO coefficient almost as large as SBN:60. (See References 9, 10,12 , and 69).

Some problems in growing:

1. Difficult to determine true congruent melting composition, therefore striation problems.

2. Container contamination particularly with iridium crucible.

3. Cracking of crystals when cycling through the phase transition temperature.

4. Lower dielectric constants than $\operatorname{SBN}\left(\varepsilon_{33}\right)$ and different temperature effects. 
Table 11. Data sheet for PBN:60 (Pb+-x $\left.\mathrm{Ba}_{x} \mathrm{Nb}_{2} \mathrm{O}_{6}\right)(x=1.0$ to 0.22$)$

\begin{tabular}{|c|c|}
\hline Crystal type & $\begin{array}{l}\text { Tetragonal tungsten bronze }(4 \mathrm{~mm}) \text { or orthorhombic } \\
\text { depending on the ratio of } \mathrm{Pb} / \mathrm{Ba}\end{array}$ \\
\hline Crystal habit & Square \\
\hline EO coefficients & $\begin{array}{l}r_{33}(x=0.4)=1000 \mathrm{pm} N \\
r_{51}=- \\
r_{13}=\end{array}$ \\
\hline Figure of merit & $\left(r_{33}\right) 12170 \mathrm{pm} / \mathrm{N}$ \\
\hline Index of refraction & $\begin{array}{l}\mathrm{n}_{\mathrm{e}}=-- \\
\mathrm{n}_{\mathrm{0}}=-\end{array}$ \\
\hline Relative dielectric constant & $310\left(e_{3}\right) ; 560\left(e_{1}\right)$ \\
\hline Curie temperature & $350^{\circ} \mathrm{C}$ \\
\hline Growth temperature & About $1350^{\circ} \mathrm{C}$ \\
\hline Crystal growth technique & Czochralski with if heating \\
\hline Size & $0.8-1 \mathrm{~cm}$ \\
\hline Quality & Some cracks, good quality. \\
\hline \multirow[t]{2}{*}{ Comments } & $\begin{array}{l}\text { Large unit cell bronze with } r_{33} \text { EO coefficient larger } \\
\text { than that for SBN:60. (See References } 9-12 \text { ) }\end{array}$ \\
\hline & $\begin{array}{l}\text { Of special interest, as can have coexisting phases } \\
\text { (tetragonal and orthorhombic) at a morphotropic } \\
\text { phase boundary where EO properties as well as } \\
\text { dielectric, pyroelectric, and piezoelectric properties } \\
\text { can be large. }\end{array}$ \\
\hline
\end{tabular}

\subsection{RANKING OF MATERIALS}

The electrooptic materials listed in Table 2 will be used to select the optimum candidate for deflector applications. The ranking of the materials necessarily involves some arbitrary judgement. However, it has been shown in the body of this report that the most critical factor is the size of the figure of merit or (since the indices of materials considered are nearly the same) the EO coefficient. If that quantity is not large enough the rest of the parameters are unimportant. Equally important is the prospect for growing usefully sized optical quality crystals which can be easily poled, machined, and polished. Also important are problems with twinning and cracking. The particular component for the EO coefficient has been shown in the report to be important. Nearly all the materials considered have 
either large transverse, $r_{33}$, or longitudinal, $r_{51}$, coefficients. The former allows a large linear EO deflection while the latter has a relatively small quadratic EO deflection unless the electric field is extremely large.

The ranking could be carried out with the aid of a matrix constructed with the first column a list of candidate materials and the top row negative and positive characteristics for which each material would be rated and the other columns filled with weighting factors. Many of the characteristics are not known that well for some of the materials, thus any weighting factor becomes rather arbitrary and a quantitative ranking could be misleading. In that light a relative comparison together with elimination on the basis of critical factors will be used. If the example of Section 3 for resolvable spots is used, then the EO coefficient should be $336 \mathrm{pm} / \mathrm{V}$ or figure of merit of about $4000 \mathrm{pm} / \mathrm{V}$. Even if we degrade this requirement to $2000 \mathrm{pm} / \mathrm{V}$ (200 resolvable spots) then BSN, KLN, LiNbO3, $\mathrm{LiTaO}_{3}, \mathrm{KD}^{*} \mathrm{P}$, AND KDP are eliminated as top candidates. The remaining materials are then the top eight in Table 2. Four of these materials have $r_{51}$ as their large EO coefficient, which we have shown is not desirable for deflector purposes. This leaves only four tungsten bronze materials, SBN:75, PBN:60, SBN:60 and BSKNN, to pick from. SCNN has not been considered since not enough is known about it yet. PBN:60 and BSKNN are more difficult to grow than SBN and have not been grown in sizes as large as SBN can be grown. Less work has been done with these two materials and optimum growth parameters are not yet established. In the SBN system SBN:60, as discussed earlier, is the congnent melting composition and therefore is the easiest to grow and has the best quality. It can be grown striation-free (according to Neurgaonkar) with no cracks and in large sizes. SBN:60 has a smaller figure of merit than SBN:75 but the latter is more difficult to grow with good quality.

On the basis of the discussion in the preceding paragraph a ranking of the top four materials would be: 1) SBN:60, 2) SBN:75, 3) BSKNN-2, 4) PBN:60. The ranking of the second group of four is based on the use of the two crystals

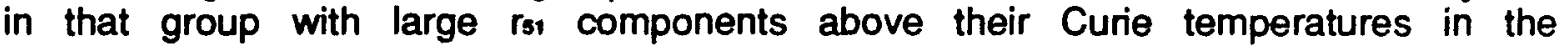
quadratic mode. KTN is rated the highest in this group due to its extremely large EO coefficient. It can be operated at room temperature in some compositions or somewhat above, where it has a cubic structure. It will, however, have an EO coefficient which is very temperature dependent. The second rated crystal in this group has to be $\mathrm{BaTiO}_{3}$ in spite of the twin problems and difficulty with poling. It also should be operated above its Curie temperature (approximately $120^{\circ} \mathrm{C}$ ) in the quadratic mode. The last two materials both have figures of merit too low to achieve a large number of resolvable spots. They both have approximately the same figure of merit; however, $\mathrm{LiTaO}_{3}$ has an $\mathrm{M}_{\mathbf{r}}$ slightly smaller than that of $\mathrm{LiNbO}_{3}$. The former should be rated higher, however, due to its photorefractive damage threshold and the possibility that it is less sensitive to acoustic shock. The ranking of the eight materials is shown in Table 12.

\subsection{MATERIAL RECOMMENDATIONS}

Based on the previous discussion and ranking (Section 4.3, Table 12), the recommendation is to start growing SBN:60. A Czochralski crystal puller capable of 
the operating characteristics described above for the tungsten bronze crystals should be obtained. Special attention should be given to the capability of automatic diameter control (ADC). According to Neurgaonkar, platinum crucibles should be used in preference to iridium for growth of these materials. The purest starting materials should also be obtained.

Table 12. Ranking of EO materials

\begin{tabular}{lcc|}
\hline Material & Rank & \\
SBN: 60 & 1 & \\
SBN: 75 & 2 & \\
BSKNN-2 & 3 & \\
$\mathrm{PBN}: 606$ & 4 & \\
$\mathrm{KTN}$ & 5 & Use above room temperature (quadratic) \\
$\mathrm{BaTiO}_{3}$ & 6 & Use above $120^{\circ} \mathrm{C}$ (quadratic) \\
$\mathrm{LiTaO}_{3}$ & 7 & \\
$\mathrm{LiNbO}_{3}$ & 8 & \\
\hline
\end{tabular}

Once the expertise is developed on SBN:60, samples could be made for EO deflector work or other applications. At that point it may be desirable to attempt other tungsten bronze materials, such as SBN:75, or doped materials, depending on the direction of the future R\&D effort. The latter would be important if EG\&G/EM decides to get involved in the photorefractive device area. 


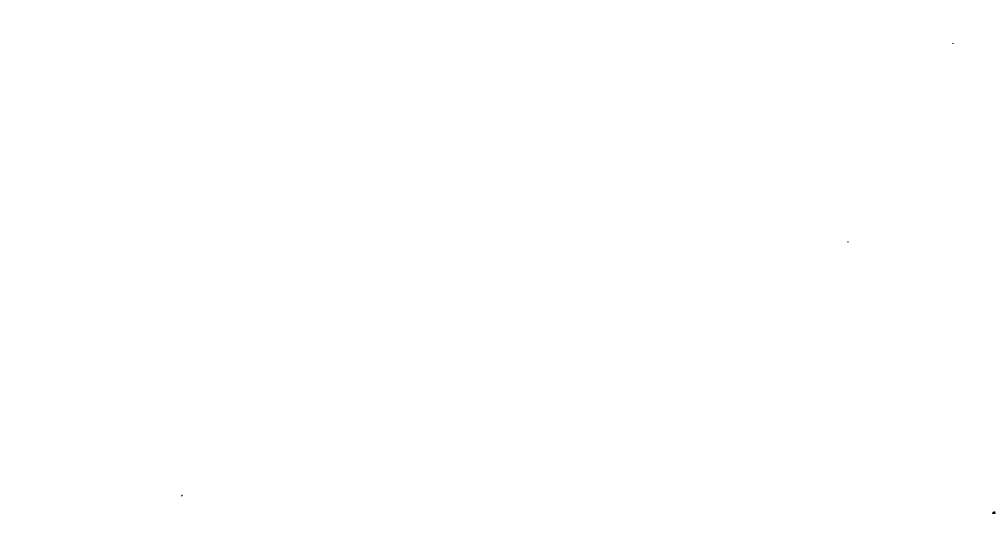




\section{TUNGSTEN BRONZE MATERIALS}

\subsection{DISCUSSION OF TUNGSTEN BRONZE MATERIALS}

Since the recommendation is to proceed with the growth of SBN, with other tungsten bronze materials as strong alternate candidates, further discussion of tungsten bronze materials is in order. The growth of these materials was discussed in the previous section and will not be treated in detail here. The Appendix contains pertinent information on tungsten bronze materials.

\subsubsection{General}

Several summary articles on tungsten bronze materials have appeared in the literature in the last two or three years. ${ }^{9-12}, 60$, Most were written by Neurgaonkar and his group at Rockwell. The main emphasis in these articles is the area of photorefractive properties of the materials. A list of tungsten bronze crystals is given in Table 13 (from Reference 18) with values for dielectric, piezoelectric, and EO constants; lattice constants; Curie temperatures; and crystal shapes. They are separated into two groups: tetragonal and orthorhombic. The tetragonal crystals all have large transverse $r_{33}$ EO coefficients while the orthorhombic crystals all have large longitudinal $r_{42}=r_{31}$ coefficients. The latter have apparently never been measured directly, but deduced from other known quantities.

Of all these materials, SBN:60 is the easiest to grow and has been the most studied. Other SBN compositions have been grown and studied from SBN:25 to SBN:75, the full range over which SBN can exist. As stated earlier, the congruent composition is SBN:60. SBN and the other tungsten bronze materials are grown with the Czochralski technique similar to the apparatus shown in Figure 12. An unusual feature of the tungsten bronze crystals grown by this technique is the presence of well-defined facets as shown in Figure 13.

\subsubsection{Morphotropic phase boundary compositions}

Several tungsten bronze and perovskite materials exhibit very large EO, piezoelectric, dielectric, and other properties near an MPB between two ferroelectric phases. This boundary occurs at nearly constant composition over a wide temperature range up to the Curie temperature. This phenomenon has been described by Jaffe et al. ${ }^{71}$ A phase diagram for $\mathrm{Pb}_{1-x} \mathrm{Ba}_{2} \mathrm{Nb}_{2} \mathrm{O}_{8}$ is given in Figure 14 where the two phases are tetragonal and orthorhombic. ${ }^{12}$ It has been shown from theoretical consideration by Cross and others ${ }^{22-74}$ that tetragonal crystals near MPB exhibit very large $r_{k 2}=r_{51}$ components based on the relationship

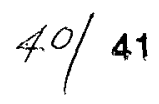


Table 13. List of important tetragonal and orthorhombic tungsten bronze crystals (From Neurgaonkar et al.")

\begin{tabular}{|c|c|c|c|c|c|c|c|c|c|c|}
\hline Composition & $\begin{array}{c}T_{c} \\
\left({ }^{\circ} \mathrm{C}\right)\end{array}$ & $\begin{array}{c}\text { Dielect } \\
\text { Coef } \\
\varepsilon_{33}\end{array}$ & $\begin{array}{l}\text { ric } \\
\varepsilon_{11}\end{array}$ & $\begin{array}{l}\text { iezoele } \\
\text { Coef } \\
d_{33}\end{array}$ & $d_{15}$ & $\begin{array}{c}\text { Electrooptic } \\
\text { Coefficient } \\
\times 10^{-12} \mathrm{~m} / \mathrm{N}\end{array}$ & $\begin{array}{l}\text { Unit Cell } \\
\qquad a\end{array}$ & $\begin{array}{l}\left(A^{\circ}\right) \\
b\end{array}$ & c & $\begin{array}{l}\text { Crystal } \\
\text { Shape }\end{array}$ \\
\hline \multicolumn{11}{|l|}{ Tetragonal-Crystals* } \\
\hline 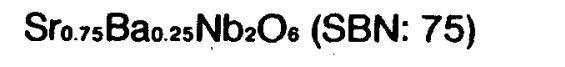 & 56 & 3400 & - & - & - & 1400 & 12.440 & - & 3.924 & C \\
\hline Sro.6Ba0.4Nb2 ${ }_{6}$ (SBN: 60) & 75 & 880 & 470 & 130 & 40 & 420 & 12.467 & - & 3.937 & C \\
\hline Sro.5Ba0.5 $\mathrm{Nb}_{2} \mathrm{O}_{6}$ (SBN: 50) & 128 & 450 & 300 & 100 & 60 & 180 & 12.475 & - & 3.952 & C \\
\hline $\mathrm{Sr}_{2} \mathrm{KNb}_{5} \mathrm{O}_{15}(\mathrm{SKN})$ & 150 & 1000 & 800 & 90 & 30 & 270 & 12.470 & - & 3.939 & C \\
\hline $\mathrm{Ba}_{2-x} \mathrm{Sr}_{x} \mathrm{~K}_{1-y} \mathrm{Na}_{y} \mathrm{Nb}_{5} \mathrm{O}_{15}(\mathrm{BSKNN})$ & 207 & 200 & 350 & 75 & 84 & 380 & 12.560 & - & 3.973 & $S$ \\
\hline $\mathrm{K}_{3} \mathrm{Li}_{2} \mathrm{Nb}_{5} \mathrm{O}_{15}$ & 405 & 115 & 306 & 57 & 68 & 80 & 12.580 & - & 4.015 & $\mathrm{~S}$ \\
\hline $\mathrm{Pb}_{0.8} \mathrm{Ba}_{0.4} \mathrm{Nb}_{2} \mathrm{O}_{6}$ (PBN: 60) & 350 & 310 & 560 & 100 & 300 & 1000 & 12.576 & - & 3.978 & $S$ \\
\hline $\mathrm{Ba}_{6} \mathrm{Ti}_{2} \mathrm{Nb}_{8} \mathrm{O}_{30}{ }^{\star \star}$ & 245 & 209 & 193 & - & - & 420 & 12.589 & - & 4.020 & $\mathrm{~S}$ \\
\hline \multicolumn{11}{|l|}{ Orthorhombic Crystals } \\
\hline $\mathrm{Pb}_{2} \mathrm{KNb}_{5} \mathrm{O}_{15}$ (PKN) & 460 & 129 & 1550 & 62 & 470 & $r_{42}=100$ & 17.780 & 17.961 & 7.784 & C \\
\hline $\mathrm{Ba}_{2} \mathrm{NaNb}_{5} \mathrm{O}_{15}(\mathrm{BNN})$ & 560 & 57 & 242 & 37 & 42 & $r_{42}=92$ & 17.590 & 17.613 & 7.982 & $\mathrm{C}$ \\
\hline $\mathrm{Sr}_{2} \mathrm{NaNb}_{5} \mathrm{O}_{15}$ (SNN) & 270 & 1500 & - & - & - & $r_{42}=400$ & 17.450 & 17.493 & 7.784 & C \\
\hline $\mathrm{K}_{2} \mathrm{BiNb}_{5} \mathrm{O}_{15}$ & 405 & 500 & 400 & - & - & - & 17.851 & 17.852 & 7.804 & C \\
\hline $\mathrm{K}_{3} \mathrm{Li}_{2} \mathrm{Nb}_{2.7} \mathrm{Ta}_{2.3} \mathrm{O}_{15}$ & 150 & 375 & 300 & - & - & - & - & - & - & C \\
\hline
\end{tabular}




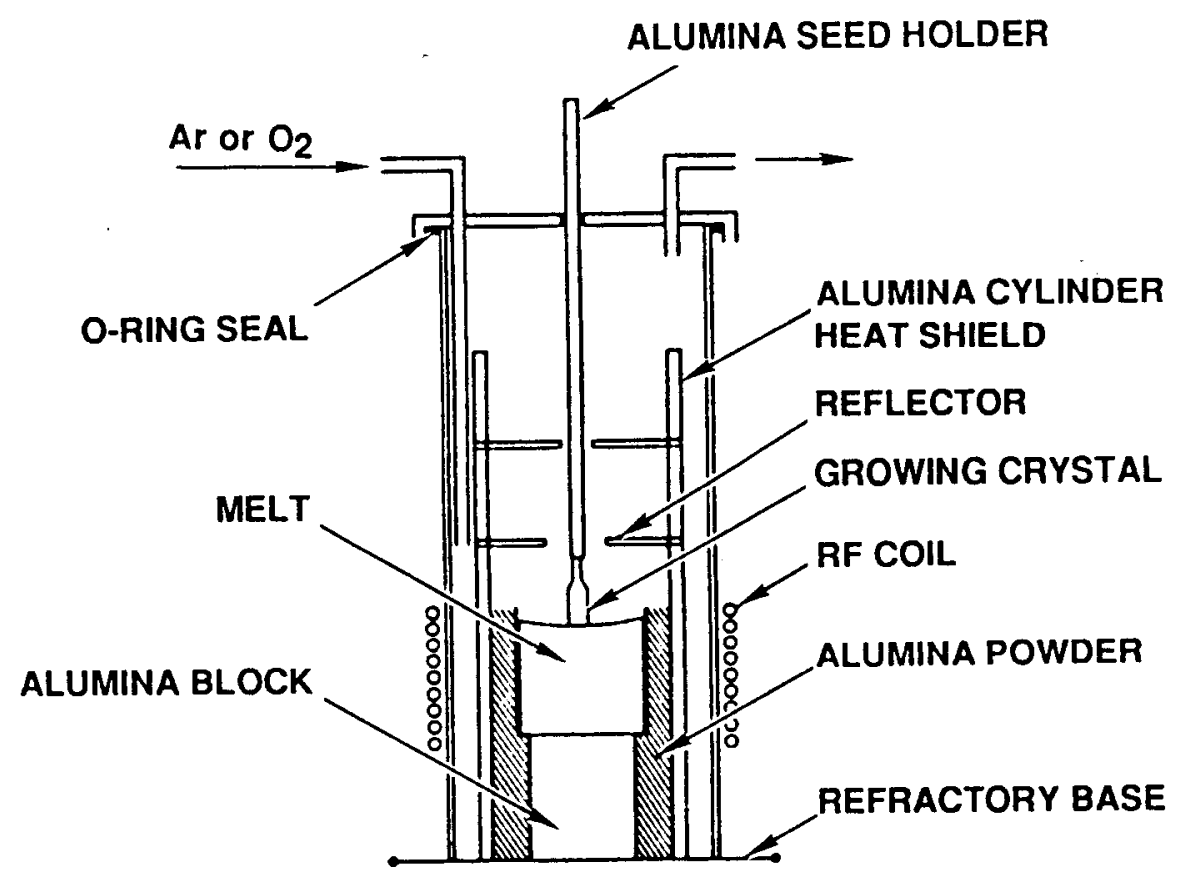

Figure 12. Czochralski crystal puller used by Neurgaonkar and coworkers to grow tungsten bronze crystals.
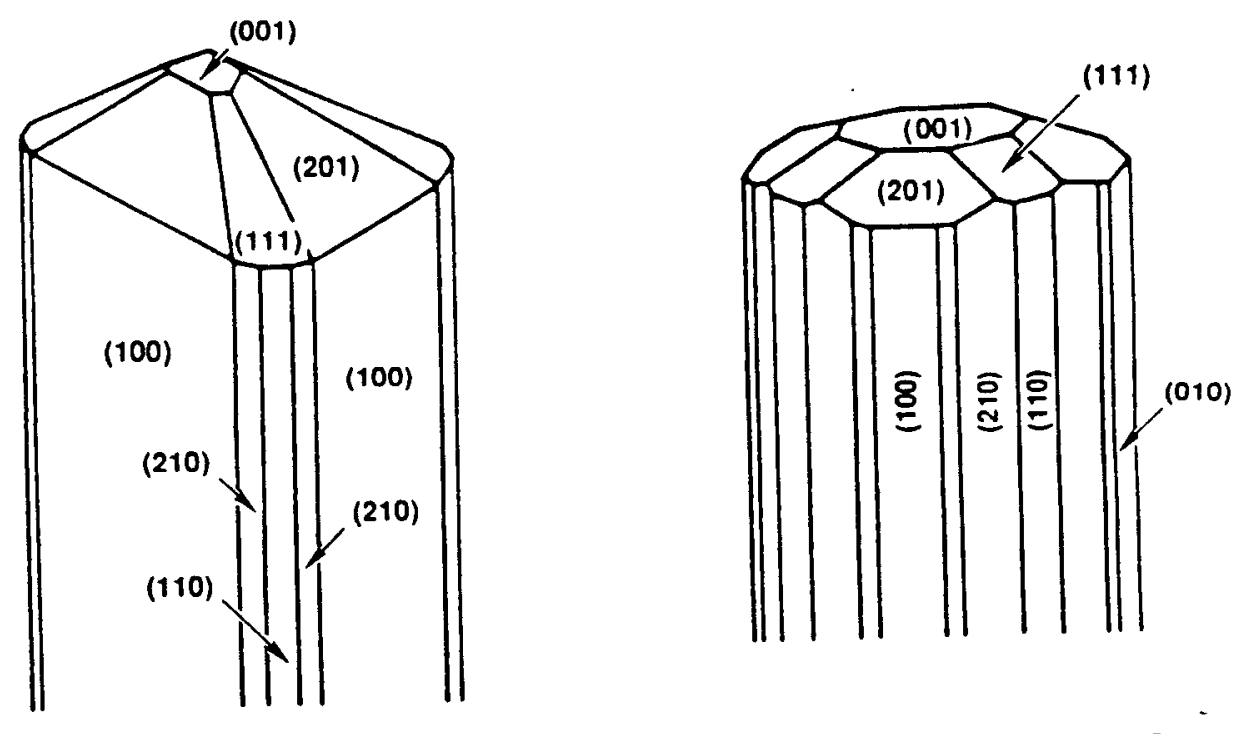

BIGGER UNIT CELL BRONZES

SMALLER UNIT CELL BRONZES

Figure 13. Facets on tungsten bronze crystals grown by the Czochralski technique. The smaller unit cell crystals such as SBN are cylindrical and have 24 facets, while the larger unit cell crystals like BSKNN and PBN:60 are square and have four facets. 


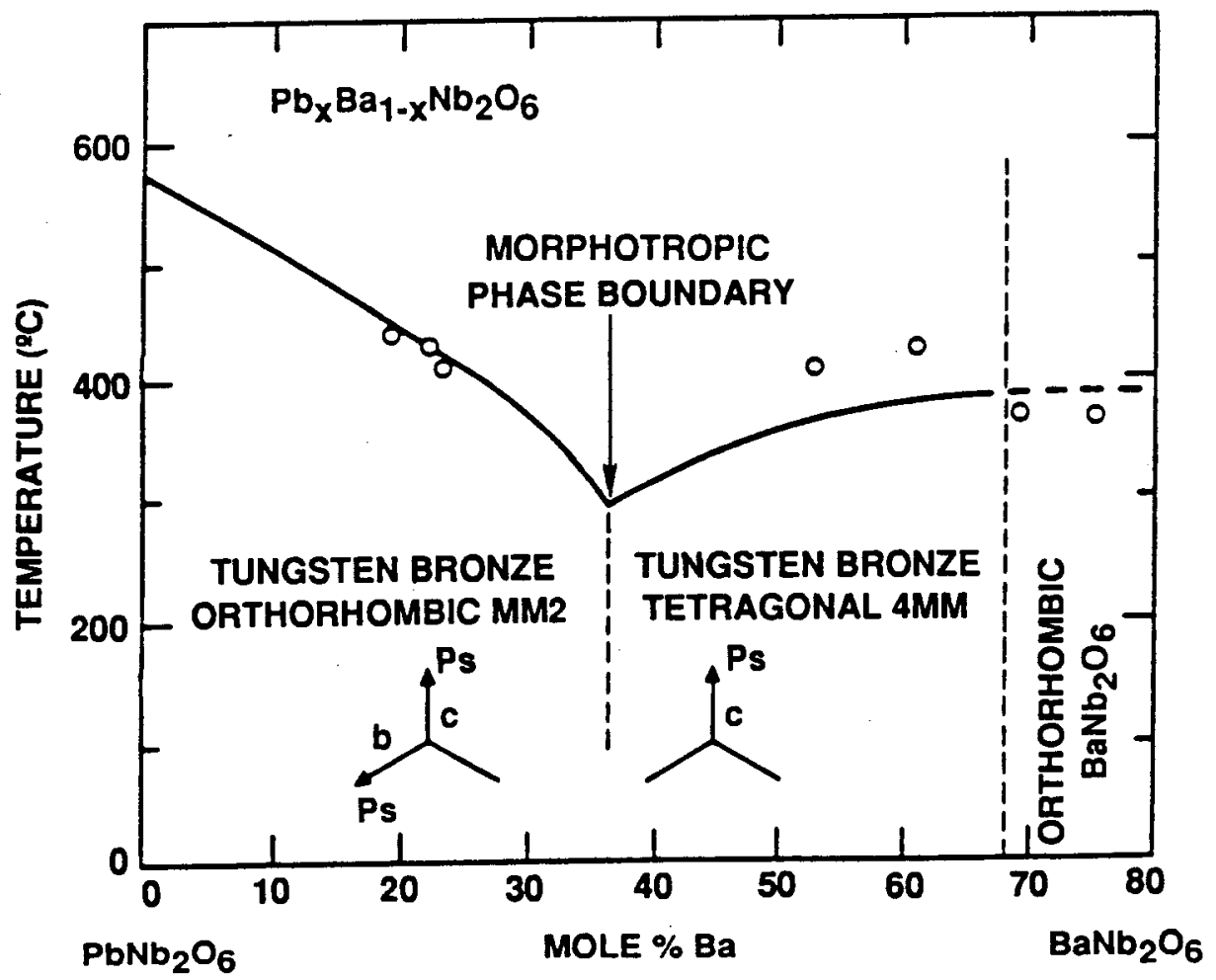

Figure 14. A phase diagram for the $\mathrm{Pb}_{\times} \mathrm{Ba}_{1-\mathrm{N}} \mathrm{Nb}_{2} \mathrm{O}_{8}$ system showing the morphotropic phase boundary where EO and dielectric coefficients can be very large.

$$
r_{42}=r_{51}=g_{44} P_{3} \varepsilon_{11} \varepsilon_{0}
$$

where $g_{44}$ is a quadratic coefficient of the high-temperature paraelectric prototype phase; $P_{3}$ is the c-axis component of the spontaneous polarization; and $\varepsilon_{11}$ is the a-axis component of the dielectric constant. The quadratic coefficient is thought to be about the same for all the tungsten bronze crystals and has been determined for SBN to be about $0.09 \mathrm{~m}^{4} / \mathrm{C}^{2}$.

Enhancements of EO properties for materials in the MPB region may be as high as 5 or 10 times larger than those for SBN:60 or $\mathrm{BaTiO}_{3}$ and therefore may be of value for EO deflection and photorefractive effects. An additional beneficial effect is that EO and other properties are largely temperature-independent. For that reason it may be worth investigating this area after competence with SBN has been achieved. Similar effects are to be expected with orthorhombic crystals where nearly temperature-independent values of $r_{30}$ and $r_{3}$ are to be expected. A list of properties at MPB for some tungsten bronze systems are given in Table 14 (from Neurgaonkar et al. ") 
Table 14. Ferroelectric properties of tungsten bronze crystals at MPB.

\begin{tabular}{|c|c|c|c|c|}
\hline System & $\begin{array}{c}X \\
\text { at } \\
\text { MPB } \\
\end{array}$ & $\begin{array}{c}T_{c} \\
\left({ }^{\circ} \mathrm{C}\right)\end{array}$ & $\begin{array}{l}\text { Dielectric } \\
\text { Constant } \\
\text { at R.T. }\end{array}$ & $\begin{array}{c}\text { Electro-Optic } \\
\text { Coefficient } \\
\times 10^{-12} \mathrm{~m} / \\
\end{array}$ \\
\hline $\begin{aligned}(1-\mathrm{x}) \mathrm{PbNb}_{2} \mathrm{O}_{6} & -(\mathrm{x}) \mathrm{BaNb}_{2} \mathrm{O}_{6} \\
& +\mathrm{La}^{3+}(2 \%) \\
& +\mathrm{La}^{3+}(6 \%)\end{aligned}$ & 0.37 & $\begin{array}{l}300 \\
230 \\
115\end{array}$ & $\begin{array}{l}1900 \\
1700 \\
3500\end{array}$ & $\begin{array}{l}\geq 1600^{\star} \\
420^{\star \star} \\
780^{\star \star}\end{array}$ \\
\hline$(1-x) \mathrm{Pb}_{2.5} \mathrm{Nb}_{5} \mathrm{O}_{15}-(\mathrm{x}) \mathrm{Sr}_{2} \mathrm{NaNb}_{5} \mathrm{O}_{15}$ & 0.75 & 135 & 2200 & Large \\
\hline 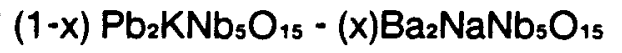 & 0.25 & 255 & 1340 & Large \\
\hline (1-x) $\mathrm{Ba}_{2} \mathrm{NaNb}_{5} \mathrm{O}_{15}-(\mathrm{x}) \mathrm{Sr}_{2} \mathrm{NaNb}_{5} \mathrm{O}_{15}$ & 0.60 & 170 & $>500$ & Low \\
\hline $\begin{array}{l}(1-\mathrm{x}) \mathrm{Pb}_{2} \mathrm{KNb}_{5} \mathrm{O}_{15}-(\mathrm{x}) \mathrm{Sr}_{2} \mathrm{NaNb}_{5} \mathrm{O}_{15} \\
{ }^{\star} \text { Single crystal samples. } \\
{ }^{\star} \text { Ceramic samples. }\end{array}$ & 0.70 & 155 & 930 & Medium \\
\hline
\end{tabular}

\subsubsection{Striations}

Striations are difficult to prevent in solid solutions and are often present in tungsten bronze materials. The effect is minimized if a congruent mixture is grown. The congruent mixture for SBN was estimated by Megumis to be about SBN:59. Additionally, growth conditions and dopants are significant factors in striations. The influence of using $A D C$ in growing $S B N: 60$ is shown in Figure 15 where a crystal grown without $A D C$ exhibited severe striations. An improperly set $A D C$ system also produces striations while a properly adjusted ADC system resulted in striationfree crystals, according to Neurgaonkar and Cory. Additionally Neurgaonkar et a ${ }^{76}$ claim that Ce-doped SBN:60 can be grown striation-free while Fe-doped SBN:60 is highly striated under all growth conditions. Discussions on striations produced in relation to thermal oscillations are given in References 77-79.

\subsubsection{Photorefractive Properties}

If applications other than EO deflection are pursued, the photorefractive properties of tungsten bronze materials would be very important. (See References $11,12,60,61,68$, and 80.) All materials considered in this report are photorefractive. This is not a desirable feature for EO deflectors as the effect can cause beam distortion. The effect is caused by free-carrier production by photons. The carriers migrate out of the illuminated region to surrounding dark regions and get trapped. A space charge is produced which produces an electric field which in turn 


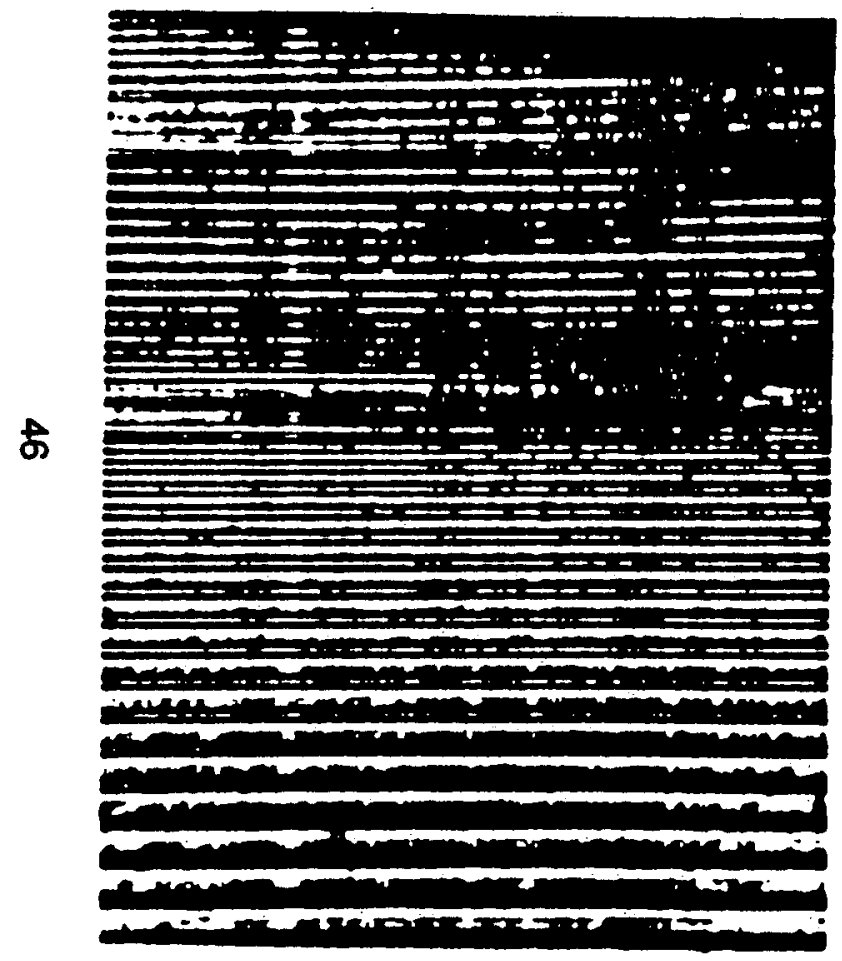

SBN:60 CRYSTAL GROWTH WITHOUT ADC SYSTEM

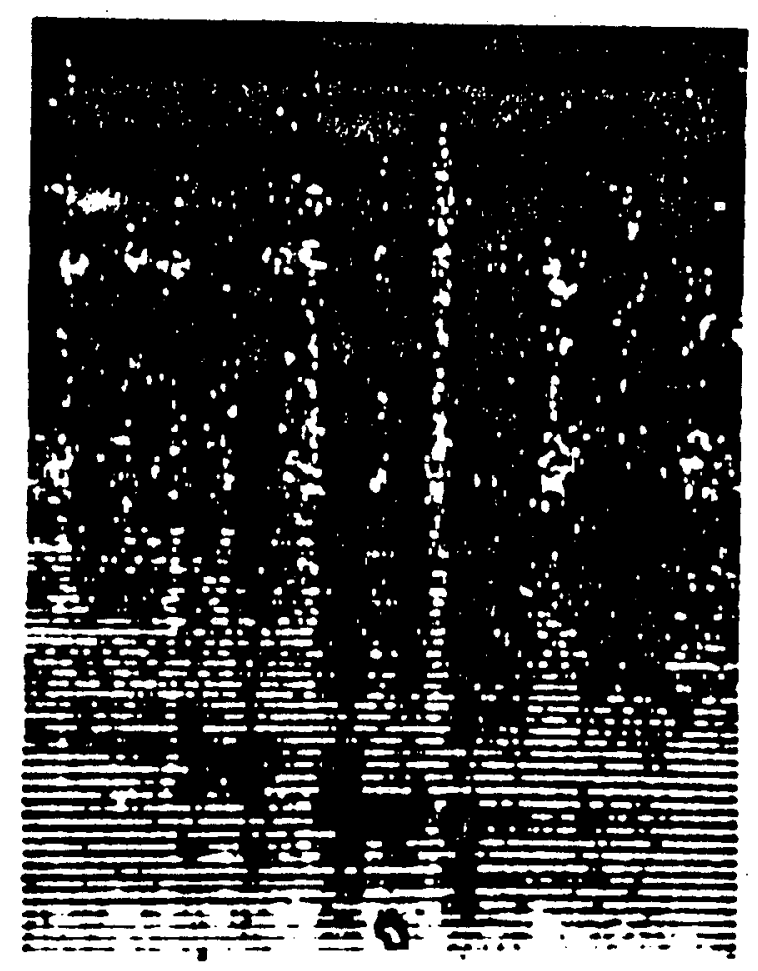

SBN:60 CRYSTAL GROWTH WITH ADC SYSTEM (UNSTABLE CONDITIONS)

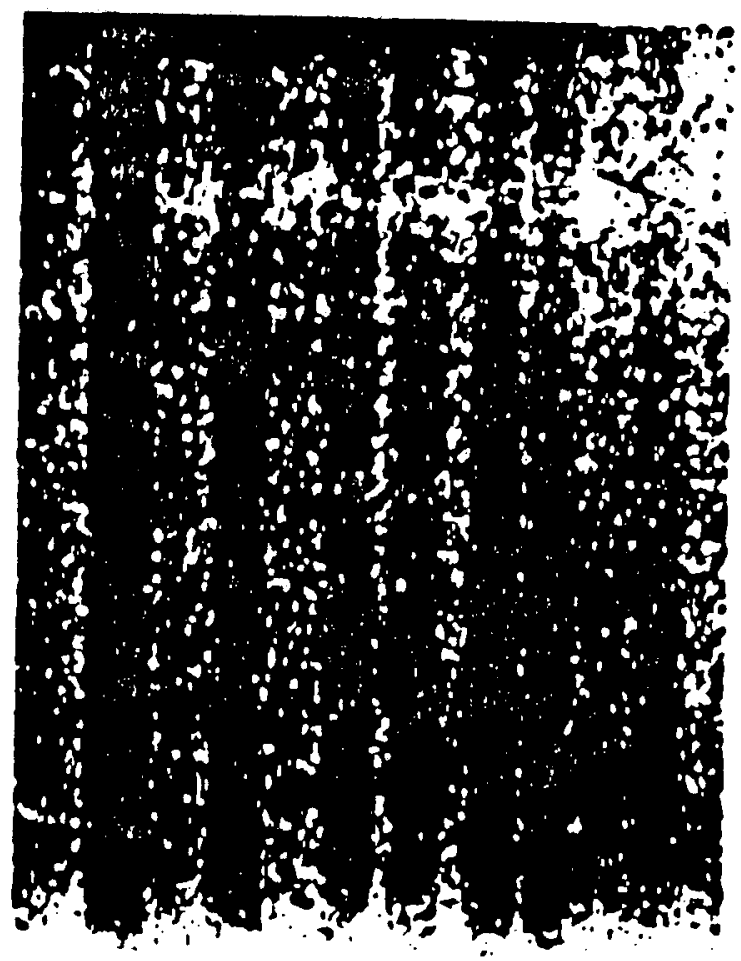

SBN:60 CRYSTAL GROWTH WITH ADC SYSTEM AFTER ESTABLISH CONDITIONS

Figure 15. Striations in SBN:60 with and without automatic diameter control. 
produces a change in the refractive index through the linear EO effect as shown below:

$$
\Delta \mathrm{n}_{\mathrm{i}}=\frac{1}{2} \mathrm{n}_{\mathrm{i}}^{3} \mathrm{r}_{\mathrm{ij}} \mathrm{E}_{\mathrm{i}}
$$

The space-charge field, $E_{i}$, is given by:

$$
E_{i}=\frac{1}{\varepsilon \varepsilon_{0}} \int p d x=\frac{1}{\varepsilon \varepsilon_{0}} \int J d t
$$

where $\rho$ is the charge density, $\varepsilon$ is the dielectric constant, and $J$ is the current density which is a complex function of the light intensity, time and crystal properties including photovoltaic constant, free carrier diffusion, pyroelectric constant, and excited state polarization. Prediction of the space-charge field, $\varepsilon_{i}$, is very difficult. However, it is known that doping the materials with certain easily ionized impurities has the effect of increasing the photorefractive effect due to the addition of free carriers. Doping SBN:60 with $\mathrm{Ce}$ has produced an increase in the photorefractive sensitivity by two orders of magnitude from $10^{-5}$ to $10^{-3} \mathrm{~cm}^{2} / \mathrm{J}(76-81)$. The minimum photorefractive response time for a given material has been shown by Yeh ${ }^{*}$ to depend on the rate of energy absorption by the photoionizing species. Doping has also been shown to reduce the photorefractive effect. For example Bryan et al. ${ }^{22}$ have shown that doping $\mathrm{LiNbO}_{3}$ with $\mathrm{Mg}$ increased the photorefractive damage threshold by two orders of magnitude. The reduced effect was shown to be a result of a hundred-fold increase in photoconductivity. 


\section{OTHER RECOMMENDATIONS}

In addition to the material recommendations in Section 4, this section discusses recommendations relating to getting ready to make use of EO materials for deflection purposes.

\subsection{BUILD OPTICAL EXPERTISE}

Since it will be some time before the crystal growing effort produces crystals with optical quality, the time should be utilized in building a capability for measuring the optical and other characteristics including quality of EO crystals. Until an SBN crystal is available, a material like $\mathrm{LNbO}_{3}$ could be used to practice on. Optical quality measurements are discussed in the next section.

\subsection{SYSTEM ASPECTS OF EO DEFLECTORS}

The systems aspects of EO deflectors should be worked on as there are specific problem areas needing attention. Critical areas are discussed below.

\subsubsection{Driver}

Drivers used in earlier work on $\mathrm{LiNbO}_{3}$ (usually utilizing Krytrons) were unsatisfactory with large jitter, poor ramp characteristics, and short lifetime. A proper driver needs to be developed. The load is pure capacitance which depends on the dielectric constant for the material and the crystal dimensions.

\subsubsection{Iype of Deflector}

Investigate and compare quadrupole (full and modified), separate multiple prism, multiple induced prism, and slab formats as well as complete integrated optics formats from a systems performance standpoint.

\subsubsection{Optical Coupling}

Consider optimum methods of coupling light in and out of deflectors, including fiber-optic and optical waveguide inputs. Consider cylindrical optics or geodesic lenses for slab or thin-film formats. 


\subsubsection{Detector Array}

Presently silicon linear arrays like the Reticon are suitable for the detection of fast deflected beams but they may not be satisfactory for EO deflector use particularly if wavelengths beyond $800 \mathrm{~nm}$ or so are used. There are significant developmental efforts going on in industrial laboratories which may soon produce usable arrays. These efforts should be investigated.

\subsection{OTHER APPLICATIONS}

The materials to be grown have many other potential applications which may be useful for NTS or SDI experiments and some consideration should be given to them. A list is presented below with brief discussion and pertinent references:

1. Optical function generator with temporal resolution as small as 10 ps. The basic idea here is to scan a light beam across an aperture which has a spatially-dependent transmission factor. ${ }^{15}$

2. Sensitive modulators. Using materials like SBN as EO modulator instead of KDP or $\mathrm{LiNbO}_{3}$ provides much more sensitive devices. This means that smaller crystals of the newer materials can provide the same modulation as large crystals with smaller EO coefficients, or much larger modulation for crystals of the same size as less sensitive materials.

3. Sensitive integrated optics components such as Mach-Zehnder interferometers or fast optical switches. In the same manner as in item (2) above, integrated optics components relying on the linear EO effect in optical waveguides can be made much more sensitive by using the new materials in place of $\mathrm{LiNbO}_{3}$ as a substrate. Methods for producing waveguides in the substrate can probably be adopted from the technology developed for $\mathrm{LNbO}_{3}$

4. Photorefractive effects for several applications. This is an area of very great interest presently by DOD and other agencies. The basic effect, the change in index of refraction produced by light; is discussed in Section 5.1.4. A number of potential applications are being pursued. They include:

a. Phase coniugation. This effect is a relatively new area of optics in which a phase-reversed reflected wave is produced by nonlinear interactions in a material. Phase-conjugate waves are produced in photorefractive materials by two-wave and four-wave mixing. All of the crystals discussed in this report exhibit a photorefractive effect. The effect can be enhanced by doping with specific materials as discussed in Section 5.1.4. (See Reference 83 for details of this effect, Reference 61 for information on two-wave mixing in doped and undoped SBN, Reference 84 for two-wave mixing in BSO, and Reference 85 for mixing in $\mathrm{BaTiO}_{3}$ ) Applications include phase-conju- 
gate mirrors for improving laser beam quality ${ }^{\mathbf{6}}$; correcting for atmospheric turbulence ${ }^{87}$; and self-pumped phase-conjugate mirrors. ${ }^{63}$

b. Optical computing elements. See References 88 and 89 .

5. Sensitive microwave detector. Electrooptic crystals can be used to detect and measure microwave $E$ fields. Materials having large EO co-efficients would be more sensitive.

6. Pyroelectric detector Materials like SBN have been shown to be good pyroelectric detectors for infrared wavelengths. ${ }^{4}$,

7. Substrate for high-temperature superconducting films. SBN has lattice constants which closely match those of the current favorite materials being studied for high-temperature films on SBN. To my knowledge nothing has appeared in the literature on this work yet but several papers are appearing at conferences on this subject.

8. SAW devices. The new EO crystals also have acoustooptic (AO) interactions and can be used for surface acoustic wave devices. (See Reference 90 for materials selection criteria for $\mathrm{AO}$ devices.)

9. Millimeter wave modulators. Rockwell (Neurgaonkar) has investigated and shown that tungsten bronze crystals are useful for modulators at $\mathrm{mm}$-wave frequencies. 


\section{QUALITY MEASUREMENTS}

This topic was not part of the stipulated area of coverage for this report, but contains some thoughts and ideas developed during the search for information on materials selection for EO deflectors.

\subsection{CRYSTAL STRUCTURE DEFECTS}

Standard $x$-ray techniques should be employed for determination of crystal defects and lattice structure. The crystal group at EG\&G/EM SBO is already familiar with these techniques so no further discussion is warranted here.

\subsection{OPTICAL QUALITY}

Optical quality measurements are very important as the performance of an EO deflector is intimately related to the optical quality of the crystal as well as the magnitude of the EO coefficient. Distortion in the medium will cause the number of resolvable spots to decrease. A few methods for determining optical quality are given below.

\subsubsection{Spot Deterioration}

Focal spot deterioration is a very simple yet very important measurement to make on the deflector crystal. It consists of sending a collimated beam into the crystal with a suitable aperture stop and measuring the spot size at the focal point of a lens placed in the beam after it has passed through the crystal. The size (and shape) of the focal spot compared to the theoretical diffraction limited Airy pattern indicate the degree of distortion produced by the medium. It is necessary to make this measurement with voltage applied to the crystal as well as with zero field. Additionally, the measurement should be made as a function of optical intensity at different wavelengths so that photorefractive effects can be quantified. Figure 16 illustrates the method. 

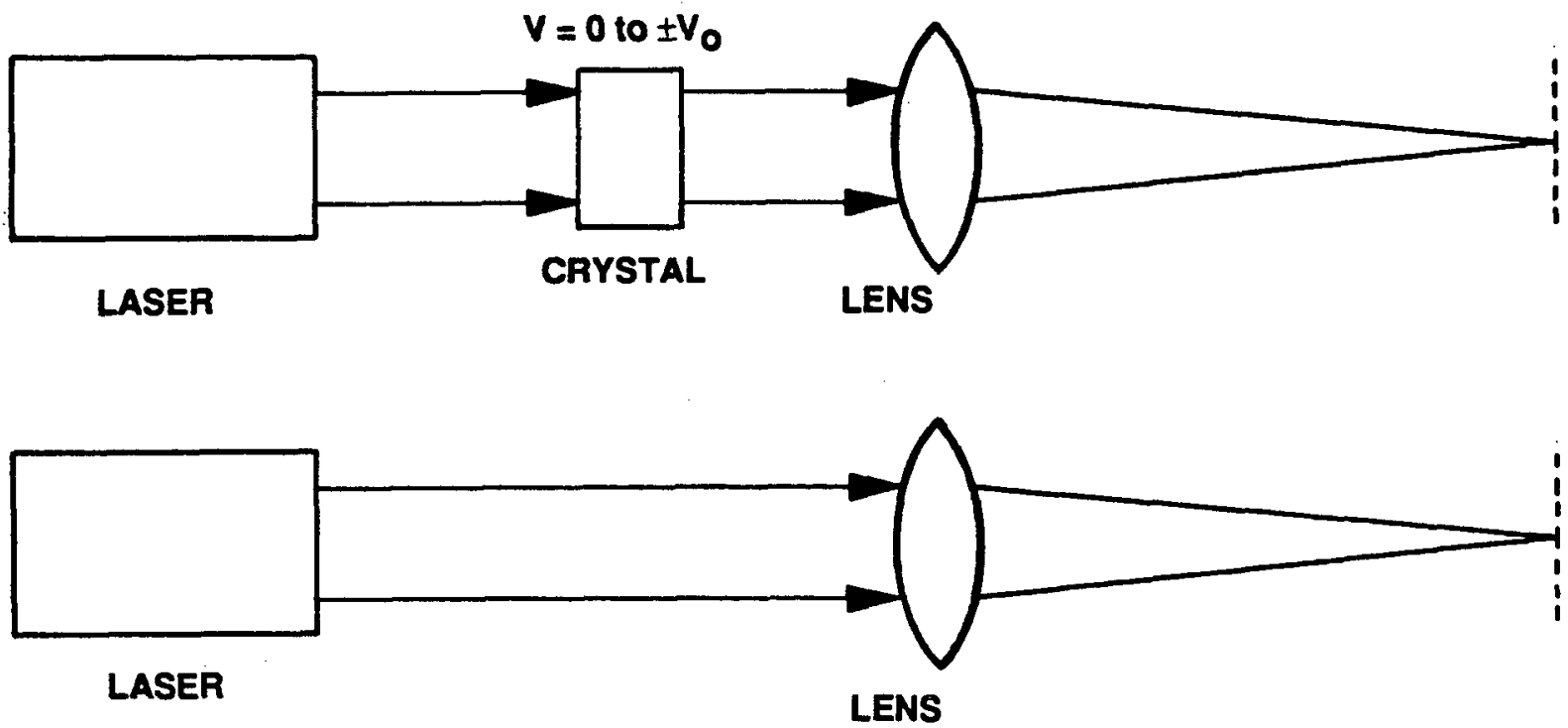

Figure 16. Optical quality by spot deterioration at the focal point of a lens in the exit beam on an EO crystal illuminated by a collimated beam.

\subsubsection{Polarimetry}

Optical defects can be enhanced for visual examination by placing the crystal between crossed polarizers and using photography or microphotography to record the transmitted light. Striations and other defects can be studied in this way.

\subsubsection{Interferometry}

The use of standard interferometric techniques can be used to determine the amount of phase distortion in terms of fractional wavelengths in the medium. The basic idea is illustrated in Figure 17. In practice the crystal surfaces may interfere with the measurement so they should be antireflected or the crystal placed in an index matching fluid (not so easy with an index of 2.3). This measurement should be carried out in zero and maximum electric field conditions. Intensity variation at different wavelengths will determine the effects of photorefraction on distortion. 


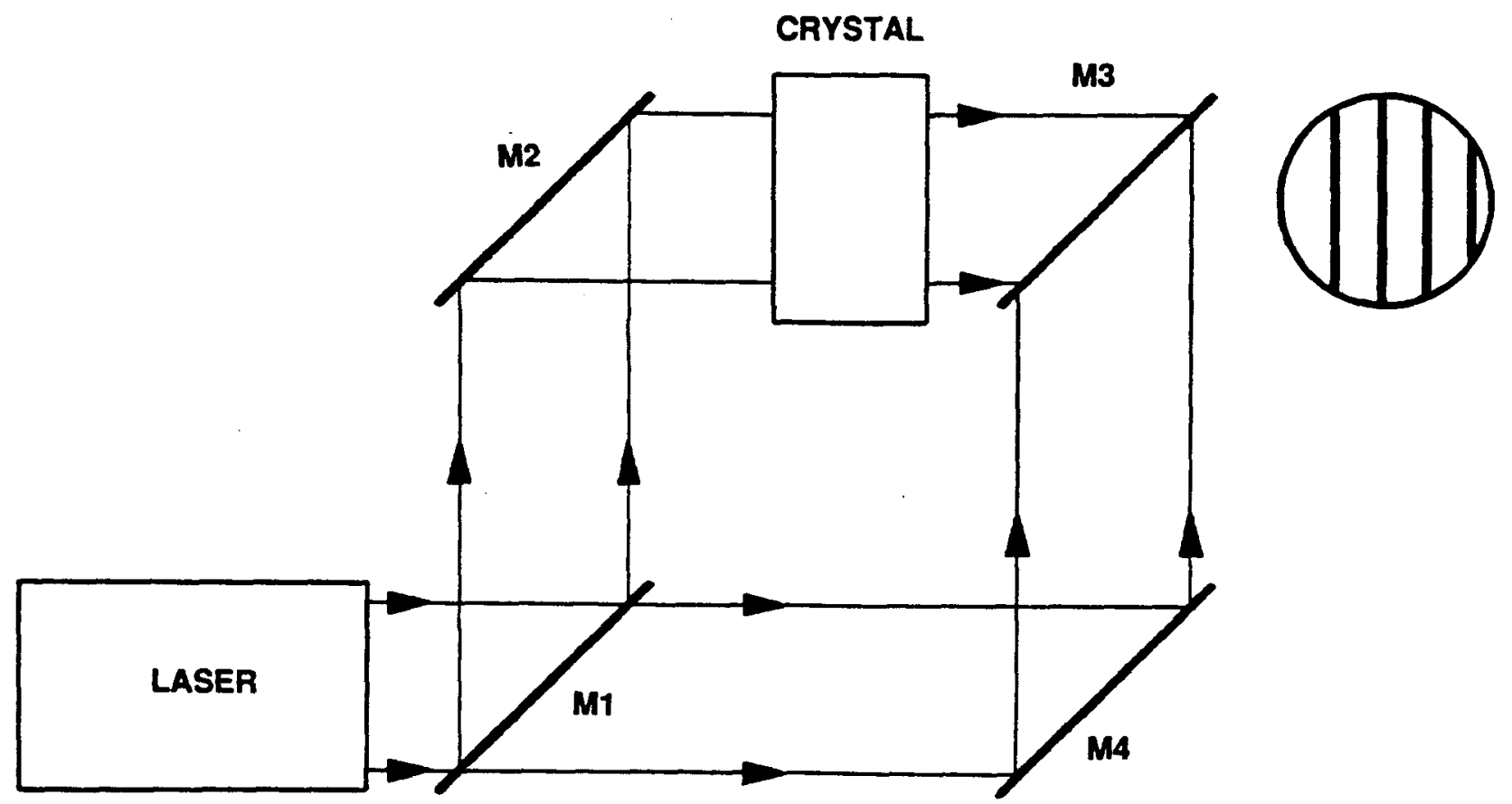

Figure 17. Quality measurement of an EO crystal using an interferometric technique.

\subsection{MEASUREMENT OF EO COEFFICIENT}

This is a very important measurement to make since the EO coefficient is the major factor in determining the theoretical maximum number of resolvable spots for a deflector. A few suggestions are given here, but the technique used should be carefully thought out before starting. The phase retardation method has been used most frequently and is quite sensitive, although direct deflection may work well for materials with large coefficients.

\subsubsection{Phase Retardation}

This technique can be used to measure the dc or if transverse coefficient of a uniaxial crystal by placing the crystal between crossed polarizers with the addition of a Soleil-Babinet compensator between the crystal and the last polarizer (Figure 18). The compensator is added as a convenience for nulling the effects of the static natural birefringence of the crystal. A dc electric field is applied parallel to the $z$ axis, with light propagating along the $y$ axis and polarized at $45^{\circ}$ to the $z$ and $x$ axes (as in Figure 10, but with the polarization rotated $45^{\circ}$ ). This produces a relative phase shift between the extraordinary and ordinary components resulting in a modulation of the intensity of the transmitted light. The applied voltage is increased until the transmitted light is extinguished from which the half- 


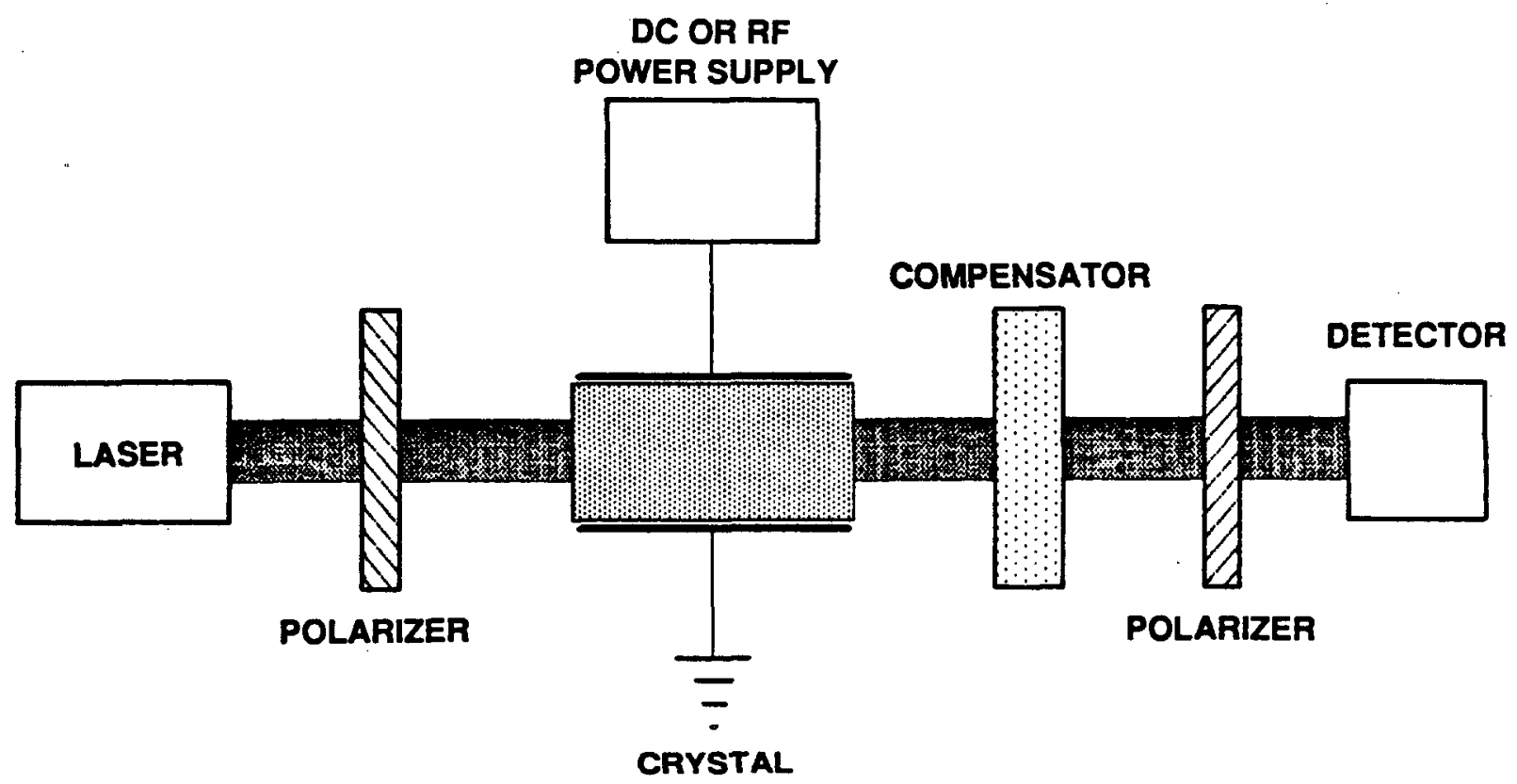

Figure 18. Phase retardation technique for measuring EO coefticient.

wave field-length product is obtained. The transmittance (ignoring absorption, reflection, and scattering losses) for the crystal and other components is given by:

$$
T=\sin ^{2} \frac{\Gamma}{2}
$$

where $\Gamma$ is the relative phase retardation for the complete system given by:

$$
\Gamma=\frac{2 \pi L}{\lambda}\left(n_{e}-n_{o}\right)+\frac{2 \pi L}{\lambda}\left(\Delta n_{t}\right)+\phi_{c}
$$

where the first term on the right is due to the static birefringence, the second the induced retardation caused by the electric field and the third term a variable retardation produced by the compensator. The compensator retardation is set to cancel the static retardation leaving only the induced term. For a uniaxial crystal such as SBN with light propagating perpendicular to the $z-x(c-b)$ plane along the $y(b)$ axis, polarized at $45^{\circ}$ to the $z$ (c) axis, and the electric field applied parallel to the $z$ axis, the magnitude of the change in index is:

$$
\Delta n_{t}=1 / 2\left(n_{e}^{3} r_{33}-n_{0}^{3} r_{13}\right) E
$$


The half-wave field product $(E \cdot L))_{2}$ is given by:

$$
(E \cdot L)_{\lambda / 2}=\frac{\lambda}{\left(n_{e}^{3} r_{33}-n_{0}^{3} r_{13}\right)}
$$

from which the effective EO coefficient,

$$
r_{c}=\left(\frac{n_{e}^{3}}{n_{0}^{3}}\right) r_{33}-r_{13}
$$

can be determined. The quantities $r_{x}$ and $r_{r}$ can be separated by deflection and then determined separately.

The longitudinal coefficient can also be determined by orienting the crystal such that the light propagates along the $z$ axis, is polarized at 45 degrees to the $x$ axis in the $x-y$ plane and the electric field is parallel to the $x$ axis (as in Figure 10 with the polarization rotated 45 degrees.) The $r_{s t}$ coefficient then can be determined through the second order change in index as described by Equation (29).

These measurements should also be made at if modulation frequencies corresponding to the minimum response time desired. If a quarter wave of retardation is added before the last polarizer in Figure 18, and a sinusoidal voltage with amplitude $V_{0}$ applied:

$$
\mathrm{V}=\mathrm{V}_{\mathrm{o}} \sin \omega_{\mathrm{m}} \mathrm{t}
$$

then the combined retardation is:

$$
\Gamma=\pi / 2+\Gamma_{\mathrm{m}} \sin \omega_{\mathrm{m}} \mathrm{t}
$$

where $\Gamma_{\mathrm{m}}={ }_{n} \mathrm{~V}_{0} / \mathrm{V}_{\mathrm{n}}$ and the transmittance is:

$$
T=1 / 2\left(1+\sin \left(\Gamma_{m} \sin \omega_{m} t\right)\right)
$$


If the modulation amplitude, $V_{0}$, is kept small compared to the half-wave voltage, $V x$, then

$$
T=1 / 2\left(1+\Gamma_{m} \sin \omega_{m} t\right)
$$

and the modulated intensity is sinusoidal like the modulation voltage. The transmittance is measured as an $\mathrm{rms}$ or peak value from which $V_{\mathrm{o}} / V_{\mathrm{r}}$ is determined and $r_{c}$ is calculated from that ratio and the measured value of the input voltage amplitude.

\subsubsection{Angle of Minimum Deviation (AMD)}

This method is a variation of a method undergraduate physics students use in optics laboratories to measure the index of refraction of materials. It has recently been adapted for change in index measurements by Lee and Jacobs ${ }^{21}$ to measure the rate of change of index of refraction with temperature. The same technique could be used to determine a change in index with applied electric field. The arrangement is illustrated in Figure 19, where a prism of EO material is shown in the form of an isosceles triangle with included angle $\alpha$, and base of length $L$. Electrodes would be deposited on the two large faces of the prism with the $z$ axis perpendicular to the plane of the paper. Light is incident at an angle $i$, refracted at the first surface at an angle $r$, and the exit beam emerges from the second prism surface at an angle of $\Theta \mid 2$ with respect to the internal beam in the prism. The latter is parallel to the base of the prism at the angle of minimum deviation.

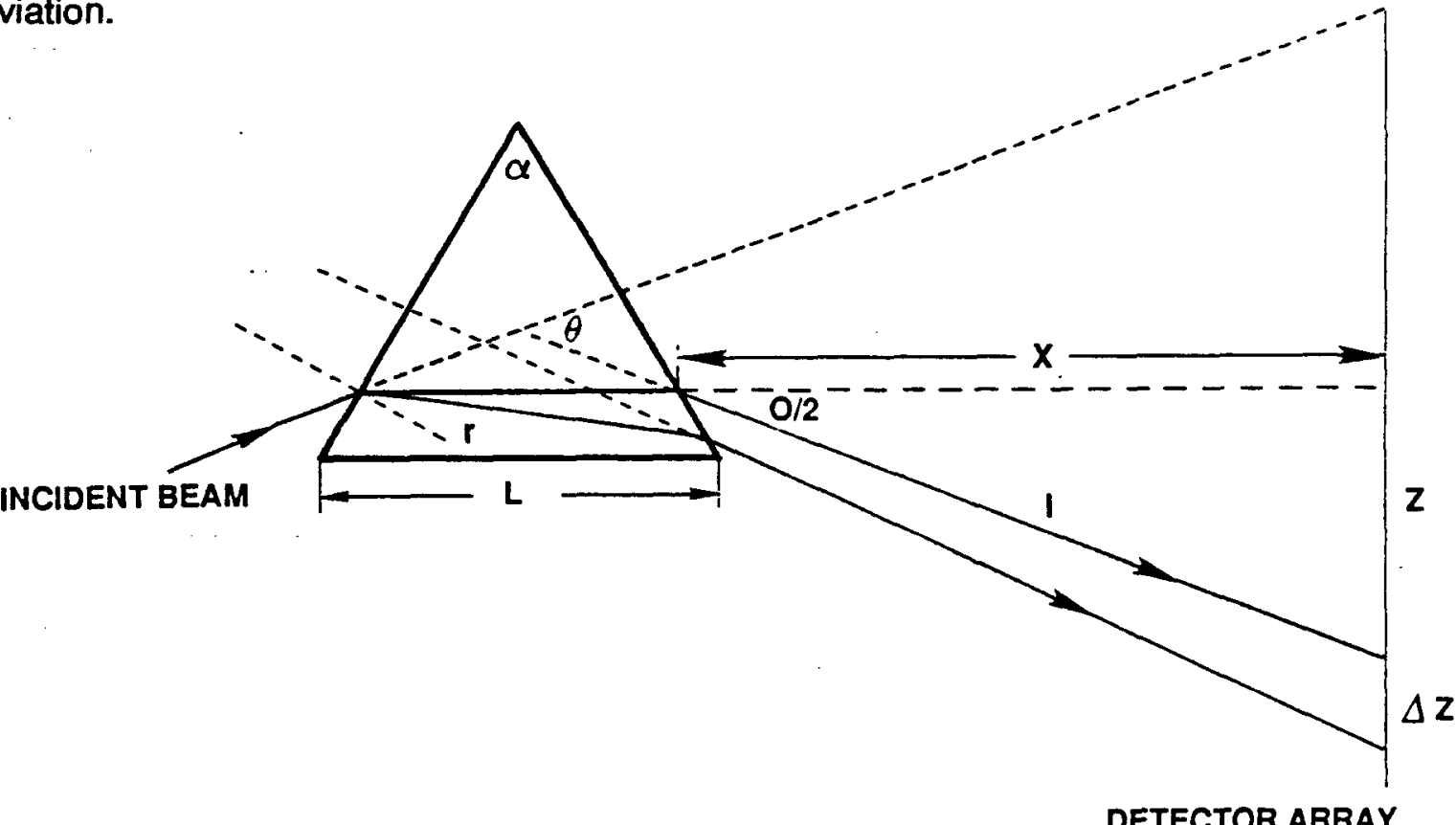

Figure 19. Measuring the EO coefficient using a method based on the AMD of a prism. 
At the angle of minimum deviation with no field applied:

$$
\mathrm{n}=\frac{\sin \mathrm{i}}{\sin \mathrm{r}}=\frac{\sin \left(\frac{(\theta+a)}{2}\right)}{\sin (\alpha / 2)}
$$

Now if an electric field is applied, the exit beam is deflected by an angle $\Delta \Theta$. The change in index can be written:

$$
\Delta \mathrm{n}=\frac{2 \cos \left(\frac{(\theta+\alpha}{2}+\frac{\Delta \theta}{4}\right) \sin \left(\frac{\Delta \theta}{4}\right)}{\sin (\alpha / 2)}
$$

If we substitute $x=1 \cos (\Theta / 2), z=1 \sin (\Theta / 2)$ and solve for $\Delta \Theta$ :

$$
\Delta \Theta=\tan ^{-1}\left(\frac{\operatorname{lsin}(\Theta / 2)+\Delta z}{\operatorname{lcos}(\Theta / 2)}\right)-\frac{\Theta}{2}
$$

Values for $n$ and $\Theta$ are found by finding the AMD. Then 1 and $\Delta z$ are measured and $\Delta \Theta$ is calculated from the preceding relation from which $\Delta \mathrm{n}$ is determined using Equation (44). The EO coefficient, ro for a uniaxial crystal is then determined from the relation:

$$
r_{33}=2 \frac{\Delta n}{n_{e}^{3} E}
$$

\subsubsection{Interferometry}

The EO coefficient could be measured by placing the crystal in one arm of an interferometer and measuring the fringe shift produced by applying an electric field. The rs component of a uniaxial crystal could be measured directly by using the geometry of the phase retardation method but polarizing the beam parallel to the $z$ axis as in Figure 10a. In that situation the phase shift produced by the applied field is:

$$
\Delta \phi=\frac{\pi}{\lambda} n_{e}^{3} r_{33} L E
$$


or

$$
r_{33}=\frac{\lambda}{\pi n_{e}^{3} L E} \Delta \phi
$$

This method would require very good optical quality of the crystal and surface reflections would have to be eliminated.

\subsubsection{Phase Modulation}

A variation of the phase retardation method could be used in which the geometry in Figure 18 is used, except that the input wave is polarized parallel to the $z$ axis. The applied if field causes the output light to be phase modulated. The transmitted light is:

$$
\left(E_{\text {opt }}\right)_{\text {out }}=\left(E_{\text {opt }}\right)_{0} \sin \left(\omega t+\phi \sin \omega_{m} t\right)
$$

where $E_{\text {opt }}$ is the amplitude of the optical electric field. The phase amplitude, $\phi$, is given by

$$
\phi=\frac{\pi n_{e}^{3} r_{33} L}{\lambda}\left(E_{\text {opt }}\right)_{0}
$$

The phase could be determined from the distribution of the side bands produced in the output energy.

\subsubsection{Speckle Photography}

A technique utilizing double speckle photography was developed by Bernardo and Soares ${ }^{22}$ for measuring the static birefringence of uniaxial crystals. Some variation of this method could possibly be used to measure the induced birefringence. 


\subsubsection{Deflection}

A simple measurement of the deflection angle produced by any one of the deflection methods could be used to determine the EO coefficient. For the twoprism example, Equation (6) would be used to determine the change in $n$ from the angular deflection. This method requires larger material lengths than the phase retardation or interferometric method. 


\section{CONCLUSIONS}

It is essential to find a material which has better properties than $\mathrm{LiNbO}_{3}$ if a deflector with a large number of resolvable spots is to be developed. While that material has produced 100-200 resolvable spots in deflectors, driver requirements and materials problems make it marginal for practical application in any device with more than 50 resolvable spots.

Recommendations on a choice for EO crystals to grow for eventual application as light beam deflectors have been given. The strongest candidate recommended is SBN:60. It does not have the largest EO coefficient but is apparently the easiest of the materials, known to have large EO coefficients, to grow in large sizes with good optical quality.

Aside from the size of the EO coefficient, the optical quality of the crystal is extremely important in the EO deflector application. If distortion caused by photorefraction, striations, voltage-induced refractive variations, or crystal defects are large enough, the number of resolvable spots achievable will be reduced even if the deflection is large. For this reason emphasis on obtaining high-quality crystals is essential and optical quality measurements are important.

Measurements of EO coefficients are important as few have been made for SBN. Coefficients for some of the other new materials may not have been measured at all but calculated from theory. Also, measurements as a function of temperature are important especially for materials operated near their Curie temperatures.

Other applications of these EO materials should be given consideration so as not to put all the eggs in one basket. There is always the possibility that the EO deflector may not work well enough to use practically. (Other applications are discussed in Section 6.3.) The area of photorefractive devices is attracting a great deal of attention currently.

There is some possibility that other EO materials such as the organic materials being studied now mainly for their nonlinear optical properties may be of use in the future as linear optical devices. Presently they are too slow to be useful. (See Lytel et al. ${ }^{.3}$ and Patel ${ }^{94}$ for a summary of the state of the art.) 

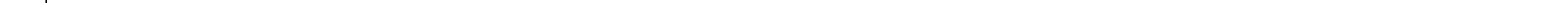


\section{REFERENCES}

1. Holman, R.L., L.M.A. Johnson and D.P. Skinner, "Desirability of electro-optic materials for guided-wave optics," Eng. Opt. 26 134-142 (1987).

2. Ballman, A.A. and H. Brown, "The growth and properties of strontium barium metaniobate $\mathrm{Sr}_{1-x} \mathrm{Ba}_{\times} \mathrm{Nb}_{2} \mathrm{O}_{6}$, a tungsten bronze ferroelectric," J. of Crystal Growth 1, 311-314 (1967).

3. Dudink, O.F., A.K. Gromov, V.B. Kravchenko, Yu. L. Kopylov, and G.F.Kuznetsov, Sov. Phys. 15, 330 (1970).

4. Brice, J.C., O.F. Hill, P. A.C. Whiffen, and J.A. Wilkinson, J. Cryst. Growth 10, 133 (1971).

5. Maciolek, R.B. and S.T. Liu, "Preparations and properties of low loss $\mathrm{Sr}_{1 \times \mathrm{B}} \mathrm{Ba}_{\times} \mathrm{Nb}_{2} \mathrm{O}_{8}$ ferroelectric single crystals," J. Electr. Mat. 2, 191-201 (1973).

6. Neurgaonkar, R.R., W.K. Cory, W.W. Ho and W.F. Hall, "Tungsten bronze family of crystals for acoustical and dielectric application," Ferroelectrics 38, 857-860 (1981).

7. Neurgaonkar, R.R., M.H. Kalisher, T.C. Lim, E.J. Staples and K.L. Keester, "Czochralski single crystal growth of $\mathrm{Sr} .{ }_{11} \mathrm{Ba}_{30} \mathrm{Nb}_{2} \mathrm{O}_{6}$ for surface acoustic wave applications," Mat Res. Bull. 15, 1235-1240 (1980).

8. Staples, E.J. and R.R. Neurgaonkar, "Surface acoustic wave transduction and poling in ferroelectric strontium barium niobate," Ferroelectrics 38882 (1981).

9. R.R. Neurgaonkar, J.R. Oliver and L.E. Cross, "Ferroelectric properties of tetragonal tungsten bronze single crystals," Ferroelectrics 56, 31-36 (1984).

10. Neurgaonkar, R.R., W.K. Cory and J.R. Oliver, "Growth and applications of ferroelectric tungsten bronze family crystals," Ferroelectrics 51, 3-8 (1983).

11. R.R. Neurgaonkar, and W.C. Cory, "Progress in photorefractive tungsten bronze crystals," Opt. Soc. of Amer. B/3, 274-282 (1986).

12. Neurgaonkar, R.R., W.K. Cory, J.R. Oliver, M.D. Ewbank and W.F. Hall, "Development and modification of photorefractive properties in tungsten bronze family crystals," Opt. Eng. 26, 392-405 (1987). 
13. Yariv, A. and P. Yeh, Optical Waves in Crystals, John Wiley \& Sons. 1984.

14. Kaminow, I.P. and E.H. Turner, An Introduction to Electrooptic Devices (I.P. Kaminow, ed.), Academic Press. 1974.

15. Gottlieb, M., C.L.M. Ireland and J.M. Ley, Electrooptic and Acoustooptic Scanning and Deflection, Marcel Dekker, Inc. 1983.

16. Thomas, S.W., "Crystal streak camera," Proc. 12th International Congress on High Speed Photography and Photonics, pp. 499-503. 1976.

17. Ireland, C.L.M., "The use of a LiNbOs deflector in a $\sim 100$ ps resolution streak camera," Opt. Comm. 27, 459-462 (1978).

18. Chen, F.S., J.E. Geusic, S.K. Kurtz, J.G. Skinner, and S.H. Wemple, "Light modulation and beam deflection with potassium tantalate-niobate crystals," J. Appl. Phys 57, 388-398 (1966).

19. Ninomiya, Y., "Ultrahigh resolving electrooptic prism array light deflectors," IEEE J Quant. Elect. QE-9, 791-795 (1973).

20. Ninomiya $\mathrm{Y}$., "High $\mathrm{S} / \mathrm{N}$ ratio electrooptic prism-array light deflectors," IEEEW J. Quant.Elect. QE-10, 358-362 (1974).

21. Garside, B. and R. Park, personal communication.

22. Ireland, C.L.M., "A 20 ps resolution crystal streak camera," Opt. Comm. 30, 99-103 (1979).

23. Ireland, C.L.M., personal communication.

24. Davis, P., J. Chang, J. Fanning, and G. McNeill, "Photonic data recorder development update," Proc. SPIE 720, $31-37$ (1986).

25. Elliot, R.A. and J.B. Shaw, "Electrooptic streak camera: theoretical analysis," Appl. Opt. 18, 1025-1033 (1979).

26. Fowler, V. and J. Schlafer, "A survey of laser beam deflection techniques," Appl. Opt. 5, 1675-1682 (1966).

27. Fowler, V.J., C.F. Buher, and L.R. Bloom, "Electrooptic light beam deflector," Proc. IEEE (Correspondence), 52, 193-194 (1964).

28. Beasley, J.D., "Electrooptic laser scanner for TV projection display," Appl. Opt. 10, 1934-1936 1971).

29. Meyer, R.A., "Optical beam steering using a multichannel lithium tantalate crystal," Appl. Opt. 11, 613-616 (1972). 
30. Thomas, S.W., SPIE 189, 528 (1978).

31. Schmidt, U.J., Philips Tech. Rev. 36, 117 (1976).

32. Meyer, H., D. Riekmann, K.P. Schmidt, U.J. Schmidt, M. Rahlff, E. Scroeder, and $W$. Thrust, "Design and performance of a 20-stage digital light beam deflector," Appl. Opt. 11, 1732-36 (1972).

33. Jelsma, L.F., "Update on progress toward a crystal streak camera using new materials," SPIE Conference on Optical \& Optoelectronic Applied Science \& Engineering, Session on High Speed Photography, Videography, and Photonics V, paper 832-29, August 16-21 (1987).

34. Jelsma, L.F., personal communication.

35. Pressley, R.J., ed., Handbook of Lasers, The Chemical Rubber Co., Cleveland, $451-456$ (1971).

36. Cook, W., Jr. and H. Jaffe, "Electro-optic coefficients," Landdolt-Bornstein, New series, K.H. Hellwege, ed., Vol 11, Springer-Verlag 552-651 (1979).

37. Spencer, E.G., P.V. Lenzo, and A.A. Ballman, "Dielectric materials for electrooptic, elastooptic, and ultrasonic device applications," Proc. IEEE 52, 20742107 (1967).

38. Nassau, K., et al, J. Phys. and Chem. of Solids 27, 989-996 (1966).

39. Lenzo, P.V., E.G. Spencer and K, Nassau, "Electrooptic coefficients in single domain ferroelectric lithium niobate," J. Opt. Soc. 56, 633-635 (1966).

40. Nelson, D.F. and R.M. Mikulak, "Refractive indices of congruently melting lithium niobate," J. Appl. Phys. 45, 3688-3689 (1974).

41. Bryan, D.A., R.R. Rice, R. Gerson, H.E. Tomaschke, K.L. Sweeney, and L.E. Halliburton, "Magnesium-doped lithium niobate for higher optical power applications," Opt. Eng. 24, 138-143 (1985).

42. Castelli, L., "Lithium niobate applications in optics and acousto-optics," Laser Focus 21, 120-123 (1985).

43. Reisman, A. et al, J. Amer. Chem. Soc. 80, 6503-6507 (1958).

44. Bond, W.L., "Measurement of the refractive indices of several crystals," J. Appl. Phys. 36, 1674-1677 (1965).

45. Anonymous, "Lithium niobate and lithium tantalate optical crystals," Crystal Technology brochure. 
46. Bonner, W.A., E.F. Dearborn, and L.G. Van Uitert, "Growth of potassium tantalate-niobate single crystals for optical applications," Bull. Am. Ceramic Soc. 44, 9-11 (1965).

47. Fukuda, T. and $\mathrm{H}$. Hirano, "Growth and electrical properties of $\mathrm{KTa}_{2} \mathrm{Nb}_{1-\mathrm{x}} \mathrm{O}_{3}$ single crystals," J. Phys. Soc. Japan 24, 430 (1968).

48. Johnson, C.J., "Some Dielectric and electro-optic properties of $\mathrm{BaTiO}_{3}$ crystals," Appl. Phys. Letters 7, 221-223 (1965).

49. Johnston, A.R., "The strain-free electrooptic effect in single crystal barium titanate," App. Phys. Letters 7, 195-198 (1965).

50. Johnston, A.R., "Dispersion of Electrooptic effect in $\mathrm{BaTiO}_{3}$," J. Appl. Phys. 42, 3501-3507 (1971).

51. Linz, A., V. Belruss, and C.S. Naiman, Proc. Electrochem. Soc., Spring Meeting, 87 May 9-13 (1965).

52. Remeika, J.P., "A method for growing barium titanate single crystals," J. Am. Chem. Soc. 76, 940-941 (1954).

53. Kaminow, I.P., "Barium titanate light phase modulator," Appl. Phys. Letters 7, 123-125 (1965).

54. Kaminow, I.P., "Barium titanate light modulator, II," Appl. Phys. Letters 8, 305 (1966).

55. Ewbank, M.D., P. Yeh and J. Feinberg, "Photorefractive Conical Diffraction in BaTiO, "Opt. Commun. 59, 423-428 (1986).

56. Valley, G.C., "Competition between forward and backward stimulated photorefractive scattering in $\mathrm{BaTiO}_{3}, " \mathrm{~J}$. Opt Soc. Am. B 4, 14-19 (1987).

57. Lenzo, P.V., E.G. Spencer and A.A. Ballman, "Electrooptic coefficients of ferroelectric strontium niobate," Appl. Phys. Letters 11, 23-24 (1967).

58. Lenzo, P.V., E.H. Turner, E.G. Spencer, A.A. Ballman, Electrooptic coefficients and elastic-wave propagation in single-domain ferroelectric lithium tantalate," Appl. Phys. Letters 8, 81-82 (1966).

59. Ho, W., W.F. Hall, R.R. Neurgaonkar, R.E. DeWames, and T.C. Lim, "Microwave dielectric properties of $\mathrm{Sr} .{ }_{1} \mathrm{Ba} .30 \mathrm{Nb}_{2} \mathrm{O}_{8}$ single crystals and 35 and 58 $\mathrm{GHz}$," Ferroelectrics 38, 833-836 (1981).

60. Shrout, T.R., L.E. Cross, P. Moses, H.A. McKinstry, and R.R. Neurgaonkar, "Higher order electrostriction in ferroelectric tungsten bronzes," Ferroelectrics 38, 881 (1981). 
61. Rakulic, G.A., A. Yariv, and R. Neurgaonkar, "Photorefractive properties of undoped cerium-doped and iron-doped single-crystal Sr ${ }_{0.6} \mathrm{Ba}_{0.4} \mathrm{NbO}_{6}$," Opt. Eng., 25 1213-1216 (1986).

62. Salamo, G., M.J. Miller, W.W. Clark III, G.L. Wood and E.J. Sharp, "Strontium barium niobate as a self-pumped phase conjugator.," Opt. Comm. 59, 417-422 (1986).

63. Miller, M.J., E.J. Sharp, G.L. Wood, and W.W. Clark III, G.J. Salamo, and

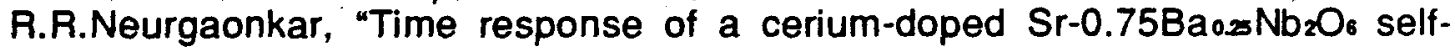
pumped phase-conjugate mirror," Opt. Letters 12, 340-342 (1987).

64. Glass, A.M. "Investigation of the electrical properties of $\mathrm{Sr}_{1-\times} \mathrm{Ba}_{2} \mathrm{Nb}_{2} \mathrm{O}_{6}$ with special reference to pyroelectric detection," J. Appl. Phys. 40, 4699-4713 (1969).

65. Karlov, N.V., G.P. Kuz'min, Yu. S. Kuz'minov, B.A. Kuritzen, V.V. Osiko and A.M. Prokhorov, "Fast-Response Pyroelectric Detector Based on Baa.23 Sra.75 Nb2O6 Crystals," Ferroelectrics 33, 223-230 (1981).

66. Kohigashi, T.H., T. Terauchi, S. Kuroda, K. Kubota and K. Yoshimitsu "X-ray study on the diffuse transition in 0.3 wt.\% $\mathrm{Pr}^{3+}$ doped $\mathrm{Sr}_{0.6} \mathrm{Ba}_{0.4} \mathrm{Nb}_{2} \mathrm{O}_{6}$ crystal," Ferroelectrics 34 123-126 (1981).

67. Antsign, V.D., V.M. Egorov, E.G. Kostov, V.K. Malinovsky, and L.N. Sterelyukhina, "Ferroelectric properties of thin strontium barium niobate films," Ferroelectrics 63, 235-242 (1986).

68. Gwenter, P., "New applications of ferroelectrics for optical devices," Ferroelectrics 53, 157-158 (1984).

69. Rodriguez, J., A. Siahmakoun, G. Salamo, M.J. Miller, W.W. Clark III, G.L. Wood, E.J. Sharp, and R.R. Neurgaonkar, "BSKNN as a self-pumped phase conjugator., Appl. Opt. 26, $1732-1736$ (1987).

70. Esener, .C., J.H. Wang, T.J. Drabik, M.A. Title, and S.H. Lee, "One-dimensional silicon/PLZT spatial light modulators," Opt. Eng. 26, 406-413 (1987).

71. Jaffe, B., W.R. Cook and H. Jaffe, Piezoelectric ceramics, Academic Press, London and New York (1971).

72. Neurgaonkar, R.R., J.R. Oliver and L.E. Cross, Final Technical Report, DARPA Contract N00014-82-c-2466 (1986).

73. DiDomenico, M., Jr., and H. Wemple, "Oxygen-octahedra ferroelectrics. I. Theory of electrooptical and nonlinear optical effects," J. Appl. Phys. 40, 720-734 (1969). 
74. Wemple, S.H. and M. DiDomenico, Jr., "Oxygen-octahedra ferroelectrics. II. Electrooptical and nonlinear optical device applications," J. Appl. Phys. 40, 735-752 (1969).

75. Megumi, K., N. Nagatsuma, K. Kashiwada and Y. Furuhata, "The congruent melting composition of strontium barium niobate," J. Mat. Sciences 11, 15831592 (1976).

76. Neurgaonkar, R.R., Semi-Annual Technical Report \#4, Contract N00014-82-c2466.

77. Brice, J.C. and P.A.C. Whiffen, "Solute striae in pulled crystals of zinc tungstate," Brit. J. Appl. Phys. 18, $581-585$ (1967).

78. Brice, J.C., "Analysis of the temperature distribution in pulled crystals," J. Cryst. Growth 2, 395-401 (1968).

79. Whiffen, .A.C. and J.C. Brice, "The suppression of thermal oscillations in Czochralski growth," J. Cryst. Growth 10, 91-96 (1971).

80. Yeh, P., "Fundamental limit of the speed of photorefractive effect and its impact on device applications and material research," Appl. Opt. 26, 602-604 (1987).

81. Megumi, K., H. Kozuka, M. Kobayashi, and F. Furuhata, "High-sensitive holographic storage in Ce-doped SBN," Appl. Phys. Letters 30, 631-633 (1977).

82. Bryan, D.A., R.R. Rice, R. Gerson, H.E. Tomaschke, K.L. Sweeney, and L.E. Haliburton, "Magnesium-doped lithium niobate for higher optical power applications," Opt. Eng. 24, 138-143 (1985).

83. Fisher, R.A., ed. Optical Phase Conjugation, Academic Press, New York (1983).

84. Huignard, J.P., H. Rajbenbach, Ph. Refregier and L. Solymar, "Wave maxing in photorefractive bismuth silicon oxide crystals and its applications," Opt. Eng. 24, 586-592 (1985).

85. Motes, A. and J.J. Kim, "Beam coupling in photorefractive BaTiO 3 crystals," Opt. Lett. 12, 199-201 (1987).

86. Steel, D.G. and R.A. McFarlane, "Laser oscillator using resonator with a selfpumped phase conjugate mirror," Opt. Lett. 8, 208 (1983).

87. Lind, R.C. and G.J. Dunning, "Demonstration of real-time compensation of atmospheric turbulence by non-linear phase conjugation," CLEO confererence, Baltimore, MD, May 1983 and Laser Focus, Sept. 1983. 
88. Tanguay, A.R., Jr., "Materials requirements for optical processing and computing devices," Opt. Eng. 24, 002-018 (1985)

89. Yeh, P. and A.E.T. Chiou, "Optical matrix-vector multiplication through fourwave mixing in photorefractive media," Opt. Letters 12, 138-140 (1987).

90. Chang, 1.C., "Selection of materials for acousto-optic devices," Opt. Eng. 24, 132-137 (1985).

91. Lee, J-C, and S.D. Jacobs, "Refractive index and $\Delta n / \Delta T$ of $C r: N d: G S G G$ at 10641064 nm," Appl. Opt. 26, 777-778 (1987).

92. Bernardo, L.M. and O.D.D. Soares, "Birefringence measurements by double speckle photography," Appl. Opt, 26, 769-772 (1987). 


\section{APPENDIX: REPORT OF VISIT TO NEURGAONKAR'S LABORATORY}

TO: Mel Nelson/Dr. Larry Franks, EG\&G Santa Barbara Operations

FROM: Dr. Vern N. Smiley

SUBJECT: Visit to Dr. R. Neurgaonkar's laboratories at Rockwell International Science Center at Thousand Oaks, CA on 5/7/87

\section{INTRODUCTION}

Dr. Ratnakar R. Neurgaonkar (often called $R^{2}$ by those who know him well) is Manager of the Ferroelectrics Materials Department at the Science Center. I will refer to him as RN throughout the rest of this memo. The Science Center is located in a beautiful isolated area overlooking a canyon and surrounded by pine and other trees. It is referred to as the "Country Club" by other Rockwell personnel working at other locations. He told me that he has a funding level of $\$ 4 \mathrm{M}$ which represents $10 \%$ of the total funding for the Center. He receives funding from ONR, DARPA, AFOSR, ARO, and other sources for his work on growth of ferroelectric crystals.

RN is in the enviable position of being the only source in this country, to my knowledge, of large high-quality SBN and other tungsten bronze ferroelectric crystals which are in demand presently by several groups. He stated that there are only two Ferroelectric Groups in the US - his and one at Penn State where he got his doctorate. The materials he is working on, which include SBN and several other tungsten bronze crystals, are sought after for several research activities including:

1. Photorefractive research for several potential applications in the areas of:

$$
\begin{aligned}
& \text { Optical computing } \\
& \text { Phase conjugation } \\
& \text { Image amplification } \\
& \text { Digital beam steering } \\
& \text { Self-oscillators } \\
& \text { Volume holography }
\end{aligned}
$$

2. High temperature superconductors- his current interest is turning toward thin films of high $T$ superconductors. By coincidence it turns out that these films have nearly identical lattice constants to those for SBN so the latter works very well as a substrate for growing the films by epitaxy. Additionally SBN has no phase transitions below room temperature so it can be cooled down to very low temperatures without problems. 
3. $\mathrm{mm}$ Wave Devices- These materials work well as $\mathrm{mm}$-wave devices such as modulators and switches. $\mathrm{RN}$ has been very active in this area.

4. Pyroelectric detectors- These materials work well as pyroelectric detectors for ir radiation. $\mathrm{RN}$ has also been active in this area.

He has four laboratories three of which he showed me hurriedly (he was in the midst of preparing three proposals). The fourth, and most important lab, is the crystal pulling lab where all the tungsten bronze crystals are grown. The reason for not showing me the lab had nothing to do with proprietary concerns. He was growing BSKNN with which he is still in the early stages of establishing the proper growth conditions and he did not want any unknowns such as possible vibrations to interfere with the developmental process. If he were growing SBN, he would gladly have shown me the lab as he has conditions for growth of that material well established. The three labs he did show me had the following processes going on:

1. Sputtering-where thin films of high temperature superconductors are deposited. Also I assume that electrodes are put on crystals in this lab.

2. Liquid phase epitaxy-He is growing SBN by liquid phase epitaxy (LPE). Poling also is done in this lab.

3. Ceramic lab-SBN and other materials are compressed into ceramic form suitable for piezoelectric and possibly $\mathrm{mm}$-wave applications but not optical applications.

Additionally, one of the above labs has equipment for measuring low frequency dielectric and piezoelectric constants as a function of temperature. The tungsten bronze materials exhibit a Curie-Weiss behavior near the Curie temperature and so these constants increase dramatically as $T_{c}$ is approached. I asked him if EO coefficients, particularly at high frequency are being measured. He said that that is not his area of expertise but they are being measured in another lab at the Center. He also mentioned that Larry Jelsma at LLNL has a few of his crystals of SBN:60 and is successfully measuring the EO coefficient and is getting deflection.

RN is also growing $\mathrm{BaTiO}_{3}$ in one of his labs using the top-seeded solution growth technique. He apparently grows some crystals successfully but does not pursue this area actively since the tungsten bronze materials are so much easier to grow and pole and they have the properties his customers are looking for.

He showed me several examples of doped and undoped SBN crystals which to the eye appeared to be of high optical quality. The doped SBN:60 with iron or cerium was colored. One example of undoped SBN:60 had a diameter of $2.5 \mathrm{~cm}$. 


\section{SPECIFIC QUESTIONS}

I asked Dr. Neurgaonkar several specific questions generated by Mike and others at my presentation at Marina Del Rey on 5/4/87. The questions and answers were as follows:

1. Platinum crucibles-Is there a melting problem?-He uses platinum almost universally and had a strong negative reaction when I mentioned iridium crucibles. He has no melting problems with platinum.

2. Impurities - Are impurity measurements made on grown crystals or in starting materials? He indicated that he does not measure impurities in grown crystals to see if crucible material is present nor does he do spectroscopic analyses of impurities in starting materials. He uses the purest starting materials available. I did see an $x$-ray spectrometer in one of his labs, however, which I assumed was for determining the percentage of dopants in doped crystals.

3. Poling-What is the easiest material to pole and how is it done?-I was shown how Rockwell does poling on SBN and similar materials. It is a very simple technique utilizing a metal plate with a spring clamp. The crystal with electrodes is placed on the plate with the clamp and immersed in oil in a glass container. A high-voltage supply is connected to the plate and the spring clamp. The container is placed on a hot plate and the oil and crystal brought to a temperature above the Curie temperature and cooled down with $5-8 \mathrm{kV} / \mathrm{cm}$ applied field. No special furnace or other apparatus is required. I asked how electrodes are put on. He indicated that any technique will work-painting them on, sputtering or other techniques.

1 asked him about poling barium titanate. His response was that this is an entirely different matter and that basically barium titanate can not be poled.

4. Crystal Growing Equipment-Do you buy commercial equipment or make your own? He purchases basic commercial equipment and modifies it to suit his needs.

5. Striations-Are they due to impurities, how do you prevent them? $\mathrm{He}$ didn't say much about it but did indicate that some people see striations in any crystal whereas others do not see them or are not bothered by them. He has grown "striation-free" crystals but did not elaborate on how he does it. This subject is discussed in his publications in somewhat more detail.

6. Temperature Control of Solid/Liquid Interface - How do you control this important parameter? His response was that "This is the trick; if 1 told you how 1 do it you could grow your own crystals." From comments made by RN and others in the literature, one would conclude that this quantity is even more important when growing non-congruent mixtures such as SBN:75 compared to SBN:60 which is a congruent mixture. 
7. PBN:60-Is this more difficult to grow and what is the melting temperature? He indicated that it is more difficult. I forgot to ask him the melting temperature but found a value in the literature of 1350 deg $C$ which is lower than the value I reported at Marina Del Rey.

8. SBN:75-Have you grown this much and is it more difficult to grow? He has grown it but not nearly as much as SBN:60 as there has not been that much interest in it. He indicated that it is somewhat more difficult to grow in large sizes. I pointed out that the reported value for the EO coefficient of SBN:75 is considerably larger than that for SBN:60 (a factor of three) and therefore of interest to people wanting to use it for electro-optical applications. His response was that it is not that important; SBN:60 already has an EO coefficient much greater than the material most commonly used, $\mathrm{LiNbO}_{3}$ so why bother with trying to squeeze a little bit more out of it.

9. Polishing-Is SBN easy to polish and what techniques do you use to do it? He indicated that it is quite easy to polish to an optically flat surface using standard glass polishing techniques. Nothing special is required. He showed me several examples of polished crystals which to the eye appeared to have an excellent polish.

10. Machining-What techniques do you use to cut and machine the crystals? He said that standard glass-cutting equipment works very well. I assumed from this that standard diamond saws are used for cutting and that some machining can be done without shattering the crystals. He showed me samples of plates cut from boules 1 in. in diameter.

\section{DISCUSSIONS ABOUT INTERACTING WITH SBO}

I asked RN if he would be interested in interacting with $E G \& G / E M$ in terms of furnishing some crystals. I also mentioned that SBO might have some interest in growing their own materials. He said that he would be interested in working with EG\&G/EM but that he could not do anything at the funding level of $\$ 25 \mathrm{k}$ that had been discussed a couple of years ago. He has to have $\$ 100 \mathrm{k}$ to $\$ 150 \mathrm{k}$ to do anything because of his large overhead at Rockwell. That was why he wanted to work with one source only, Larry Jelsma of LLNL, previously.

He was somewhat pessimistic about anyone growing their own SBN or other tungsten bronze crystals as it took him 9 years to perfect the technique. However, he said he would be happy to come to SBO and look at the present facilities and give his advice and also to talk about the possibility of developing some materials for EG\&G/EM. He suggested doing something different from what Larry Jelsma is doing. Perhaps getting involved with his current favorite topic of high temperature superconductors or photorefractive work. 


\section{DISTRIBUTION}

DOE/NV

K. Powers/R. Friedrichs

DOE/TIC

Oak Ridge, Tennessee

S. Lanier

Los Alamos National Laboratory

W. Anderson

R. Day

N. King

P. Lyons

\section{Livermore National Laboratory}

R. Fortner

L. Jelsma

v. Slivinski

EGSG/EM， AVO

T. Edwards

J. Spector

EGEG/EM, GVO

R. Lynn

C. Sawyer
EG\&G/EM, RO

G. Hughes

EG\&G/EM, LAO

B. Broste

M. Dunham

J. Manning

EGEG/EM， LVAO

M. Carlisle

E. Hagen

H. Lamonds

R. Spiers

T. Thompson

J. Trabert

B. Whitcomb

P. Zavattaro/J. Michael

Archives/Technical Library

EG\&G/EM， SBO

L. Hocker

C. Hudson

B. Marshall

R. Monchamp

M. Nelson

Publications

EGEG/EM， WCO

J. Champeny 